\title{
Building Design Guidelines for Solar Energy Technologies
}

Final Report

DOE/SF/17538--T3

DE9 $0 \quad 012500$

To the AIAIACSA Council on Architectural Research

Principal Investigator: Prof. Baruch Givoni

Research Assistant: Arch. Tarek Labib

Graduate School of Architecture and Urban Planning

University of California, Los Angeles

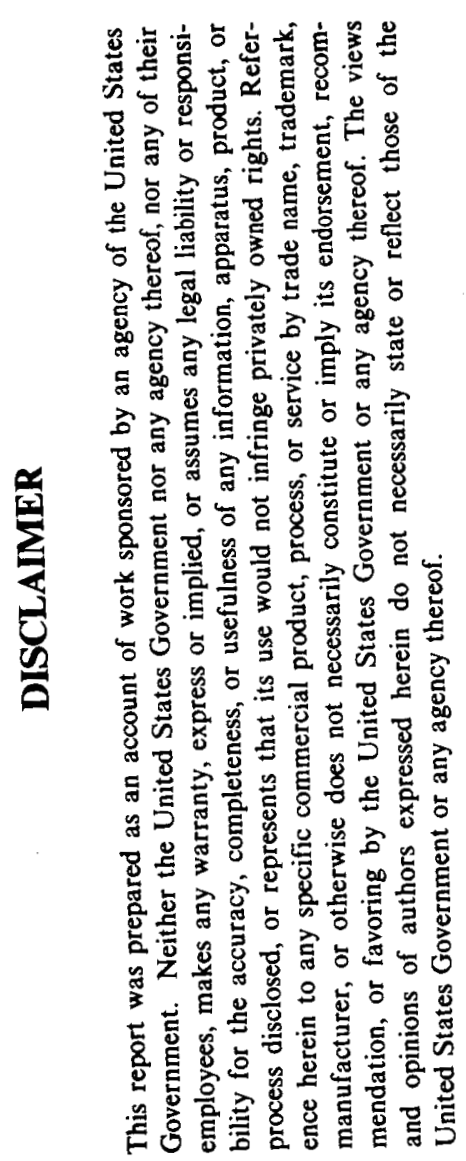

\section{Consultants:}

Dr. D. Balcomb, SERI

Eng. F. Dubin, New York

Mrs. A. Dunning, Santa Fe

Prof. M. Milne, UCLA

Mr. W. Nichols, Santa FE

January. 1989

This document is

YLICLY RELEASABLR

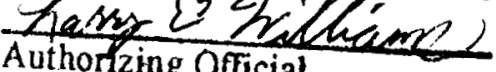
Authorizing Official

[nte:09/19/2006 


\section{DISCLAIMER}

This report was prepared as an account of work sponsored by an agency of the United States Government. Neither the United States Government nor any agency Thereof, nor any of their employees, makes any warranty, express or implied, or assumes any legal liability or responsibility for the accuracy, completeness, or usefulness of any information, apparatus, product, or process disclosed, or represents that its use would not infringe privately owned rights. Reference herein to any specific commercial product, process, or service by trade name, trademark, manufacturer, or otherwise does not necessarily constitute or imply its endorsement, recommendation, or favoring by the United States Government or any agency thereof. The views and opinions of authors expressed herein do not necessarily state or reflect those of the United States Government or any agency thereof. 


\section{DISCLAIMER}

Portions of this document may be illegible in electronic image products. Images are produced from the best available original document. 


\section{Building Design Guidelines for Solar Energy Technologies}




\section{Table of Content}

Introduction

Conventional and Innovative solar technologies

1. Residential Solar Buildings

1.1 Overview: Experience with Residential solar Buildings in the USA.

1.2 Main Lessons Derived From the Monitored Residential Buildings

1.3 Factors Limiting the Solar contribution for Heating

1.4 Suggestions of Research which may Increase the Solar Fraction of the Heating Load.

1.4.1 Introductory Comments

1.4.2 Solar Energy Collecting Elements

1.4.3 Latent Heat Storage

1.5 References and Bibliography on Solar Buildings

2. Nonresidential Buildings

2.1 Introduction

2.2 The DOE Nonresidential Experimental Building Program

2.2.1 Main Lessons from the Performance of the Buildings

2.2 .2 Discussion of specific Items of Performance

2.3 Boundaries of the Conditions to which the Lessons Learned from the DOE Program Can Be Applied

2.4 References on Daylighting and Nonresidential Buildings

3. Characteristics of Various Passive Solar Heating Systems

3.1 Direct Gain

3.1.1 Location of Solar Glazing for Direct Gain

3.1.2 Size of Solar Glazing

3.1 .3 Choice of glazing Type

3.2 collecting storage walls

3.2.1 Masonry Collecting/Storage Walls

3.2 .2 Collecting/storage Water Walls

3.3 Sunspaces

3.3.1 General Discussion of Sunspaces

3.3.2 Modified Greenhouses

3.3.3 Sun Porches

3.3.4 Application of Sunspaces to Different Building Types

3.3.5 Sunspace/Building Relationship

3.3.6 The connecting Wall between Sunspaces and Adjoin Rooms

3.3.7 Thermal Mass Inside the Sunspace 
3.4 Remote Below-Floor Passive Collectors and Rockbed Storage

3.5 Insulated Collecting Walls

3.5.1 The Trombe Insulated collecting Wall

3.5.2 The Barra-Constantini System - Insulated Wall Collector and Concrete Ceiling storage

4. Design Guidelines for Residential Solar Buildings

4.1 Design Guidelines for Solar Neighborhoods

4.2 Building Design Guidelines for Active Solar Heating Systems

4.3 General Architectural Guidelines for Energy Conservation

4.4 General Guidelines for Passive Solar Heating

4.5 Design Guidelines for Various Passive Solar Systems

4.5.1 Direct Gain

4.5.2 Thermal Storage Walls

4.5 .3 Sunspaces

4.6 Bibliography: Books with Guidelines for Solar Buildings

Appendix A. Results of Various Experimental Studies

A.1 Results of Various Experimental Studies

A.2 Summary of the AIA Research Corporation Report

A.3 Summary of SERI Reports on Monitored Buildings

A. 4 Summary of SERI - National Study

Appendix B. Technological Developments in PCM! Thermal Storage

B. 1 Introduction

B.2 Experience with PCM IN Solar Buildings

B.3 PCM Incorporated in Conventional Building Materials and New Packaging Technologies

B. 4 Comments on Potential Application of PCM

B.5 References on PCM for Solar Heating and Cooling

Appendix C. Glazing with Changeable Thermal Properties

Appendix D. Core Daylighting of Nonresidential Buildings D. 1 Generic Types of Light Guides

Appendix E. Concepts of Opaque Walls with Changeable Properties 


\section{Introduction}

There are two main objectives to this publication. The first is to find out the communalities in the experience gained in previous studies and in actual applications of solar technologie in buildings, residential as well as nonresidential. The second objective is to review innovative concepts and products which may have an impact on future developments and applications of solar technologies in buildings.

The available information and common lessons were collated and presented in a form which, hopefully, is useful for architects and solar engineers, as well as for teachers of "solar architecture" and students in Architectural Schools.

The publication is based mainly on the collection and analysis of relevant information. The information included previous studies in which the performance of solar buildings was evaluated, as well as the personal experience of the Author and the research consultants.

The state of the art, as indicated by these studies and personal experience, was summarized and has served as basis for the development of the Design Guidelines. In addition to the summary of the state of the art, as was already applied in solar buildings, an account was given of innovative concepts and products. 'such innovations have occurred in the areas of thermal storage by Phase Change Materials. (PCM) and in glazing with specialized or changeable properties. Interesting concepts were also developed for light transfer, which may enable to transfer sunlight to the core areas of large multi story nonresidential buildings. These innovations may have a significant impact on future developments of solar technologies and their applications in buildings.

This publication is oriented toward three different audiences: practicing architects and solar designers, architectural students interested in design of solar buildings, and persons interested in options for advancing the state of the art by new technical developments. Different section in the publication may be of interest to each one of these groups.

Sections 1 and 2 summarize the field experience in residential and nonresidential buildings, respectively, based on Reports on monitored buildings.

Section 3 discusses the characteristics of the different passive solar heating systems. It is illustrated and provides a background for the specific design guidelines. Section 4 presents the actual building design guidelines. It may be the main sectio of interest to practicing Architects and is well illustrated.

Appendix A provides more information on the results of the studies in which the performance of the solar buildings was evaluated.

Appendix $B, C$ and $D$ deal with technological innovations which may affect future application of solar energy in buildings. Appendix $B$ deals with new developments in Phase Change Materials (PCM) . 
Appendix $C$ deals with switchable glazing which can be changed from a transparent to a reflective state and back, according to changing needs.

Appendix D presets ideas developer at LBL on transmission of daylight to core areas of building.

Appendix E presents ideas about changeable opaque walls.

Conventional and Innovative Solar Technologies.

Balcomb (1986) summarizes a decade of experience with passive solar buildings, with conventional solar technologies, in the USA. He cites an estimate that more than 200,000 residential and 15,000 commercial buildings have utilized solar energy in the country. In residential buildings the main application is solar heating and in commercial buildings it is daylighting. Passive cooling was mainly in the form of prevention of overheating by such means as shading and ventilation.

To date a number of solar technologies have demonstrated, in actual application in solar buildings, their satisfactory thermal and functional performance. In the area of solar heating of residential buildings it was mainly the various passive solar systems, which have exhibited reliability and low maintenance requirements.

In "very sunny" regions like NM it was demonstrated that solar energy can provide most of the heating energy (up to 70-80\%), with solar glazing to floor area ratio of about $0.18-0.25$ (e.g. houses of Balcomb, M. Jones, Williamson, etc., see summary of AIA - 78 and SANDIA - 79 reports). In the Denver area solar heating fractions around and above $50 \%$ have been demonstrated. Even in Mid America and the Northeast regions solar heating fractions of around $40 \%$ have been achieved (see summary of SERI reports of the "Class - $B$ " buildings monitoring program in Appendix: $A-4)$.

In nonresidential buildings the contribution of solar energy is mainly in daylighting. It is possible, with appropriate control of the electrical lighting system, to save electricity not only for lighting, but also for cooling, and to improved the quality of the indoor environment and the satisfaction of the users (see summary of the DOE nonresidential building Program in section: 2.2).

It can be concluded, therefore, that, already today, conventional solar technologies such as daylighting and the various "basic" passive heating systems (Direct Gain, Thermal storage Walls, Sunspaces, Convective Loops, etc.), as well as their components of conventional glazing and thermal storage materials, could be applied with confidence and on a larger scale than was done to date.

In recent years, however, there have been developments of new concepts and products which, potentially, can increase significantly the contribution of solar energy in meeting the thermal and lighting needs of buildings. They can further improve the energy performance (reduce total consumption) and indoor comfort in buildings, residential as well as nonresidential. 
Such developments have occurred, for example, in the area of switchable glazing, which can either transmit or reflect solar radiation according to changing needs. Such glazing, if and when it will become commercially available, could provide optimal daylight while minimizing the cooling load on the building durin periods of excessive solar radiation and/or high temperatures (see Appendix: C).

New developments occur also in the area of thermal storage by Phase Change Materials (PCM) incorporated and encapsulated in conventional building materials. In previous applications of PCM, containerization of the PCM caused many problems. The integrated PCM may enable higher storage capacity while minimizing the problems of structural load and "wasted" space which accompany conventional thermal storage materials (see Appendix: B).

One of the problems which may limit the effective heat storage capacity of the "integrated" PCM is the rate at which they can be charged (e.g. With solar heat or with night "cold") and the heat flow between the elements and the indoor space, when the stored energy is utilized. This problem is related to the low thermal conductivity of the PCM materials. Design solutions to deal with this problem are suggested in Appendix: B .

New concepts are also being developed in the area of light transmission, opening the option of daylighting of core areas of large nonresidential buildings, which at present have to rely exclusively on electrical lighting (see Appendix: D).

The principal investigator bears full responsibility for the content of this Report and the specific design guidelines. 


\section{Section 1}

\section{Residential Solar Buildings}

\subsection{Overview: Experience with Residential Solar Buildings in the USA.}

At the start of the "solar period" most emphasis was given to the "active" solar systems for space heating. However, experienc has demonstrated that the inherent simplicity of passive solar heating systems makes them more acceptable than the active solar systems.

The most widely used system of passive solar heating in the USA is Direct Gain (in Europe, where masonry construction is very common, Trombe walls are used very often). The application of Direct Gain to low mass buildings cause some intrinsic problems and limitations to the performance of the solar buildings in the country.

Most of the solar buildings in the US have wood frame construction, as is common in the building industry in the country as a whole. This construction type has direct implications for the cost, performance and applicability of different solar heating and cooling systems

As high level of thermal storage is not provided by the structu materials in the buildings common in the USA, storage has to be provided by additional materials, a factor which increases the cost and technical complexity of providing a high storage capacity. The low structural heat storage capacity limits the capability to collect and store solar energy to only one night's storage, and at most to one cloudy day.

In consequence, the contribution of solar energy to the heating needs depends mainly on the cloudiness conditions. In sunny NM a Solar Heating Fraction (SHF) of about 0.8 has been achieved. In the Denver area the best performance was around 0.6 and in Mid America and the Northeast about 0.5 . These values can be considered as the "near upper" 1 imits achievable with the presen solar technologies.

In fact, when thermal storage in passive solar buildings is provided by conventional, sensible heat, materials this limit of the duration of the storage capacity is inherent. The surface temperature of the storage elements can not be raised above the upper limit of the comfort zone without causing heat discomfort. This factor sets the upper limit for the storage capacity. And when the surface temperature drops below the lower limit of the comfort zone the heat still stored in the material, at temperatures within the comfort range, is useless as a heating source.

Having thicker walls made of sensible heat storage materials, either in a Direct Gain or in thermal storage walis situation, will have only limited effect on the effective storage capacity. After one night, or at most one cloudy day, the surface temperature of the storage elements will drop to the lower limit 
of the comfort zone and render the elements ineffective in sustaining indoor comfort.

In Direct Gain buildings it is not possible to increase the area of the solar glazing beyond a certain limit without causing overheating, even in winter, on clear days. This feature sets a limit on the amount of solar energy which effectively can be collected and stored during sunny days with solar windows.

on the basis of the field experience Balcomb (1986) recommends that the total solar glazing area (of all the passive systems) would be limited to the size that wguld result in an average indoor temperature no higher than $72{ }^{\mathrm{F}}(22 \mathrm{C})$. This condition sets also a practical limit on the storable energy. In any case he recommends that the Direct Gain solar glazing area would not be greater than $13 \%$ of the floor area, to minimize the likelihood of glare, ultraviolet fading of materials and loss of privacy.

More solar energy can be collected in a given building, above the amount collected by the solar windows, by other passive systems, like a thermal storage (Trombe) walls, etc. But the construction of a masonry or water wall in a wood frame building involves additional cost. The thermal storage capacity of such walls is also limited to about one cloudy day, so that the problem of collecting and storing solar energy for cloudy days can not be solved even by thermal storage walls.

Another factor which limits the thermal storage capacity in passive solar buildings is the rate of heat flow into the storage element (during the charging stage) and the flow from the storage to the indoor space (during the utilization stage). With the small temperature gradients common in passive buildings between the indoor air and the storage elements surfaces the stored heat per unit area of the storage is quite limited. This is one of the major factors limiting the amount of storable solar energy. In summary, the main problems limiting the practically achievable solar contribution for heating are:

-The limitations on the size of "solar windows" caused by risks of overheating, glare, loss of privacy, deterioration of fabrics, etc...

-Use of masonry or water glazed walls as collecting elements is not an integral structural solution in wood frame buildings and involves extra cost.

-The practical limit of thermal storage with the common, sensible heat materials, to one day.

-The cost and technical problems of providing high thermal storage capacity in low mass, frame construction, buildings.

\subsection{Main Lessons Derived from the Monitored Residential Buildings.}

Several experimental studies, in which the performance of solar residential buildings were monitored and evaluated quantitatively, have been conducted for the DOE and were reported in several Reports and articles. The performance of some buildings was covered in more than one Report. All the Reports of these 
studies provide only details on the performance of the individua buildings. They do not present a comparison of the performances of the different" buildings and analysis of probable factors affecting the variability between them.

The solar gain of the buildings was estimated in these studies by calculating the total heat loss, from the product of the heat loss coefficient and the measured Degree-Days, and subtracting from it the measured and calculated internal heat production and the auxiliary heat.

The Reports of the studies on monitored residential buildings (see reference list at the end of the section) will be summarize and their results evaluated in this section.

Although numerous computer simulation studies have evaluated the performance of different types of solar buildings in different climatic regions, the present evaluation will be based only on the field experience with solar buildings, as obtained by actual monitoring of their performance and reported in the Reports listed above.

\subsubsection{Comments:}

\section{a) Criteria and Performance Evaluation of Solar Buildings}

The main criterion used in the above studies for evaluating the performance of the solar systems was the Solar Faction in meetin the Heating load of the building (SHF), after taking into accoun the internal heat generation. This is a valid criterion when one wants to estimate the actual contribution of solar energy systems, as applied in practice, to the heating energy needs.

However, this criterion by itself has some limitations when the objective is to evaluate the efficiency of a given solar building and/or the potential of solar heating in a given region to contribute to the heating needs.

The actual, measured, solar heating fraction of a given building depends on the size of the solar glazing and the thermal quality of the building, as well as on the climatic conditions during the monitoring period, mainly the solar radiation and the outdoo and indoor temperatures.

Thus, for example, a given building may have a large SHF, even with an inefficient solar system, if the solar glazing area is large enough or if the indoor temperature is kept by the occupa at low level and the swing is large enough. On the other hand, a building with an efficient system can have a low SHF if the solar glazing area is small, or if the building is poorly insulated and/or kept at high temperature (and therefore require more heat).

The overall energy demand of the building and the life style of the occupants have real impact on the performance of the solar system and are essential factors in simulating and predicting the actual energy use. However, they obscure the effects of the design details of the solar building and mainly, in the case of passive systems, the relationship between the collection and storage elements and the rooms where the heat is needed.

It seems to the author that a more direct criterion to evaluate the potential of solar systems in a region with a given climate, 
characterized by the available solar energy, is the efficiency of the solar building, defined as the ratio of the unit area solar gain to the impinging radiation. This parameter can be obtained from the data published in some of the Research Reports. By taking into account the differences in solar radiation in different regions it enables pooling together performance data from different climatic regions.

This parameter normalizes the results with respect to, and minimize the impact of, the factors affecting the overall energy demand of the building (heat loss coefficient, outdoor temperature) and occupants life style (indoor temperature). They enable to focus attention on the potential of the solar system itself, and on the impact of the building design details on the performance of the solar heating system.

It should be realized that this parameter also is not "absolute" criterion of performance. In general, the contribution of a solar system does not increase I inearly with its size, and beyond a given size there is a progressive drop in the incremental useful energy gain. However, this effect can be evaluated by expressing this performance parameter as a function of the solar glazing to floor area ratio and, it seems to the author, it provides a more general evaluation basis than just the SHF.

When the efficiency of the individual buildings is expressed as a function of the solar gain per unit area of the solar glazing it is possible to identify the less efficient buildings and to look for explanations for the lower performance.

The architectural design of the buildings, and mainly the coupling between the solar collection and storage elements on one hand, and the rooms where heat is needed on the other hand, may have significant effect on the performance of the solar building. Analysis of the performance of selected buildings, especially those with lower "system efficiency" than the average, has shown the importance of this factor.

In some cases of performance, either better or worse than the average, the design details of the buildings and the solar systems were analyzed to get indications of probable causes of this deviation from the average performance. Poor "coupling" between the solar collecting elements and the rooms where heat is needed was often observed in buildings with low "solar efficiency". This factor is not expressed explicitly by the mathematical models predicting the performance of a solar building but in reality it may have a significant effect.

The use of the "efficiency" criterion has brought to light an interesting problem: the definition of "solar glazing" in "cloudy" regions. In a number of buildings the "efficiency" was around 100\%. In two of the monitored buildings, in Georgia and Oklahoma, the "efficiency" was much higher than 100\%. In all these buildings the computed solar gain was greater than the total amount of solar radiation incident on the south glazing. In most of these sites the horizontal radiation, in winter, was greater than the incident (vertical south) radiation. In sunny regions the radiation on vertical glazing is higher than the horizontal.

Even if problems of calibration may have occurred, this relationship indicates prevalent overcast sky conditions. In this case solar gain from eastern and western windows would be 
of the same order of magnitude as the gain from southern ones. These windows were not considered in calculating the size of the "solar glazing" while the actual gain through them did affec the calculated solar contribution.

If this is the case it would have significant implications for the design of solar buildings in cloudy regions and the glazing data used in modelling their performance. It would mean that in cloudy and not very cold regions (e.g. Seattle) east and west windows, with glazing of high thermal resistance (e.g. Low-E glass), can also be useful as source for solar heating and shoul be taken into account as such.

\section{b) Architectural Integration of Solar Systems}

Most of the scientific research on passive solar buildings has treated the building as a "load", like a "black Box" with some abstract properties like heat loss coefficient, heat capacity, etc., exchanging heat with the environment and obtaining energy from the collecting elements. Very little attention was paid to the spatial relationship between the solar energy elements and the spaces in the building where heating is needed and the actua paths of heat flow within the building.

However, the integration of the energy system with the building as a whole may have significant impact on the performance of the passive solar building, where in many cases there are no defined lines of heat flow as is the case in active solar system

(e.g. pipes and ducts).

The issues of integration are different in the cases of active and of passive solar systems. In the case of active solar system the architectural implications are limited to the provision of an adequate area for the solar collectors and space for the thermal storage (e.g. a water tank or a rock bin). The architect has, of course, to address the visual relationship between the collectors and the building as a whole.

In contrast with active systems the basic concept of a passive system involves architectural integration of the elements of the solar system, both the energy collection and the thermal storage, with some structural elements of the building.

In contrast to active solar buildings, where the heat flow from the collectors to the storage and the various rooms is directed by pipes and ducts, in passive solar buildings the heat flow path from the collecting elements to the rooms where heat is needed and/or to thermal storage elements is often not defined.

In the absence of direct links between the collecting points and the different rooms excess heat may be in some parts of the building, causing overheating, while in other parts the auxiliar heating has to be activated to maintain the desired comfort level. This reduces the efficiency of the solar system below the potential achievable with better design of the building.

\subsubsection{Discussion of Specific Lessons from the Monitored Buildings}

a) Regional differences in the Performance of the Solar Buildings

one of the observations which can be made, when the best performance data from the solar buildings sumarized in the 
different studies are pooled together, is the regional differences in performance.

The contribution of solar energy to the heating needs was different in the different climatic regions, depending on the cloudiness conditions. In sunny NM solar contributions of about 80\% have been achieved. In the Denver area the best performance was around $60 \%$ and in Mid America and the Northeast about $50 \%$. These value can be considered as the "near upper" limits achievable with the present solar technologies. However, large variations in performance (measured by the criteria discussed above) were noticed in individual buildings.

Some of the factors which may have set the upper limits and probable factors affecting the variability of the performance, as well as personal suggestions of means for improving the solar utilization beyond the performance of the monitored buildings, by applying new concepts and technological developments, are discussed below (1.3).

b) Direct Gain Buildings

Direct Gain is the most common solar heating system in the USA. Direct Gain is the most efficient method to collect solar energy because the energy is collected at the lowest usable temperature, besides the benefits of daylight and view offered by southern glazing. As long as the collected solar energy is utilized during the same day, without need for long term storage, the overali efficiency of the "system" is. very high and most of the heating load can be provided by the solar energy, yielding a high solar Heating Fraction (SHF).

The main limitations on the achievable sHF in Direct Gain buildings, when the size of the solar glazing exceeds a certain limit, are caused by problems of overheating, glare, furniture deterioration by excessive daylight etc., as well as by the practical limit of thermal storage to no more than one day (see more discussion of this point below).

\section{c) Performance of Different Solar Systems}

Buildings with Trombe walls, water walls and with sunspaces, in general, exhibited thermal performance comparable to buildings with Direct Gain. This can be seen from Figure 1.1, showing the Solar Heating Fraction (SHF) of the buildings reported in the SERI reports with the different systems, as a function of the calculated Solar Load Ratio (SIR) of the same buildings. The SLR is the ratio of the available solar radiation to the heat demand of the building.

The SLR is the basis on which the Los Alamos correlational formulae calculate the solar Saving Fraction for different types of passive solar buildings. In expressing the measured performance of the buildings as a function of the SLR, which is an "objective" parameter, however, the performance of the different systems is shown independently of the specific assumptions of the Los Alamos models for the relative effectiveness of the different systems.

In figure 1.1 the different solar systems are marked differently and so they can be distinguished. It can be seen that, while there is a general increase in the SHF with increasing SLR up to about 1.4, and there is no clear separation between the distribution of the different systems up to that limit of SLR. 


\section{Solar Lood Ratio/Solar Heoting Fraction}

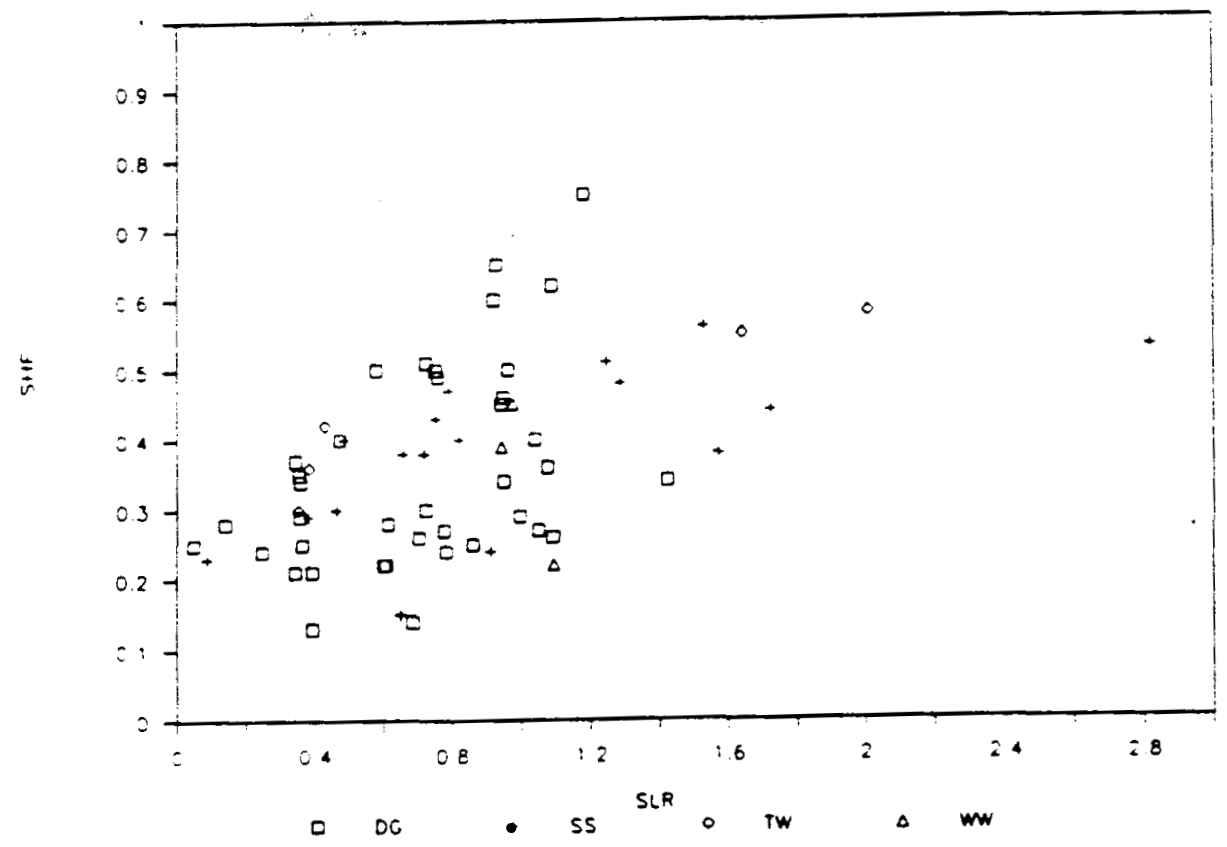

FIG.1.1: Solar Load RatiolSolar Heating Fraction.

It is of interest to note that for buildings with SLR ratio of above about 1.4 (apparently with larger solar glazing area than the rest). there is no increase in the SHF. Also, there were no buildings with Direct Gain above this limit.

d) Role of Thermal Storage

Lack of sufficient thermal storage in Direct Gain buildings often has caused overheating, venting out heat and low performance. (See for example buildings DMF and DMI in the Denve region in the SERI study).

This can be solved by sufficient thermal storage, coupled thermally with the indoor space, which will suppress the indoor swing around the average. As a basis for design Balcomb suggests that the storage should be sized to limit the indoor temperature swing to no more than $9 \sigma_{F}\left(5^{C} \mathrm{C}\right)$.

The effect of heat capacity on the performance of Direct Gain buildings in semi cloudy regions is vividly illustrated by comparing the performance of two similar buildings in vermont. These buildings are the Green Mountain Home (GMH) in Royalton (elevation $1500 \mathrm{ft}$. Jan DD 1445 - AIA and Sandia Reports) and the NEK building in south Royalton (Elevation $700 \mathrm{ft}$. Jan. DD 825-SERI two reports): (The performance of the GMH building is discussed in details in Appendix A).

Both buildings are two stories frame construction and have Direc Gain to all the rooms, with similar floor areas and ratios of solar glazing to floor area, $9.5 \%$ and $10.4 \%$, respectively. The Heat Loss Coefficient of the GMH was 10,212 Btu/DD and that of 
the NEK 6600 Btu/DD. Thus the total heat demand of the GMH building was significantly higher.

The main difference between the solar systems of the two buildings is in the provisions for thermal storage. In the NEK building the first floor slab was the only mass for thermal storage. In the GMH building the storage consisted of a concrete floor slab and concrete blocks and gravel under the floor slab, with elaborate air flow system which transferred heat between the rooms and the storage.

The measured performance of the two buildings was quite different. The SHF of the GMH, with about $10 \%$ of solar glazing, was close to $40 \%$, while that of the NEK building (with about the same solar glazing to floor area ratio) it was $22 \%$ (of a lower load) in each of the two monitored years.

The comparison of the performance of these two buildings suggests that with sufficient thermal storage, and effective coupling between the storage and the collecting elements on one hand and the building's rooms on the other hand, it would be possible to increase significantly the useable solar contribution in cloudy regions.

This proposition is supported by the performance of the MIT solar building \# 5 . This building has a solar glazing to floor area ratio of $21 \%$ and a PCM thermal storage (see more details in Appendix B). The SHF, reported in the AIA Research Corp. Report, was almost $60 \%$. The MIT building is described in more details in Appendix A.

Discussion of the issue of thermal storage is presented below (1.3). The possibilities of providing storage for several cloudy days by PCM is discussed in Appendix $B$.

\section{e) Operable Insulation}

Another conclusion which can be derived from the monitored buildings concerns the issue of operable insulation. In most buildings with operable insulation there were problems with their operation and no apparent energy conservation was achieved by them. It can be suggested that the daily operation of moveable insulation is beyond what can be expected from "ordinary" persons.

\subsection{Factors Limiting the Solar Contribution for Heating}

The amount of solar energy impinging on a house in winter, even in the cold and less "sunny" regions of the USA, is several times greater than its heat loss when it is well insulated.

For example, in Boston the solar radiation in January on horizontal surface is about 15,650 and on a vertical southern surface 20,460 Btu/sqft*month $(49.3$ and $64.5 \mathrm{KWh} / \mathrm{sm} *$ month, respectively). The DD in January is $1042 \mathrm{~F}$ *days. Assuming a two story, 2000 sqft building with a southern wall area of 800 sqft and roof area of 1000 sqft (horizontal projection), the total radiation impinging on the house is:

$(800 * 20,460+1000 * 15,650)=32018 \mathrm{Kbtu} /$ month. 
For a well insulated house with a heat loss coefficient of about $10,000 \mathrm{Btu} / \mathrm{F} *$ day and internal heat generation of $3000 \mathrm{Kbtu} / \mathrm{month}$ the total monthly heating needs would be: (1042*10,000$3000)=7420 \mathrm{kbtu} / \mathrm{month}$, namely about one quarter of the impinging radiation.

Even with a collection efficiency of $30 \%$, typical to common solar collectors, the required heating energy is less than what could be collected. But, with present solar buildings, the field experience, as well as simulations, demonstrate solar fractions in the Northeast of about $50 \%$ even in well designed solar buildings. With present day solar technology this fraction can not be significantly increased, but recent developments may change the prospects for greater solar fraction.

Analysis of the main factors which prevent the attainment of a larger solar fraction of the heating needs in buildings, by either passive or by active systems, even if only in qualitative terms, would therefore be useful and may suggest ways for improvement.

These factors are to some extent specific to the different solar systems but some main general issues can be distinguished. They can broadly by divided into three general areas, albeit interrelated:

-Energy collection issues.

-Thermal storage issues.

- Integration of the solar elements with the architectural design of the building.

The architectural integration of the solar elements seems to have a pronounced effect on the efficiency of the solar heating systems, as was evident from the analysis of the deviation of performance of individual buildings from the average performance. However, this issue does not involve any new technologica developments and the situation can be improved by appropriate "education" of architects designing solar buildings.

on the collection aspect: the amount of collected solar energy can theoretically be increased linearly with the size of the "collectors" (collecting elements in passive systems), provided that the temperature at which the energy is collected and stored remains nearly constant.

The area of southern wall and roof in private homes, as well as the area of the south wall in townhouses and apartment buildings with a southern orientation, is potentially more than sufficient almost in all regions of the country, to collect in winter solar energy sufficient to provide most of the heating needs of well insulated buildings.

In practice, however, there are several factors which limit the size of the collection elements and the amount of solar energy which can be utilized in a building. The useable area of collection is intimately related to the available thermal storage. The following discussion will deal mainly with passive and hybrid solar systems.

From the thermal storage aspect the main factor limiting the solar fraction is the fact that, with present storage technologies, the thermal storage capacity is limited in practice 
to one night, and at most to one cloudy day. It means that on cloudy days auxiliary energy has to be used.

In sunny regions, such as NM, the frequency of cloudy days is low and the achievable solar fraction is above $80 \%$, with solar glazing to floor area ratios of less than 0.2 . In this climate there is no need to increase significantly the solar glazing area. On the other hand, in the Boston area, for example, sequences of several cloudy days are common. Without the ability to store excess solar heat from sunny days there will be no gain in increasing the collection area.

In Direct Gain buildings, which by far are the most common type, it is not possible to increase the area of the solar glazing beyond a certain limit without causing overheating, even in winter, on clear days. In DG buildings the swing of the indoor air temperature is larger than that of the storage. This feature sets a limit on the amount of solar energy which effectively can be collected, and stored in sensible heat storage materials, during sunny days.

It should be stressed, however, that Direct Gain is the most efficient method to collect solar energy because. the energy is collected at the lowest usable temperature, besides the benefits of daylight and view offered by southern glazing. Therefore it can be recommended that in all solar buildings direct gain will be included with glazing area up to a certain limit, e.g. about 10-15\% of the floor area of the heated space. Within this size limit it is also not too difficult to provide control means, such as moveable insulation, to minimize heat loss in winter and overheating in summer.

Increasing the glazing area beyond this limit will often cause overheating of the interior of the building. In this case excess heat will be vented out or the glazing will be shaded, and both "remedies" will reduce the amount of energy available for storage. For the same reason it is also not possible to include an active storage system to store excess solar heat in DG buildings, e.g. a rockbed charged by a fan, because the upper limit of human comfort sets a limit for the indoor air temperature which is too low for charging a rockbed.

Excessive sunlight causes too much glare, deterioration of the materials of furniture, fabrics, etc. This factor also limits the practical size of the solar glazing and the amount of collectable energy in Direct Gain buildings.

In summary, the basic nature of DG sets limits on the amount of solar energy which can be collected and stored, and on the solar heating fraction that can be achieved in regions where cloudy days are common in winter. Suggestions for overcoming these limitations are presented later on.

When thermal storage walls, like Trombe Walls, are the main solar collection and storage elements, the problems of glare and fading and deterioration of materials are eliminated. But even in this case there are some factors which limit their potential solar contribution.

First, the depth of a space which can effectively be heated by radiation and natural convection from a vertical warm wall is about twice the height of the wall. As a result Trombe walls can heat only rooms adjoining the wall. As the air temperature 
in rooms heated by thermal storage walls is lower during the daytime than in $D G$ rooms, it is not possible to transfer heat, by convection, from the solarized rooms to other rooms.

Second, the amount of solar heat which can be stored, and later utilized, in a high mass wall is limited. This amount does not increase linearly with the thickness of the wall. Increasing the thickness of a concrete wall beyond about $16^{\prime \prime}(40 \mathrm{~cm})$ does not improves its effective storage capacity and solar contribution.

Increasing the thickness of a wall increases the thermal resistance from its core to the interior. In cloudy days most of the stored heat flows outward, and with time the resistance of the inner layers reduces progressively the heat flow inward. As a result, it is practically impossible to have usable heat storage for more than one cloudy day even in thick masonry walls

In summer, in regions with hot summers, a large glazing area cause high rate of conductive heat gain and overheating, even when the glazing is shaded from direct radiation. Furthermore, buildings with large area of Trombe walls may be overheated in summer as a result of reflected solar radiation absorbed in the glazed dark wall.

Therefore, in regions with hot summers and cold winters, such as Mid America and the central Atlantic regions, the total amoun

of solar glazing, and of collectable solar energy for heating, is limited not only by the capability to store excess energy from sunny days for use in cloudy days, but also by the risks of overheating.

\subsection{Suggestions of Research which may Increase Solar Utilization in Residential Buildings}

\subsubsection{Introductory Comments:}

At present the economic reality of low fuel cost may be the main factor which limits the application of solar energy for heating, and the "technical" factors may be of secondary importance. But even in the solar buildings which have been built during the "energy crisis" period, with economic incentives, the actual realized contribution of solar energy was, by and large, less than the climatic potential.

The state of low fuel cost may change in the future, and with it the economics of solar energy utilization. Solving the technical limiting factors would then be also of practical value Analysis of the technical factors which have limited the achieve solar contribution is therefore of interest. Research now could anticipate such probable development and advance the state of the art to be able to deal with it, when the need arises.

In summary, the main factors limiting the practically achievable solar contribution for heating, as was pointed out above, are: -The limitations on the size of "solar windows" caused by risks of overheating, glare, loss of privacy, deterioration of fabrics etc. 
-Use of masonry or water glazed walls as collecting elements is not an integral structural solution in wood frame buildings and involves extra cost.

-The practical limit of thermal storage with the common, sensible heat materials, to one day.

-The cost and technical problems of providing high thermal storage capacity in low mass, frame construction, buildings.

Recent technical developments may improve the situation with respect to these limiting factors and enable in the future to increase significantly the amount of collected and stored solar energy.

As is discussed in detail in Appendices B and C, there are some new developments in the areas of Phase Change Materials (PCM) incorporated and encapsulated in common building materials, as well as in switchable glazing which can change back and forth between transparent and reflective states. These developments, if and when they become commercially available at reasonable cost, may enable in the future to have much higher storage capacity and greater area of solar glazing, to provide a higher fraction of solar heating without overheating.

However, technological developments in materials' sciences, by themselves, may not insure viable and more efficient solar buildings.

Incorporation of these new materials in a solar heating or cooling system may make it necessary to find solutions to a number of problems, as outlined below.

The following ideas and technical suggestions for energy collection and storage are presented in a hope that, if they would be developed into a workable technology, they could help in providing a greater contribution of solar energy for space heating in the building types common in the USA.

\subsubsection{Solar Energy Collecting Elements}

In view of the high collection efficiency of "solar windows" and the daylight and view to the south that they provide, it seems that the best way to collect solar energy on a clear day for the same day's use is by Direct Gain. This can be a reasonable criterion for sizing "solar windows".

Comment: High thermal resistance glazing, such as the "Low-E" glazing (claiming a conductance of about $0.15 \mathrm{Btu} / \mathrm{Sf} . \mathrm{F} / ;$; 0.85 w/sqm. C), could minimize the heat loss through the windows during the nights and cloudy days, without night insulation.

The problem is therefore to have an additional collecting system, for solar heat which would be stored and used in cloudy days, compatible with the prevailing building construction types in the country. A proposal to this end is presented below.

\section{a) Insulated wall collectors}

It is surprising that, in view of the wood frame construction of residential buildings common in the USA, and the fact that stud walls can be highly insulated without much extra cost, no research and actual applications have dealt with the development of integral wall collectors, similar to the system which has 
been developed in Europe by Barra (see the Barra-Constantini system in section 3 ).

converting an insulated southern stud wall into a solar air heating collector involves adding glazing and an absorbing surface to the conventional wall. Although the wall surface itself can be the absorbing element it is advisable to add a separate element, such as corrugated metal sheet or a series of wiremesh screens, between the wall and the glazing. A separate absorber increases the collection efficiency and minimizes the likelihood of deterioration of the wall proper, by the high temperature and the large temperature swing.

wall collectors can operate in a passive or an active mode, depending on the location of the storage elements. When the storage is provided in the ceiling (see item (c) below) the air flow from the collector to the storage can be accomplished by natural convection, as in the Barra system. When the storage is in the floors a fan is needed to provide the air (and heat) flow. One of the advantages of an insulated wall collector is that during the night hours and cloudy days the heat loss throug the wall is minimal. Also heat gain in summer is minimized by the intrinsic insulation of the wall. Such a vertical wall collector will have a lower efficiency than collectors tilted and oriented for optimal solar collection (active system's collectors) but, being an integral part of the conventional wall, its cost can be expected to be significantly lower than that of a "standard" solar collector. Wall collectors can be built as an integral part of the wall during its construction or can be attached to a built wall. Existing walls can be retrofitted and converted to a solar collecting wall.

The hot air output from the wall collector can charge a thermal storage (also integrated with the building's structure) without heating the indoor space. In this way solar heat can be collecte during sunny days and, if appropriate storage is available, stored for use during few cloudy days. proposals for high capacity storage for the heat output of wall collectors, integrated with the building's structure, are presented below (see items (b) and (c)).

It is suggested therefore to initiate research and development of air heating insulated solar wall collectors, which will form an integral part of the building's structure.

\subsubsection{Latent Heat Storage}

It seems that many of the problems and limitations concerning the provision of high level of thermal storage in low-mass frame construction buildings could be overcome if storage elements based on Phase Change Materials (PCM) were available at reasonable cost and in a form that is compatible with the construction techniques common in buildings in the USA.

The subject of the use of (PCM) for themal storage, and new technical developments in this area, are discussed in details in Appendix B. Here it is reviewed and some ideas for utilizing $P C M$ in solar buildings of the construction type common in the USA are presented. For the cited references see the Appendix. The main advantages of PCM as thermal storage in frame construction low-mass solar buildings are: 
1) The quantity of heat (or cold energy) which can be stored in a given volume is larger than in conventional, sensible heat, materials. The weight saving of the storage medium is even greater than the saved volume.

2) The temperature of the storage medium undergoes a very small swing while most of the heat transfer in or out the PCM takes place. This feature is of particular interest in buildings with a combination of Direct Gain and a solar wall collector, as it enables to store and release large quantities of heat, even sufficient for several cloudy days, while the indoor space remains within the comfort range.

The following specific research subjects are suggested in the area of PCM thermal storage:

b) Latent Heat Storage in Direct Gain Buildings by Surface Elements

Solar energy penetrating directly through southern windows is distributed in the space, impinging on the interior surfaces of the walls and the ceiling. In frame construction buildings the internal surfaces are usually various types of low mass boards, which do not provide significant thermal storage.

Wallboards, ceiling tiles, and similar surface elements which contain, or are impregnated with, different types of PCM were produced in the past and are being developed at present. Such "surface elements" can be used to line the walls and ceilings of rooms with frame construction and thus provide a high level of thermal storage capacity to low-mass buildings with Direct Gain. Some developments in this direction are described briefly below and described in more details in Appendix B.

Timothy Johnson (1978) developed polymer concrete/PCM ceiling tiles for thermal storage and applied them in the MIT solar building \# 5. The tiles were 2' square and 1" thick. Their chemical core (1/2") was Glauber salt bounded by two layers of polymer concrete, which have functioned as the containers for the PCM. The tile stores about $220 \mathrm{Btu} / \mathrm{sqft}(600 \mathrm{Kcal} / \mathrm{sqm}$ or $690 \mathrm{Wh} / \mathrm{sqm})$ over a $10 \mathrm{~F},(5.5 \mathrm{C})$ swing (latent and sensible heat). This is about ten times the sensible heat capacity of a concrete tile of the same thickness with the same temperature swing.

Shapiro (1987) from Concordia University in Quebec developed and tested wall boards impregnated with organic fatty acids. The wallboards, 1/2" thick, had a total heat gapacity of about $30 \mathrm{Btu} / \mathrm{sf}$ with temperature swing of $4^{\circ} \mathrm{C}(7 \mathrm{~F})$, namely about three times the heat capacity of concrete tiles of the same thickness.

Salyer (1985) is developing passive storage systems incorporating PCM into such materials and building elements as cement, concrete, plaster, plasterboards, tiles, etc. The PCM he recommends are mainly crystalline alkyl hydrocarbons (paraffin waxes).

Issues with Interior Surface Elements Incorporating PCM

When organic PCM (e.g. waxes) are incorporated in interior surface elements like plasterboards or tiles, and used as thermal storage in Direct Gain solar heating and/or cooling by night ventilation, the first issue which should be considered is the fire hazards associated with them. Salyer (1985) claims that 
with some additives the wax PCM can be rendered self extinguishing. With any particular organic PCM this point should be carefully checked and tested.

Another issue of interest with all types of PCM surface elements when the heat source is the indoor air is the indoor air temperature range which is needed to effectively melt the PCM during the day and to freeze it during the night. When the heat transfer is mainly by convection the temperature range of the indoor air has to be significantly larger than the range of the PCM, in order to provide a temperature gradient between the indoor air and surfaces sufficient to yield the required heat flows.

In some cases the indoor air temperatures which would be needed to melt the PCM imbedded in the walls might be too high for human comfort and/or the air temperature needed for freezing it might be too low.

A possible design solution is to provide an air space behind a relatively thin layer of elements containing PCM (e.g. wall boards about 1"), and to blow the wam or cool air in this air space.

The "charging" of the PCM would need a fan to circulate the warm air during the sunny hours (in the case of solar heating), but the discharge at night would be passive, by natural heat flow from the "freezing" PCM into the indoor space. In a similar way, the PCM could be freezed at night by fan assisted cool air flow behind it while it will absorb heat from the interior when melting during the daytime. The thickness of the surface element should be limited to that depth which would enable sufficient "passive" heat flow to melt and freeze the PCM across the whole depth of the element.

c) Latent Heat Storage in Air Spaces of Ceilings and walls

PCM elements are usually of very limited thickness and therefore also of limited heat storage potential per unit surface area. However, in frame type walls and ceilings there are integral air spaces. It is possible to place PCM elements inside the air spaces in such a way that longitudinal channels are formed, containing the PCM elements. Hot or cooled air can flow through the space, charging the PCM.

An example of the use of such ceiling channels for thermal storage, although with a conventional material (concrete), is the Barra - Constantini passive solar system which has been developed and implemented in many buildings in Europe. A description of this system is given in section 3 . Here only its main features will be mentioned.

In the Barra-constantini system a solar collecting element is placed in front of an insulated southern wall, (e.g. a number of metal lath layers), covered by glazing. Thus the wall forms a vertical air heating solar collector extending from the south wall to the North wall.

During sunny hours hot air rises and flows into and across "channels" imbedded within a concrete ceiling, heating on its way the mass of the ceiling, before exiting from the channels near the northern wall of the building. The northern rooms are heated by the warm air exiting from the ceiling channels. Thus 
a relatively uniform temperature exists throughout the whole building.

In frame construction buildings PCM elements can be used for thermal storage, providing higher heat capacity than a hollow concrete ceiling.

During sunny days the PCM elements within the ceiling can be charged, while keeping near constant temperature as long as the PCM is in the melting phase. The space below the ceiling will be heated passively as the PCM ceiling acts as a radiant heating panel.

On cloudy days, after the ceiling surface "freezes", the heat stored in the PCM elements within the ceiling space can be utilized by clesed circuit forced air circulation between the indoor space and the ceiling channels.

d) Latent Heat Storage in Floors

Buildings with concrete floors can increase greatly the heat storage capacity of the floor by imbedding PCM elements inside air channels in the floor. The PCM can be charged by hot air flow from e.g. a wall collector as the one discussed above. The floor will be kept at temperature lower but close to the PCM phase transition temperature as long as all the PCM did not freeze, serving as a heating panel for the space above it. The design details of floors containing PCM elements may be different than for ceilings containing PCM.

\section{e)Electricity as Auxiliary Energy for Solar Heating}

Another issue which, although not part of the "solar utilization issues" is relevant to the subject, is the choice of the auxiliary energy system and its integration with the solar systems. In considering both heating and cooling, electricity is an attractive option but for heating it is more expensive than other fuels. Furthermore, at present, large scale coupling of solar systems to electricity may save electrical energy on the average, but it may accentuate the load management problem and, in effect, may increase the demand for generating capacity.

In winter, during sunny days, the buildings will utilize the solar energy and will not use electricity. But during cloudy days, when power use for heating may cause the winter peak, solar buildings with electrical auxiliary will turn to the auxiliary system, and so accentuate the winter peak problem.

In summer solar buildings may have a higher cooling load as compared with non-solar buildings with the similar shading and opaque envelope thermal resistance conditions. This extra cooling load is often caused by (unwanted) heat gain from passive solar elements, such as Trombe walls, large southern glazing, etc. on hot sunny days their cooling load may be the highest, again "contributing" to the summer peak load.

However, if practical ways can be found to use night electricity for heating in winter and for cooling in summer and for appropriate storage medium, and to utilized the stored thermal energy during the following daytime, the situation would be different, both for the occupant and the electrical utilities.

It seems to the author that the new developments of PCM encapsulated in conventional materials may offer practical use of night electricity for "charging" the PCM during the night, 
heating in winter and cooling them in summer, and then utilizing the stored energy, during the following day.

The following are suggestions for research on related subjects: - Development of passive cooling and solar heating technologies that utilize night electricity as auxiliary source. Such technologies would also help in load management of electrical utilities by reducing peak power loads. Solutions for residentia buildings may be different from those for nonresidential ones. -Using cool night air in combination with night electricity (as auxiliary energy) for cooling.

-Using solar energy in combination with night electricity (as auxiliary system) for heating, in passive as well as in active solar buildings.

-Development of appropriate thermal storage materials and systems for solar energy in conjunction with night electricity. -Development of PCM products and systems, integrated with conventional building materials (e.g. concrete, concrete blocks, plasterboards, etc., ) for storing solar heat, as well as night coolness, in conjunction with night electricity (as auxiliary) for heating and for cooling.

\subsection{References to Section 1}

1-AIA Research Corporation, (1978): "Passive Solar Design: A Survey of Monitored Buildings".

2-Balcomb, J.D. (1986): "Passive Solar in the United States: 1976-1986".

Passive solar Journal, $V-3$ No-4 pp.333-348.

3-Duffy, J. and D. Odegard (1986): "Solar Load Ratio Design Tool. Predictions Compared to Level B Monitoring Data". Passive solar Journal, V 3, No 1, pp.77-98

4-Haskin, D. and R.P. Stromberg (1979): "Passive Solar Buildings". SANDIA Laboratories.

5-Jones, R. (1982): "Monitored Passive Solar Buildings". Los Alamos National Laboratories.

6-SERI (1983): "Passive Solar Performance: Summary of 1981-1982 Class B Results".

7-SERI (1884): "Passive Solar Performance: Summary of 1982-1983 Class B Results". 


\subsection{Introduction}

The main characteristics of nonresidential buildings, from the viewpoints of building design and application of solar technologies, are the following:

a) The needs for lighting for the performance of the various tasks which take place in most nonresidential buildings are much higher than in residential buildings. Natural daylighting can reduce the consumption of electricity for lighting and, as daylight is more efficient thermally than electrical lighting (more lumens per watt), the load imposed on the cooling system, whether mechanical or natural, can be smaller, depending on the control of the electrical lighting. The needs for high lighting levels in nonresidential buildings and a desire to apply a "solar" approach, can be combined in design solution for a large role for daylighting.

b) In addition to the cooling load resulting from the higher lighting level many nonresidential buildings, such as offices, have various electrical equipment items which further increase the internal heat generation and the resulting cooling load. As a result, the period during which cooling is needed is extended, often even through the winter. Cooling then is needed even when the outdoor temperatures are quite low, providing more opportunities for various passive cooling systems.

c) The horizontal dimensions of many nonresidential buildings are such that not all the floor area can be daylighted by window ("core" area). The core has to be lighted exclusively by electrical lighting, which may constitute the major heat source in that area. When such buildings are multi storied there is practically no natural heat transfer between the core and the outdoors, regardless of the outdoor temperature. Cooling of the core is then needed year round.

d) The patterns of building use in nonresidential buildings are different from those of residential ones. In most cases they are not used during the night, and in many building types also not during weekends. During periods when the building is not occupied the indoor climate can be allowed to deviate significantly from the human comfort zone, provided that when occupation starts the indoor conditions are again comfortable.

Different tolerances for levels and fluctuations in the indoor conditions are required in different types of nonresidential buildings. Thus, for example, in a hospital a smaller temperatur swing is allowed than in schools or offices. The ASHRAE Standard 55-8I specifies the required indoor conditions in different types of nonresidential buildings.

The impact of this use pattern on the design of the building and the solar elements is that the needs for thermal storage in nonresidential buildings are different from those in residential 
solar buildings. On one hand there is no need to store heat for the night hours. The diurnal use pattern also offers a potential for storing "coolness" through nocturnal ventilation, when the building is not occupied, either in the structural mass or in specialized thermal storage elements, and thus reducing the daytime air-conditioning load.

At present the only major use of solar energy in nonresidential buildings is daylighting. Heating in winter of the peripheral southern zone of the buildings, besides gain from windows as a by-product of the daylight, e.g. by insulated wall collectors similar to the type which has been developed in France by Trombe (see 3.5.1), has not been applied in the USA.

A major potential use of natural energy in nonresidential buildings, which is not being utilized on any significant scale in the USA is the storage of night coolness, to reduce the cooling load during the following day, in spite of the significant energy consumption and cost of daytime air-conditioning.

The structural design details and the interior materials of most nonresidential buildings in the country do not facilitate structural storage of night coolness. However, recent developments in encapsulation of Phase Change Materials (PCM), may offer the option of storage of significant amount of nocturnal "cold energy" in forms applicable to nonresidential buildings, including their "core" areas.

As a source of the nocturnal "coolth" to charge the cold storage elements two options can be considered, separately or in conjunction:

1) Nocturnal mechanical ventilation, whenever the outdoor night temperatures are low enough.

2) Mechanical cooling of the cold storage elements during the nighttime, using off-peak low cost electricity.

The cost saving from the use of night electricity in commercial buildings is often much greater than in residential buildings. For example, in Southern California, the SDG\&E commercial rates in 1989 for on-peak Demand Charge is $\$ 14.42$ in summer and 3.35 in winter, indicating the greater severity of the summer peak (and the potential benefits from reducing the daytime air conditioning load). The energy rates are: on peak $\$ 0.07578$ and off peak $\$ 0.03706$.

In addition to the cost saving for the customer one should consider also the general public benefits which would result from reduction of the needed generation capacity, which is determined to a large extent by the peak demand for air conditioning.

\subsection{The DOE Nonresidential Experimental Buildings Program}

Within the framework of this DOE Program 15 new buildings were constructed and 4 existing buildings were retrofitted. The performance of all buildings was evaluated by several investigators. 
The results of this evaluation were summarized in three publications: (Burt Hill et al. (1987) Ternoey et al. (SERI-1985)

and Kroner (undated).

\subsubsection{Main Lessons from the Performance of the Buildings}

-Providing daylighting is very cost/effective, due to the high cost of electricity. Lighting in nonresidential buildings is a major end use energy.

-Effective daylighting can be provided to single story nonresidential buildings of any size.

-Vertical glazing was found to be superior to sloped glazing facing the sun, which was difficult to shade and thus caused direct-beam light.

-Horizontal glazing (skylights) admitted excessive heat in summer and created complications for ceiling plenum and their content.

-Diffused light was the best. Light diffusion was provided by different means in the various experimental buildings: Iight colored walls, ceilings, and special diffusing grids.

-Daylighting of the perimeter zone of the building can be provided by ordinary windows and/or clerestories with the following design details:

-windows should be equipped with shading devices which prevent direct sun beam penetration and reflect it upwards, toward the ceiling.

- Clerestories should be either shaded as above or have light shelves with sufficient depth to prevent direct sun beam penetration and upper surface reflecting the beam upwards.

-Roof monitors provided the best light for core areas (of single story buildings)'

-Roof monitors with south glazing and diffusing grid provided good daylighting, even at high lighting level.

-Distributed small roof monitors provided better lighting than one large monitor.

-Lighting of "core" areas of deep spaces improves the quality of perimeter lighting by reducing excessive brightness contrast.

\subsubsection{Discussion of Specific ltems in the Performance of the Buildings}

\section{Impact of the "Solar" Features on Energy use}

The impact of the "solar" design on the energy use of the buildings was evaluated by comparing the actual energy use of the experimental buildings with the computed (simulated) energy use of similar buildings, designed according to BEPS (Building Energy Performance Standards) at the same places, but without the "solar" features (base cases). Both the measured and the simulated energy uses were subdivided into separate components such as lighting, heating, cooling, and equipment.

with this procedure it was found out that the actual, measured, energy use of the experimental buildings was consistently below 
the computed energy use of similar, but non-solar, buildings (figure 2.2 in Burt Hill et al., 1987). On average, the passive solar buildings have used $47 \%$ less energy then similar conventional buildings. (Gordon et al.,1986)

The main factor contributing to the reduction in energy use was the daylighting, and the associated reduction in the cooling load resulting from its higher thermal efficiency as compared with electrical lighting. The main reduction in the electrical lighting was during the summer months, when it also has the main impact on the reduction in air conditioning. Auxiliary heating energy was also reduced, as well as hot water supply, due to the use of solar energy.

It should be noted, however, that the actual energy use of the buildings was higher than the predicted energy use for the same selar buildings (fig. 2.4 in Burt Hill et al.). The main factor underestimated in the simulation was the energy for heating, despite of a warmer winter than the one assumed in the simulation.

In the Report it is suggested that changes in the building's use patterns (longer operation hours and more people, because of the popularity of the solar buildings) were the main reason for this discrepancy.

Alternatively, it may be suggested that the actual heat gain from some solar elements (e.g. roof monitors) was lower than the calculated value. The actual use of cooling energy of the experimental buildings was substantially lower than the predicted value, despite a greater number of cooling degree-days than that assumed in the simulation. This is consistent with the possibility that the actual heat gain from the solar elements was lower than the one calculated, a factor which would increase the heating load in winter and reduce the cooling load in summer.

To check this issue, which has to do with the simulation validity, it would be desirable to re-run the simulations with the actual use patterns of the buildings, even though the assumed climatic would be the available weather tapes. Calculations could then be corrected for the differences in the climatic conditions.

\section{Effect of Climatic Variations on Performance}

The experimental buildings were located in different climatic regions: cold sunny (e.g. Colorado, Utah) cold cloudy (the North-East, Alaska), as well as moderate regions (North Carolina). In all of them energy saving, mainly due to daylighting, was achieved by the solar features. It is noteworthy that daylighting was effective in reducing electrical lighting even in cloudy regions.

\section{Comments on Daylighting by Roof Monitors}

-In single story nonresidential buildings (and/or the upper story of multi-storied buildings) roof monitors facing south can provide high quality daylight in very significant proportion of the total Iighting needs, provided that the solar beam is reflected by suitable diffusers so that direct sunlight is prevented. 
- Daylighting by roof monitors can be applied regardless of the floor area size of the building. Therefore in single story buildings the "core" area, where full electrical lighting has to be provided during the daytime, can be effectively eliminated from the lighting view point.

-occupants satisfaction with the lighting conditions produced by south facing monitors was very high in all of the buildings which have used such monitors.

\section{The Role of Thermal Mass in Nonresidential buildings}

The effect of thermal mass in nonresidential buildings should be considered in relation to the use patterns of these buildings and the outdoor climatic conditions. Potentially, it can have different impacts on the heating and on the cooling loads of the buildings.

When a particular building is used only during the daytime hours as many offices and schools are being used, and when the daytime temperatures are below the comfort zone, thermal mass does not contribute significantly to energy conservation, although it can minimize overheating which may result from the high light level needed in offices and schools, and thus improve the indoor comfort. However, if the thermostat is set-back to a lower level during the night hours, the mass looses during the night heat which it had accumulated during the daytime. The following morning the cool mass absorbs extra heat, thus reducina the efficiency of the heating system and causing cold discomfort during the early morning hours.

This was actually observed in the experimental buildings which had high mass, such as the Mt. Airy library in NC. and the Community United Methodist Church in Mo., especially in mornings after cloudy days (Burt Hill et al., 1987).

It can be concluded therefore that in cold regions high mass in nonresidential buildings is not compatible with large thermostat setbacks, intended to conserve heating energy.

on the other hand, in regions and during periods of high daytime temperatures and cool nights, the thermal mass in a building can reduce both the rate of heating of the interior during the daytime and its rate of cooling during the night.

In this way the mass may help in maintaining the interior temperature around the comfort level, thus reaucing the of cooling needs during the day and heating needs during the night. Compared with a lightweight building a high mass one may thus consume less energy.

\section{Mass and Nocturnal Ventilation in Nonresidential Buildings}

Ventilation of the building space during the night hours can cool the interior mass. During the following day the cooled mass can serve as a sink for the heat generated within the building, lowering the rate of its temperature rise. The nocturnal ventilation in nonresidential buildings is usually provided mechanically.

One of the problems associated with this mode of cooling is that if the night temperature is too low the mass may be cooled to 
a temperature below the lower limit of the comfort zone. With the start of the building's occupation in the next morning the radiant environment (the temperature of the interior surfaces of the mass elements) might be too cold, even if the indoor air temperature is brought to the comfort level by the heating system.

One way by which this problem can be handled is to control the duration of the ventilation by the temperature of the mass. When the mass surface temperature drops below a pre-set level the ventilation fans could be stopped. This may insure that in the morning the indoor temperature is just at the lower limit of the comfort zone.

The situation with respect to this issue may be different if and when Phase Change Materials (PCM), in the form e.g. of ceiling tiles, plaster boards, etc., with phase transition temperature around the lower limit of the comfort zone, would be used as the "cold" storage medium.

In this case it would be possible to store large quantities of cooling energy without causing significant lowering of the radiant temperature.

The development of materials, components and application methods for storing night coolness and reducing the cooling load in nonresidential buildings deserves to be a high priority item for future research. The subject of PCM is discussed in details in Appendix $B$.

To the extent that material, components and design details for storing coolness during the night hours will be available it will enable also to utilize mechanical cooling during the night (off-peak) hours and reduce the daytime load. As the cost of night electricity for commercial buildings is often very much lower than the daytime cost, this would enable to reduce the overall cost of the air-conditioning and at the same time reduce the peak demand for electricity and power generation capacity.

\subsection{Boundaries of the Conditions to which the Lessons Learned from the DOE Program can be Applied}

Almost all of the buildings which were included in the DOE Nonresidential experimental buildings program were single story ones. Consequently, regardless of the size of their floor area, they were "skin dominated" or, more accurately, "roof dominated" buildings.

The fact that the whole space in single story buildings is under a roof made it possible to provide substantial daylighting to the building's core by south facing roof monitors. As a result, the daylighting potential, out of the total lighting needs and the total energy consumption, was much greater in the experimental buildings than what would be the case in multi-story Nonresidential buildings, which comprise the majority of the nonresidential buildings in urban areas, and which usually are "core dominated". 
Another feature of single story buildings is that the heat loss during the winter through the roof and the glazing exceeds in most cases the internal heat production and the solar gain. Thus, for example, in the Mt. Airy library, the heating energy in January was about twice the cooling energy in July (Figure 4-24 in Burt Hill (1987)). This again is very different from the situation in core dominated buildings.

In fact, in all of the experimental buildings the heating energy use far exceeded the cooling. In core dominated buildings the situation is very different and the cooling loads are a major energy end use. Any "solar technologies" which would reduce the daytime cooling load can have significant impact on the total energy consumption and expenses.

In consequence, also the relative saving of energy, which resulted in the experimental buildings from the daylight features, is significantly smaller than the saving which can expected from daylighting in the perimeter zones in multi-story buildings. In such buildings the cooling load would be relativel much greater than in the experimental buildings.

Finding ways to reduce the energy consumption (and cost) of daytime cooling, in addition to the benefits of perimeter daylighting, should be a high priority item in the quest for energy saving in nonresidential buildings.

Considering the very favorable performance of the solar energy utilization in the buildings built and evaluated in the DOE program it seems very desirable to investigate the possibilities of utilizing solar energy for daylighting, heating and mainly cooling in multi-story nonresidential buildings.

In summary, the DOE Program has demonstrated, as was discussed above, that solar energy in the form of daylighting can be applied to single story buildings of any size. Daylighting of the perimeter zone of the building can be provided by ordinary windows and/or clerestories. Roof monitors with south glazing and diffusing grid provided the best light for core areas (of the single story buildings).

Under these conditions daylighting is cost effective and improve the quality of the indoor environment. With appropriate controls of the electrical lighting it can save lighting energy and reduces the cooling load.

\subsection{Suggestions of Research which may Increase Solar Utilization and Improve Energy Use in Nonresidential Buildings .}

Most of the nonresidential buildings in urban areas are multi-story buildings. A significant part of the building's volume is in the "core" and does not have direct access to sunlight. Many problems related to solar utilization are different in multi story buildings from the ones encountered in single story buildings.

The following are suggestions in the opinion of the author,

for research on subjects which, address the main areas in which 
solar technologies can be applied to nonresidential buildings, especially multi-story large ones, in addition to the present application of daylighting the perimeter zones and upper stories of buildings.

\section{A- Cooling Nonresidential Buildings by Storing Night Cold in PCM Surface Elements}

In many multi-story nonresidential (especially commercial)
buildings cooling is a major energy end use. The use of
electricity for the air conditioning accentuate the problem of
the peak load and the pressure to increase power generation
capacity. Development of the technology for storing night
coolness (e.g. by nocturnal cooling of a thermal storage
elements), which can serve as a heat sink during the following
day, can be very valuable.
Whenever the outdoor night temperature is cool enough convective
cooling of the cold storage elements by forced ventilation would
be preferable. During periods of too warm nights, mechanical
cooling of the storage elements by off-peak night electricity
could reduce the load during the daytime. such technologies
would also help in load management of electrical utilities by
reducing peak power loads. Solutions for nonresidential build-
ings may be different from those for residential ones.
Development of such technology may call for development of
appropriate theimal storage materials and systems for the
interfacing the ventilation cooling and the mechanical cooling
by night electricity.

In the context of the commercial buildings in the USA, where high mass construction (e.g. reinforced concrete walls and floors) is the exception, and where structural load is often a major issue and space is at premium, PCM ceiling and wall surfage elements, with phase transition temperature of about $15-18^{\circ} \mathrm{C}$ $(60-65 \mathrm{~F})$, seem to be an interesting solution.

Although the effective unit area heat storage capacity of PCM elements is limited by the low thermal conductivity and the resulting small thickness of such elements, the large interior surface area may provide significant capacity to absorbs during the daytime a significant proportion, or even most, of the internal heat generation.

Such cold storage elements could be cooled at night when the building is not occupied, e.g. by cool air circulation in the indoor space or, in the case of PCM ceiling tiles, in the air plenum above them. During the following day they can passively absorb heat from the indoor space and thus reduce the cooling load.

\section{B- Storing Night Cold in PCM elements Within Ceiling Air Spaces of Nonresidential Buildings}

Nonresidential buildings usually have an air space between the structural ceiling and the false ceiling, in which the various ducts, pipes, wires, etc. are placed. It seems possible to design 
these airspaces in such a way that they could be ventilated during the night hours independently of the indoor space.

If PCM elements, with phase transition temperature of about 60 of $\left(15^{\circ} \mathrm{C}\right)$, will be placed within the airspace it would enable to store cold energy during the night, either by ventilation or by the use of nocturnal mechanical cooling.

C- Solar Heating of the Southern part and the Upper Floor of the Building

The experience of the monitored experimental nonresidential buildings suggests that the daylighting elements (windows, clerestories and roof monitored) which were applied in these buildings were not very efficient in providing solar heating in winter (see discussion above 2.2.2).

It may be that the measures of glare control and prevention of direct sun beam in the interior are the reasons for the apparent low heating efficiency. In any case, it seems advisable to develope specialized solar heating systems for nonresidential buildings which would provide heat without sun penetration. systems similar to the one developed by Trombe (see 3.5 below) may be an interesting direction for such development.

\subsection{References to Non residential Buildings}

-Burt Hill Kosar Rittlemann Assoc. and Min Kantrowitz Assoc. (1987): "Commercial Building Design: Integrating Climate, Comfort and Cost". Van Nostrand Reinhold Co., N.Y.

-Gordon,H.T., P.R.Rittlemann, J.Estoque, G.K.Hart and M. Kantrowitz (1986): "Passive Solar Energy For non-residential Buildings". In: K.W.Boer, Ed.: Advances in Solar Energy. Vol. 3. Plenum Press.

-Johnson, K. and S. Selkowitz (1986): "Light Guide Design Principles". Proceedings II, Int. Daylighting Conf. Long Beach, CA.

-Kaino, T., K. Jinguji and S. Nara (1983): "Low loss poly (methilmethacrilate-d8) core optical fibers." Applied Physics Letter $42(7)$, pp. 555-563.-Kroner, $W$ (undated): "Performance Summary of Nineteen Passive Solar Commercial Buildings in the United States of Americal. Center For Architectural Research, Rensselaer Polytechnic Institute, Troy, N.Y.

-Ternoey, S., L. Bickle, C. Robbins, R. Busch and K.Mccord (1985)

"The Design' of Energy Responsive Commercial Buildings". John Wiley \& Sons. N.Y. 


\section{Section 3}

\section{Characteristics of Various Passive Solar Heating Systems}

In this section various passive solar heating systems are discussed. The main design factors affecting their performance, their relative advantages and the main problems associated with them are analyzed. Emphasis is placed on the architectural desig issues associated with the different passive solar heating systems.

Additional information, on the thermal characteristics and "solar" performance of the different systems, the reader can find in Balcomb, et al (1980), Jones et al (1982), Mazria (1979), and other books cited in the reference Iist.

The solar passive heating systems discussed in this section are:

- Direct Gain

- Collecting storage Walls:

a- Masonry walls

b- Water walls

- Sun Spaces

- Convective Loops:

a- Below floor collectors

b- Vertical wall collectors

In practice, combining several solar system in one building can increase the overall solar contribution, with a given amount of solar glazing, and mitigates some of the problems associated with the different systems.

Providing Direct Gain and Trombe walls in the same building, and even with different proportions in the same rooms, enables fast heating in the mornings and throughout the daytime from the DG, and continued heat supply during the evenings and night hours.' Combining sunspaces with Direct Gain enables having large overali collection area with heat transfer to the interior by convection, without too much direct sun penetration

With such combinations of different systems the total solar glazing area could be sized for a high solar fraction without too much risk of glare, overheating, fading of fabrics, etc., problems which are likely with the same glazing area, but with only Direct Gain as the solar heat source.

But, to simplify the discussion of the special characteristics of the different system, they will be discussed separately.

\subsection{Direct Gain}

In Direct Gain buildings the inhabited spaces are heated by the sun, admitted often through conventional windows, skylights, etc. The mass of the building fabric itself acts as the necessar 
thermal storage material, to store excess solar energy during the sunny hours and release it back during the night. Therefore, in this passive solar heating system, more then in any other system, the architectural details determine the energy performance and indoor comfort conditions. [FIg. 3.1].

Effective air circulation between "solar" rooms and "non solar" spaces is vital to the success of direct gain systems when not all the rooms have solar access. In some circumstances, fan assisted circulation, through ducts or false ceilings, may be necessary.

The main factors affecting the performance of "Direct Gain" buildings are:

-Location of solar glazing

-sizing of solar glazing

-Choice of glazing type

-Thermal quality of the building as a whole

-The amount and design details of the mass available for thermal storage

-Thermal coupling between "solar" and "non solar" rooms

-Control options applicable to direct gain systems

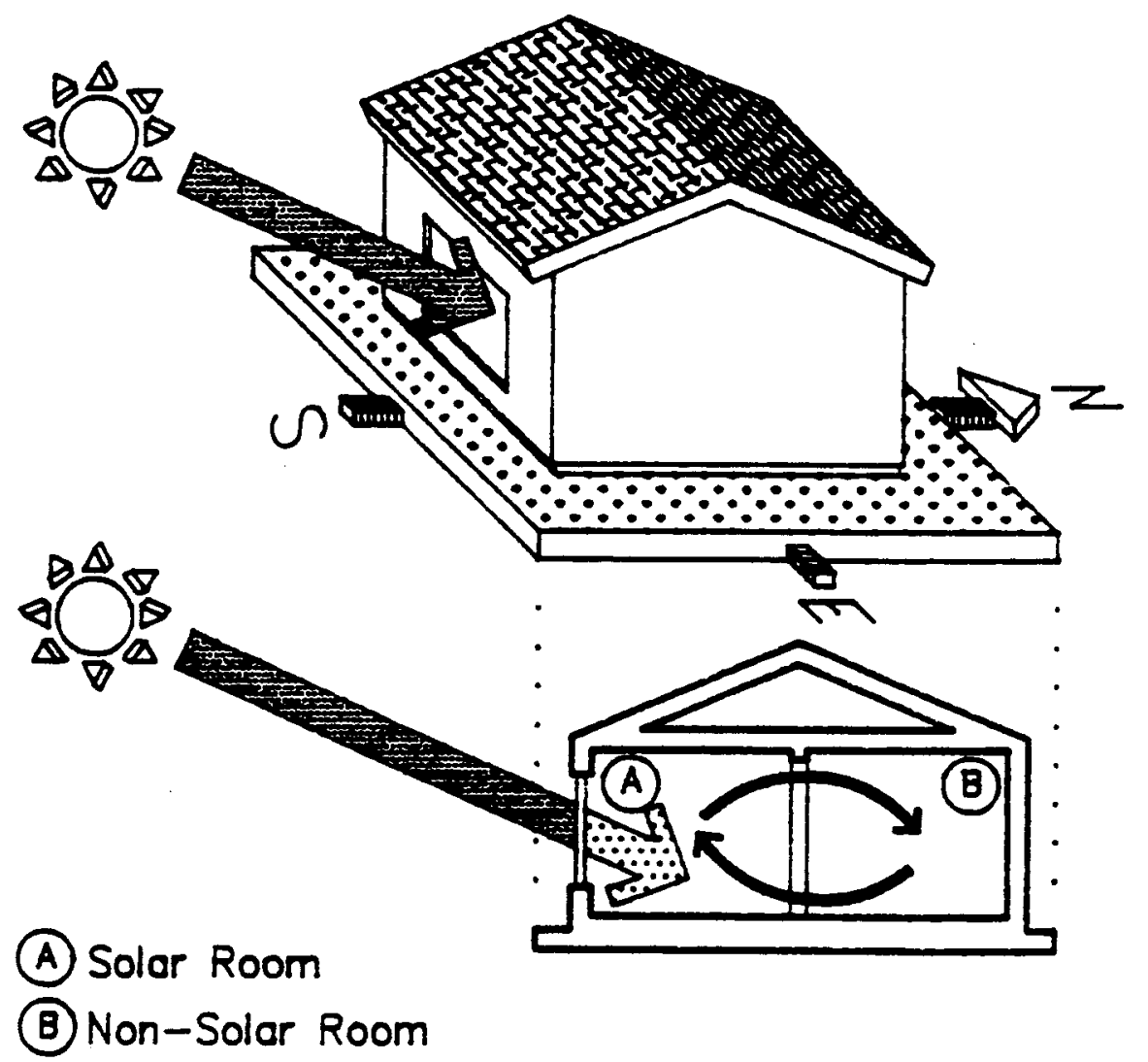

FIG. 3.A.1: Direct Gain Through Windows. 


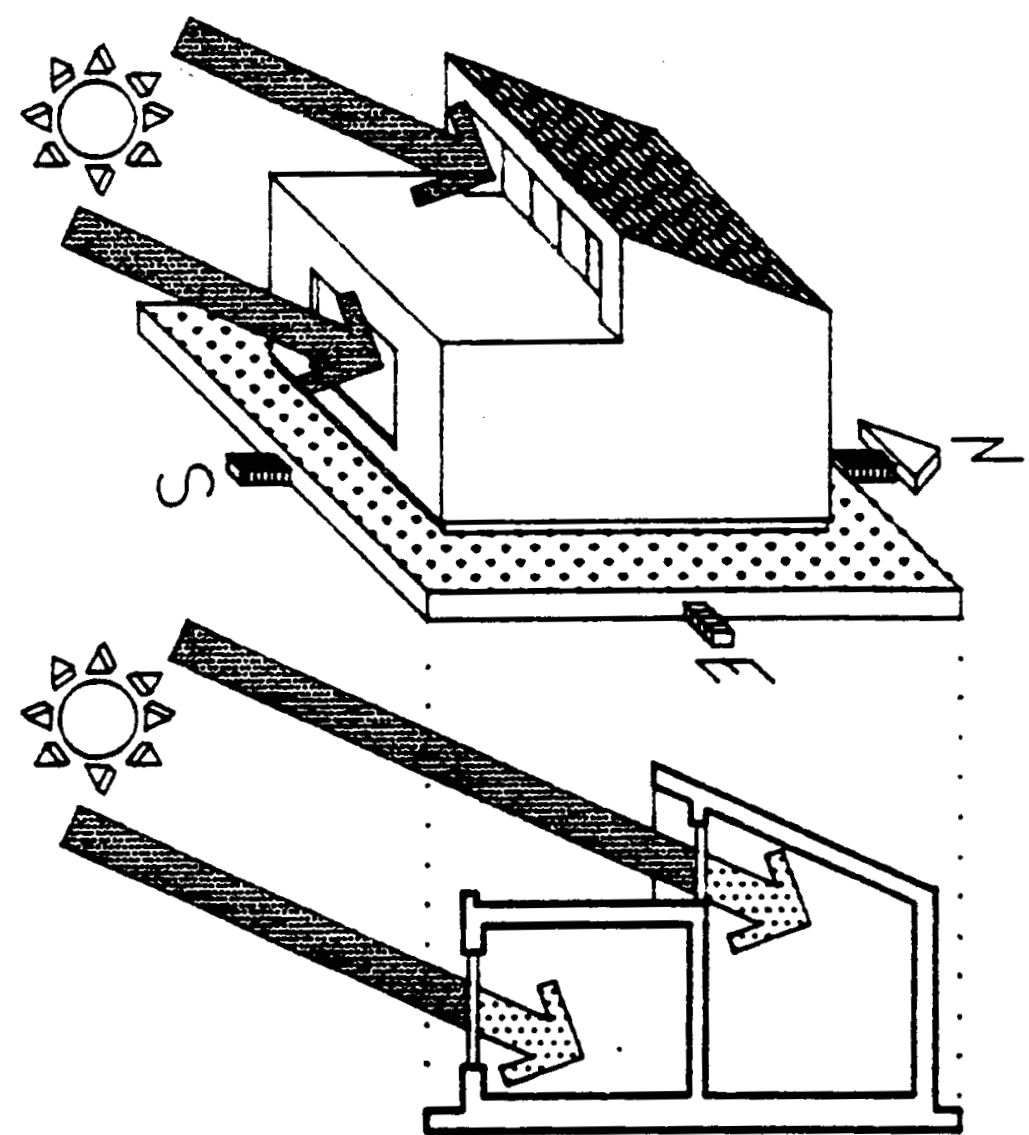

FIG. 3.A.2: Direct Gain Through Clerestory and Windows

\subsubsection{Location of Solar Glazing for Direct Gain}

The major advantage of Direct Gain systems is that significant amounts of solar energy may be collected through the elements which would be found in the building in any case, namely windows or roof monitors facing south. This makes Direct Gain demonstrable the most cost effective of all solar heating systems.From the viewpoint of energy collection, this is also the most efficient system, as energy is collected at the lowest possible temperature, namely at or near the comfort level.

There are a number of basic differences between windows, clerestories and roof monitors in their implications for buildin design. While with south facing windows the incoming energy is concentrated in southern rooms, or even in the southern parts of larger spaces, with roof monitors solar energy may be introduced directly at desired points in the building, even to rooms without southern exposure.

Furthermore, more efficient use of the building mass for energy storage is possible with roof monitors by utilizing internal partitions and even northern exterior walls (if they are sufficiently insulated externally). However, the use of the roof for solar admission is applicable only to single story buildings or to the upper story of multi storied ones. 


\subsubsection{Size of the Solar Glazing}

It is often tempting to make the area of southern glazing as large as the building design allows, in order to maximize the penetrating solar energy during the heating season. However, such incoming solar radiation may raise the indoor temperature, which may then exceed comfort conditions, even in winter in sunny days. The problem can be more serious during the spring, summer and Fall seasons.

The magnitude of such temperature rise depends on the balance between the instantaneous incoming solar radiation, the amount stored for later use, and heat loss from the building. The maximum size of solar glazing should therefore be related to the expected temperature rise on clear days, as well as the likelihood of overheating in summer.

There are two other negative effects of too large glazing areas. First, glazing is usually the weakest point in the thermal quality of the building envelope, causing excessive heat loss at night. From the solar energy utilization viewpoint the benefits from increasing size of glazing is of diminishing returns, while the heat loss at night throughout the glazing is proportional to the glazing size, unless the area of the solar glazing is equipped with operable night insulation.

second, the penalty of summer overheating in regions with hot summers, from too large areas of solar glazing, may well be greater than the winter benefits. This penalty can also be eliminated by insulated operable shades which protect the building from daytime overheating while enabling fast cooling in the evenings by large openable windows.

There is no single, simple computation method for arriving at the desired glazing size, taking into account all the various factors involved, but from experience with occupied residential buildings employing Direct Gain, the following "rule of thumb" gives guidance for the initial design.

In a region of hot summers "solar" glazing should be about 10-15\% of the total heated floor area. It may reach $35 \%$ in the "solar rooms" where it is located, as long as problems of glare, overheating, fading of fabrics, etc., are solved. Effective convective heat transfer should be secured between the "solar" and the "non solar" rooms, during the sunny hours, through large internal openings.

In cold regions larger solar glazing area (e.g. 25\% of the heated area may be appropriate, provided that high thermal resistance glazing is used (e.g. double glazing), together or with the provision of effective night insulation.

Calculations based on energy criteria alone may tend to show cost benefits in"solar saving" increases for glazing areas up to about 50\% and more of the floor area, especially in poorly insulated buildings. But the excessive solar energy may the cause thermal discomfort on clear days, and overheating in summer. It will also aggravate all the functional problems associated with Direct Gain. 
3.1.3 Choice of the Glazing Type

Many different kinds of glazing are available. The properties of the glazing, which determine its performance as a solar collector, are:

- Average solar transmittance.

- The effective $U$ value for conductive heat loss.

If night insulation is applied then different $U$ values will be effective during the daytime and at night.

comment: It should be noted that not all of the solar gain is useful in reducing auxiliary heating. With higher indoor temperatures, common in Direct Gain buildings during daytime, heat loss through the building fabric is greater. If the temperature exceeds the maximum for comfort, excess heat may be "vented out". Consequently the actual "solar saving" is usually less than the net solar energy gain.

Note that the above discussion of energy balance highlights a common inherent inconsistency in some energy conservation standards. Southern glazing contributes to the calculated building heat loss coefficient, even though in reality it may save energy when exposed to sufficient solar radiation and when sufficient thermal mass is available to store the energy for night time use.

\subsubsection{Thermal Mass and Heat Storage Capacity in "DIRECT GAIN" Buildings}

Thermal mass "stores" energy from sunlit hours, to be given off back during the night. From the point of view of the daily cycle only limited thicknesses of storage elements are useful, and this may determine the manner in which thermal mass is incorporated in the building's structural elements.

At present, the most common materials for thermal storage are masonry materials like concrete, bricks, etc. There are two other options of materials for thermal storage, beside masonry materials. One is to use water in various types of containers. The other option is to use "phase change materials" (PCM). Masonry materials and water as storage options are discussed below. The use of PCM is discussed in Appendix B.

\subsubsection{Thermal Storage by Masonry Material}

The heat capacity of masonry materials is a function of their specific heat, and of their mass. Since the specific heat of almost all masonry materials: concrete, brick, stone, adobe, etc., is similar (about 0.24 whr/kg.oc), the nominal heat capacity is essentially proportional to the total volume and the density of the material.

However, the effectiveness of a thermal storage element depends on the rate at which heat is absorbed in it and later is given back to the indoor air. Therefore, the effectiveness of various materials to serve as thermal storage is not the same, but varie with their thermal conductivity. The higher the conductivity the more efficient is the material as a storage medium. 
The overall effective capacity of a "solar" space to store excess solar energy during the daytime and to release it to the indoor space during the night is expressed by its "diurnal heat capacity". Mathematical models for calculating the "effective" diurnal heat capacity are presented in Givoni (1987).

Generally, the amount of heat capacity should be related to the amount of the penetrating solar radiation on clear days. In a given location this means that the minimum amount of heat storage should be related to the size of the solar glazing.

For a given size of the glazing the performance of the building will improve with the increase in the amount of heat capacity, up to a given limit.

As a minimum, an effective diurnal heat capacity of about 220 whr ${ }^{\circ} \mathrm{C}$ (per squm of glazing) should be considered. When the heat storage is provided by concrete it means about 1.05 tons of concrete, or about $0.45 \mathrm{cum}$. (with density of $2200 \mathrm{~kg} / \mathrm{cum}$ ) for each squm of solar glazing. In a 24 hour cycle, only a thickness of up to about $15 \mathrm{~cm}$ will be effective, so that the minimum area of a storage element made of concrete should be at least 6 times the area of the glazing. If the thickness of the storage elements is greater, the area of concrete which will be required for effective storage will not decrease proportionately, due to the lower storage potential of the deeper layers.

other masonry materials, with lower thermal conductivity, will require even larger minimum area (and thinner layers) for effective thermal storage.

\subsubsection{Water as a Thermal Storage Material in Direct Gain Buildings}

Water has much higher specific heat (about 4.5 times that of masonry materials). Therefore also the volumetric heat capacity of water is higher than that of the denser conventional building

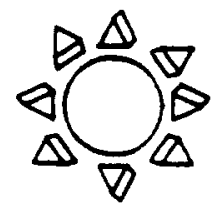

Fig. 3.A.3: Water as a

Thermal Storage in

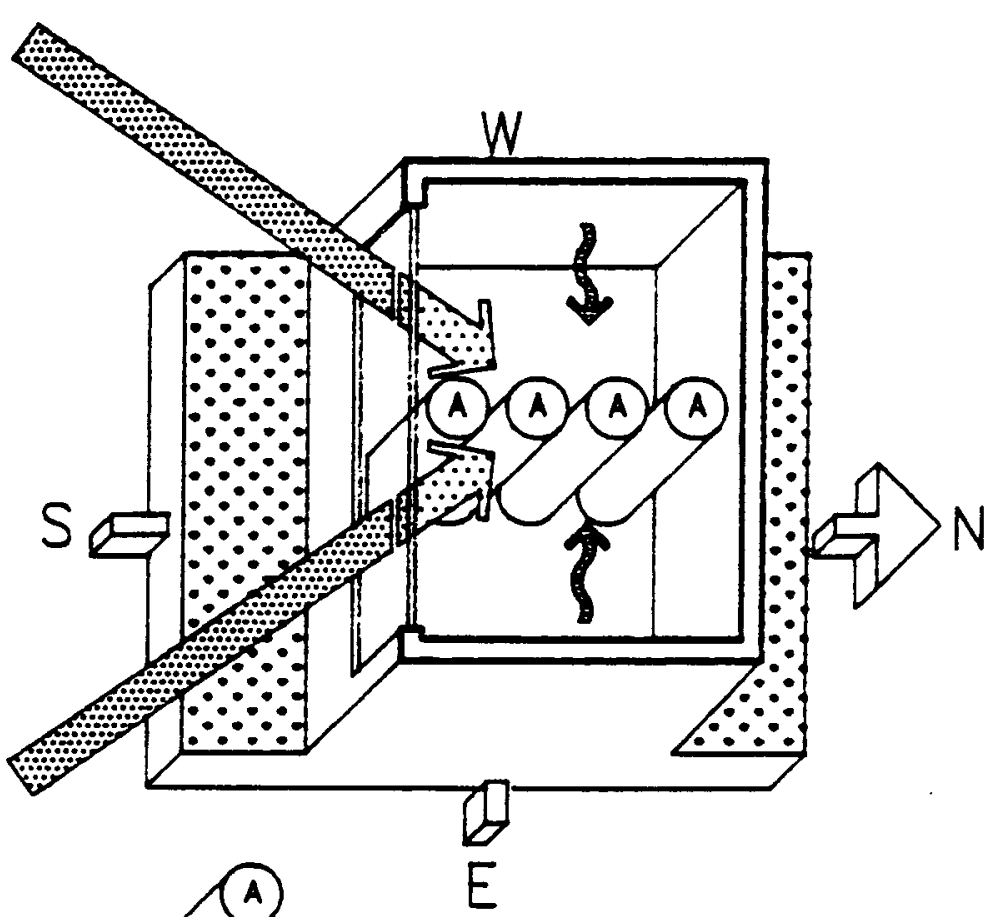

Direct Gain

- water therMal storage 
materials (more than twice).

Water in suitable containers, placed within the heated space, can provide the required storage capacity. The containers can be either opaque or transparent (or translucent). The surface area of the containers may by the limiting factor in the transfe of heat in and out of the containers and storage capacity of the water.

Common containers used in solar buildings are vertical cylinders made of steel or plastics. The water can be clear or colored by a dye. Treatment against fungi growth is recommended.

The surface area of water containers is usually much smaller than the area of the room surfaces utilized when thermal storage is in conventional building materials. The whole mass of the water is participating in the storage of the energy upon its absorption. Direct exposure to the solar beam maximizes the absorption and storage efficiency. 


\subsection{Masonry Collecting/Storage Walls}

This system was first built by Felix Trombe and Jacques Michel at odeillo, France 1967. and is commonly referred to as a"Trombe Wall" system. In the simplest form, it consists of glazing place in front of a south facing massive, conductive wall e.g. of dense concrete, with an air gap in between. The exterior surface of the wall is painted a dark color or given a "selective surfa to enhance absorption of radiation. Solar radiation penetrating the glazing is absorbed into the massive wall, raising the external surface temperature and that of the air in contact with it. The rate at which heat is transmitted through the wall to the interior is determined by the conductivity of the material and its thickness. The building interior is then heated by long wave radiation and convection from the wall's internal face. Typical thickness of such walls, in either concrete or brick, is 20-40 cm.

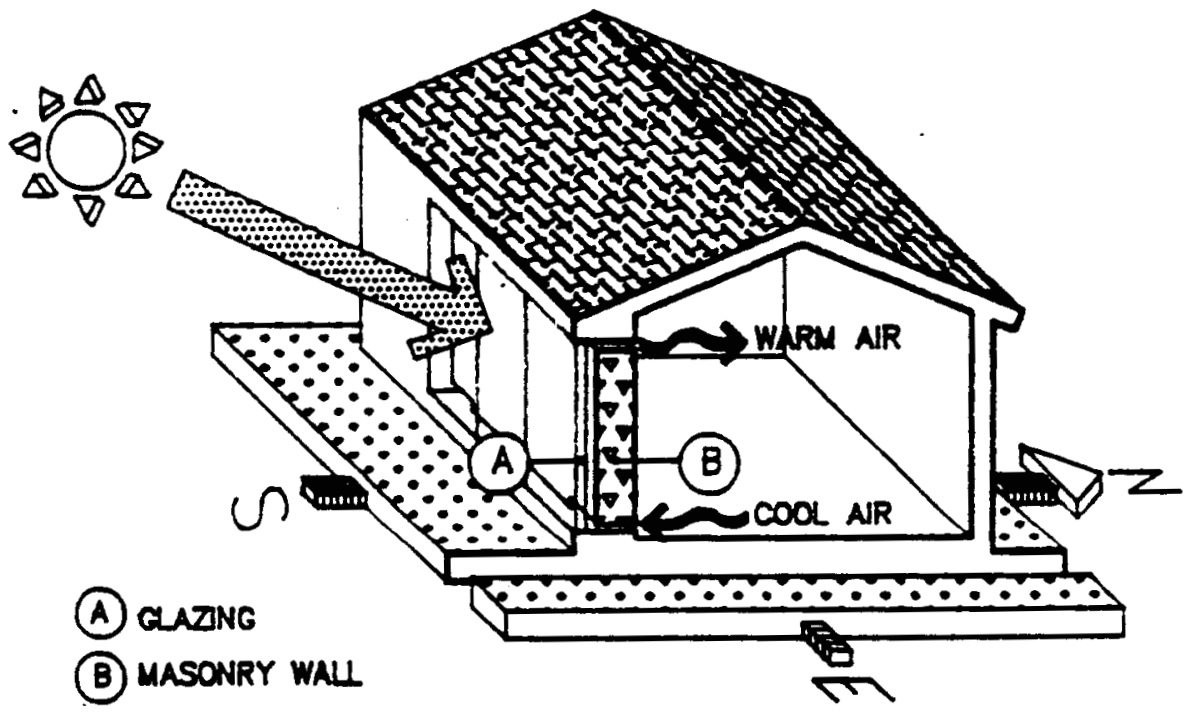

FIG. 3.B.1:Masonry Collecting/Sorage Walls

If vents are provided, both at the bottom and at the top of the wall, then the warm air in the air space between the glazing and the dark surface rises and flows into the building through the upper vents. Room air flows through the bottom vents into the airspace. Thus a thermosyphonic air flow is established, transferring heat to the room by convection.

The major advantages of thermal storage walls are: 
- The indoor temperatures are more stable than in most other passive systems.

- Direct sunshine, and its associated functional problems, are eliminated from the inhabited space.

- Installation is relatively inexpensive where construction would normally be masonry, or for retrofitting existing buildings with uninsulated massive external walls.

Some practical shortcomings and disadvantages are:

- A room relying only on this system is denied light and view from the south.

- In a climate with extended cold cloudy periods, without adequate operable insulation with closely controlled operation, the wall may become a heat sink. This drawback may be minimized by the use of a selective surface, or prevented by the effective use of operable insulation.

- summer overheating problems may outweigh winter benefits in regions with mild winters and hot summers unless effective shading, also from ground reflected radiation, is provided.

- This system can only be used in practice to heat the southern rooms of which it forms one wall. Even in such rooms the effective heating is felt only to a depth of about $11 / 2$ times the wall's height.

- In multi-story buildings applications problems with maintenance of the glazing may necessitate the provision of access balconies. Note, however, that such balconies can function as the shading overhang for the glazing below.

Some of the functional disadvantages of thermal storage wall systems may be eliminated by the incorporation of windows alongside or within the wall. Direct Gain through these windows can provide quick heating of the space in the morning, while the mass was is still cold.

The integration of windows within the wall will also avoid the darkness, blocking of view and air, and general "heaviness" associated with early examples this system.

\subsubsection{Design Factors Affecting Performance of Masonry Thermal Storage Walls}

a) Material's Properties for Thermal Storage Walls

Thermal storage walls combine in one element the functions of collection, transfer and storage of the solar energy.

For optimal energy transfer through the wall, materials of relatively high thermal conductivity are necessary. In practice, this usually means cast concrete, solid concrete blocks or dense bricks. Materials of lower conductivity, like adobe, will result in lower efficiency.

\section{b) Thickness of the Wall}

From point of view of total energy saving, the thickness will have small effect, but is a major factor from the indoor temperature view point. From this aspect, and also in considering the time of peak heating, the optimal thickness for concrete in residential buildings is approximately $30 \mathrm{~cm}$. For each $10 \mathrm{~cm}$ of concrete, there is a lag of about 2-2.5 hours between peak solar absorption, and delivery at the inside. Below a thickness 
of about $20 \mathrm{~cm}$ the internal temperature swing may be excessive.

Thin conductive walls, of about $20 \mathrm{~cm}$, will heat up rapidly at their interior and thus may be useful in winter in buildings which are used only during the day, like schools, offices, etc. To prevent too high temperature elevation additional thermal storage, in the other walls, ceiling or the floor, is desirable. Comment: In summer, and also in spring and fall, the thermal walls may cause severe heat stress unless they can be shaded effectively and, in regions with hot summers, also insulated during the daytime.

\section{c) Colors and Surface Properties}

The higher the solar absorption of the external wall surface, the higher is the heat gain through the system. The most common choice is therefore a dark paint. The heat lost outwards by reradiation from a dark painted surface is, however, also very high due to the high emissivity of ordinary paints for longwave infrared.

The heat loss to the outdoor can be reduced by applying a "selective" surface to the wall, in the form of a metallic film glued to the wall. Application of a selective film to a concrete wall requires a very smooth surface of the concrete. This point should be taken care of during the casting of the concrete.

About the same performance will be obtained if, instead of painting the wall with an ordinary black (or other dark) paint and providing it with double glazing, it will have a selective surface with single glazing. Compared with a wall with ordinary dark surface and single glazing, the one with a selective surface and a single glazing will have a significantly higher performance. For a given energy needs a smalier area will thus be required, facilitating also summer.shading and/or insulation.

\section{d) Effect of Vents on Performance}

Under optimal flow conditions about $30 \%$ of the total energy flow, in "vented" walls made of concrete about $30 \mathrm{~cm}$ thick, is by convection and $70 \%$ is by conduction. As the temperature in the air space is lowered, less heat is lost through the glazing. Therefore the overall efficiency is higher by about $10 \%$ in systems with "vented" walls as compared with unvented walls.

Note, however, that if the vents are not closed effectively at night the reverse air flow lowers the efficiency of "vented" walls well below the level of unvented ones.

Experience in buildings where vents have been installed has shown that the daily handling of the vents is bothersome, and also that the vents interfere with "furnishing" the rooms. As a result new buildings which were built in Santa $F e$, for example with collecting storage walls, mostly have unvented walls.

\section{e) Insulation and Shading of Thermal Storage Walls}

In regigns with mild winters (mid- winter average temperature about $5 \mathrm{C}$ ) night insulation may not be justified from the solar heating aspect. However, in regions with sunny summers and average mid-summer daytime temperature about $27 \mathrm{C}$, the elevation 


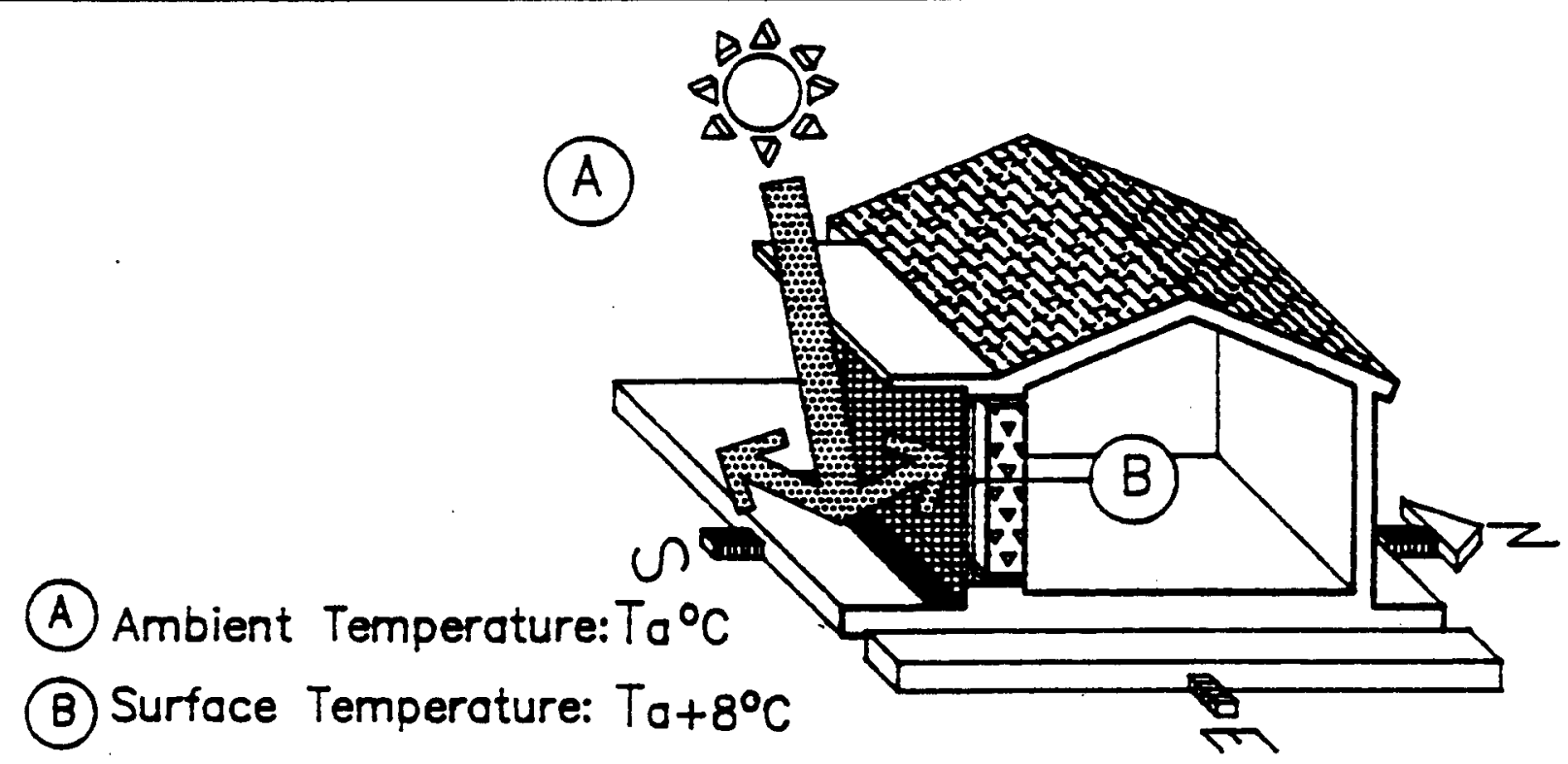

FIG. 3.B.2: Insulation \& Shading of Thermal Storage Walls

of the external surface temperature of the glazed dark wall can cause serious overheating of the interior.

A study of a UCLA student in Israel (Moses, 1983) has demonstrated that the external surface temperature of a collecting storage wall, made of concrete with a dark color (absorption about .85), when the wall and a strip in front of it were completely shaded from direct radiation by a deep overhang, is elevated above the ambient air by up to $8 \mathrm{C}$. This elevation is caused entirely by the diffused and mainly the reflected solar radiation. It demonstrates that in regions with sunny hot summers it is essential to insure complete shading of the wall, also from radiation reflected from the ground. This can be accomplished only by vertical shading, either by rollable shades or by shading panels which are installed in summer and removed in winter.

\section{f) Design Modifications for Improved Maintenance}

When an accessible space, about $2^{\prime}$ wide, is left between the glazing and the wall it is possible to clean the glazing from the inside, to repair it and also to open part of it in summer for ventilation. Such a space also enable provision of operable night insulation and summer shading protected from the winds.

This wider "air space" can facilitate greatly the application of thermal storage walls to highrise buildings, where maintenance would be very complex in the case of a wall with the conventional inaccessible air space. The author suggests that the thermal performance of such sunspaces will be studied.

3.2.2 Collecting/Storage Water Walls

As an alternative to masonry collecting storage walls, water in various containers, behind the solar glazing, can be utilized for collecting and storing solar energy. The main advantage of water as a heat storage material, compared with masonry materials, is its much higher specific heat. Compared with a value of $c=1.16$ (wh/kgC) for water, the corresponding value of 
almost all masonry materials is about $c=0.25$. Even on a volumetric basis the heat capacity of one cu-m of water ( 1160 wh/cumoc) contains about 2.5 more heat than dense concrete. With other masonry materials, like bricks etc., the comparison is even more favorable. This factor is of particular importance in high rise buildings, where space itself is expensive and extra weight lead to structural expenses, to support the heavier load.

Because of the high rate of convective heat transfer in water, the whole mass in a container heated on one side by solar energy participates almost instantaneously in the storage process, leading to lower temperature of the absorbing surface.Consequently the collection efficiency of a water wall is higher than that of concrete wall with the same absorption and glazing conditions.

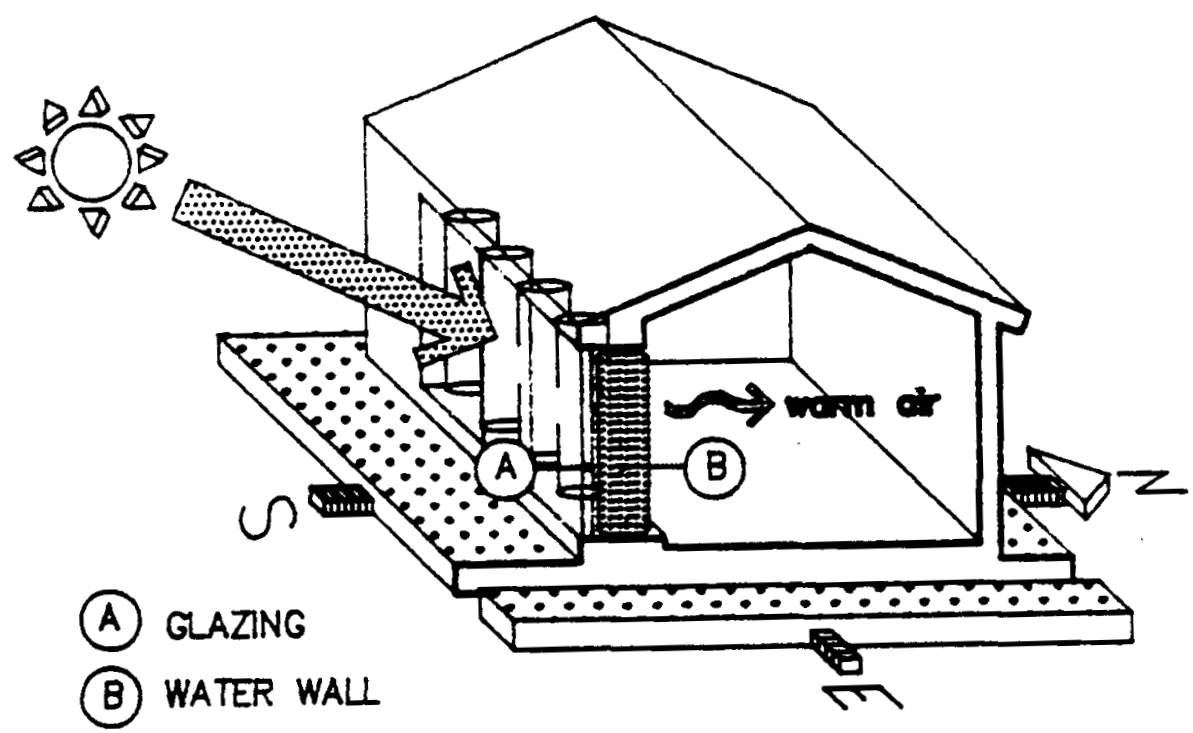

FIG. 3.B.3: Collecting / Storage Water Walls

on the other hand, at night the surface temperature of a water wall will be higher than that of the concrete wall, resulting in a higher heat loss, unless the walls are insulated at night. water walls have a very small time lag. But as their indoor temperature swing, in rooms with water walls about $20 \mathrm{~cm}$. thick, is usually very small the problem of time lag is of minor significance anyway.

The main design issue with water walls is the choice of containers. A variety of ideas about suitable containers were actualiy implemented. Steve Baer of "zomework"in Albuquerque, New Mexico, was the first who tried a water wall (except for the experimental building No. II of M.I.T. in 1947). Baer has used water filled oil drums of 55 gallons, placed horizontally on racks behind glazing. A hinged insulation panel,with reflective layer, is opened during the day (acting as a reflector to increase the impinging radiation), and is closed for the night. In summer it is possible, of course, to reverse the timin 
of opening and closing, to minimize the rate of heating and maximize the rate of cooling.

Steve Baer's house presents a very pleasing architectural interior, with natural light diffusing along the spaces between the drums. Such a drum wall may be inexpensive, because the oil drums are mass produced. Its drawback is the larger space consumed by the drums.

Jonathan Hamond, in Davis, California, has used vertical steel culverts as containers. Several buildings in Davis have used these culverts for water walls.

The containers can also be translucent plastic tubes. When filled with water they absorb part of the radiation and transmit the rest indoors. In this way the result is a combination of Direct Gain and a collecting storage wall. The indoor light transmitted through the water filled translucent tubes is soft and pleasant. It seems that most of the solar buildings with water walls in New Mexico, especially schools, use plastic tubes as the water containers. 


\subsection{Sunspaces}

\subsubsection{General Discussion}

In the section dealing with direct gain solar heating, a number of disadvantages arising from the admission of sunshine directly into the inhabited space were discussed. Most of these problems may be eliminated by the use of auxiliary spaces for the collection of heat, the so called "sun spaces".

A sunspace is a glazed area to the south of the main body of the building in which daytime temperatures are allowed to rise to higher levels and night temperatures allowed to drop to lower levels than the accepted indoor comfort range. Heat is transferred from the sunspace to the adjoining rooms mainly by convection through doors, which are open during the sunny hours and closed at night.

Sun spaces contribute to the thermal comfort in the principle spaces and to the overall liveliness of the dwelling in three main ways:

a) By becoming an intermediate environment between the interior and the exterior of the building, they buffer the main spaces from extremes of exposure, thus reducing the potential temperature fluctuation, glare and the fading of fabrics and furniture which may result from excessive indoor sunshine.

b) They may increase the heat collection capacity of a facade, by allowing larger glazing areas than in practical with Direct

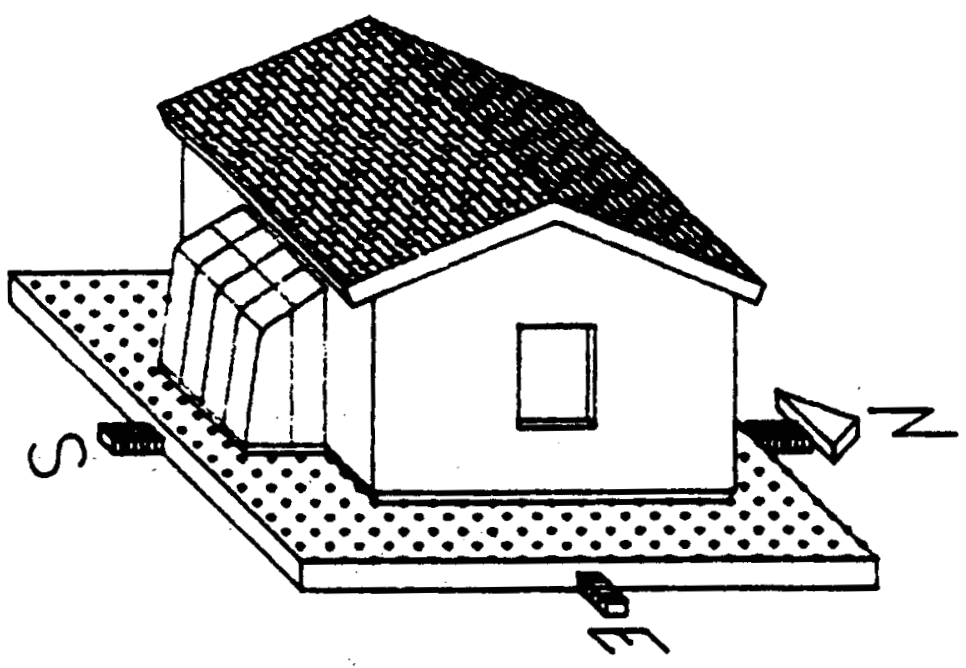

Attoched. Greenhouse

FIG.3.C1: Greenhouses Types 
Gain. Being separated from the main spaces of the building, a much greater "swing" may be accommodated in sun spaces than can be tolerated in non isolated Direct Gain systems.

c) The sunspace area itself can constitute an additional living space in the winter and the transitional seasons. With appropriate provision of shading and ventilation in summer such spaces may be pleasant environments, for intermittent use, year round.

on the other hand, the collection efficiency per unit area of Pazing of sunspaces, as compared with direct gain, is lower, mainly due to the higher daytime temperature in the sun space, which causes a greater heat loss to the outdoors.

From the viewpoint of design and thermal characteristics,two types of sun spaces may be distinguished:

A) Modified Greenhouses, with a glazed roof and often also with tilted glazed walls.

B) Sun Porches, with horizontal opaque and insulated roof and the glazing only in vertical position.

It is of interest to contrast the thermal characteristics of

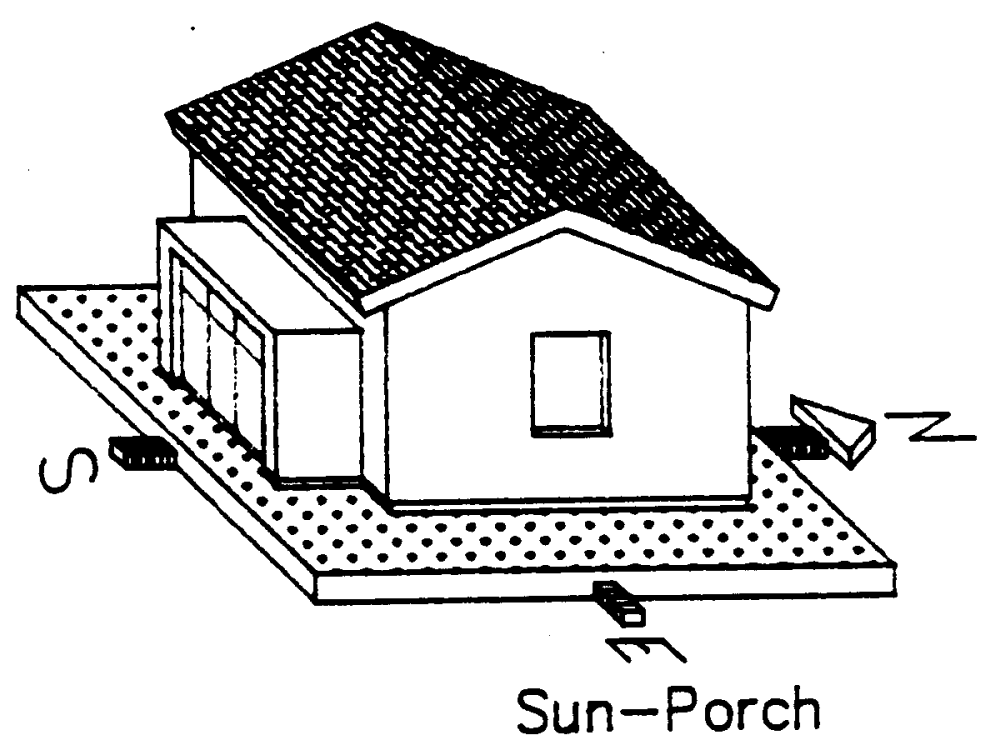

FIG.3.C2: Greenhouses Types

Direct Gain on the one hand, and of sunspaces, especially solar porches, on the other hand, during the summer, and to compare their impact on the indoor climate, assuming the same area of solar glazing.

In the case of Direct Gain, the glazing form an integral part of the building's envelope. Conductive and solar reflected heat 
gains may constitute a major part of the total heat gain, especially when the other walls and the roof are well insulated. On the other hand in the case of sunspaces the total size of the doors connecting the sunspace to the rooms behind is usually only a small fraction of the glazing area of the sunspace. When the sunspace is well ventilated, as will usually be the case in summer, its air temperature is close to that of the outdoor.

Even when the connecting doors are glazed the heat gain through them will be in proportion to their size, namely much less than in the case of a building heated by Direct Gain with the same glazing area.

Furthermore, because of the smalier size of the doors it is easier to accommodate them with operable insulation, thus minimizing heat loss at night in winter and daytime heat gain in summer.

Consequently, sunspaces with appropriate details enable better indoor comfort conditions than is achievable with Direct Gain, both during the summer and the winter. This is achieved, of course, at a higher cost of construction.

\subsubsection{Modified Greenhouses}

This type of a sunspace is characterized, from the thermal aspect, by a tilted or curved glazed roof. The glazed roof serve to maximize the incoming radiation, both by the use of a greater glazed area and by its being tilted, thereby receiving winter sunlight at a more optimal angle than vertical glazing, increasing the solar energy collection. on the other hand, such a form is also subject to the maximum heat losses during periods without sunshine, particularly loss by long wave radiation to the night sky from the horizontal part of the glazing. Therefore this type has a larger temperature fluctuations, both winter and summer, than the sun porches. Furthermore, the technical difficulties and cost of using operable shading or insulation on the horizontal and sloping surface make this configuration more susceptible to summer overheating.

\subsubsection{Sun Porches}

In this form, the opaque and insulated roof eliminates the problems of overhead glazing. As a result the potential heat gain in winter is diminished, but that for control and year round use increases greatly, especially in hot regions.

As all the glazing is vertical, conventional window elements may be utilized and if required, both shading and insulation are relatively easy to install. If a sufficient portion of the glazing is made openable, such a space becomes the equivalent of a shaded outdoor porch for summer use, shading also the wall behind. Therefore glazed porches with opaque roofs have been a traditional architectural feature in regions with cool winters and hot summers. 


\subsubsection{Applicability of Sun Spaces to Different Building Types}

Sunspaces, especially sun porches, may be applied to buildings of almost any type, height or size, provided they have a facade with a southern orientation. But there are important functional differences between applications, both from the building design considerations and from the energy aspects.

Sun porches can be applied to the south facade of any building, regardless of its height, because all the glazing is vertical.

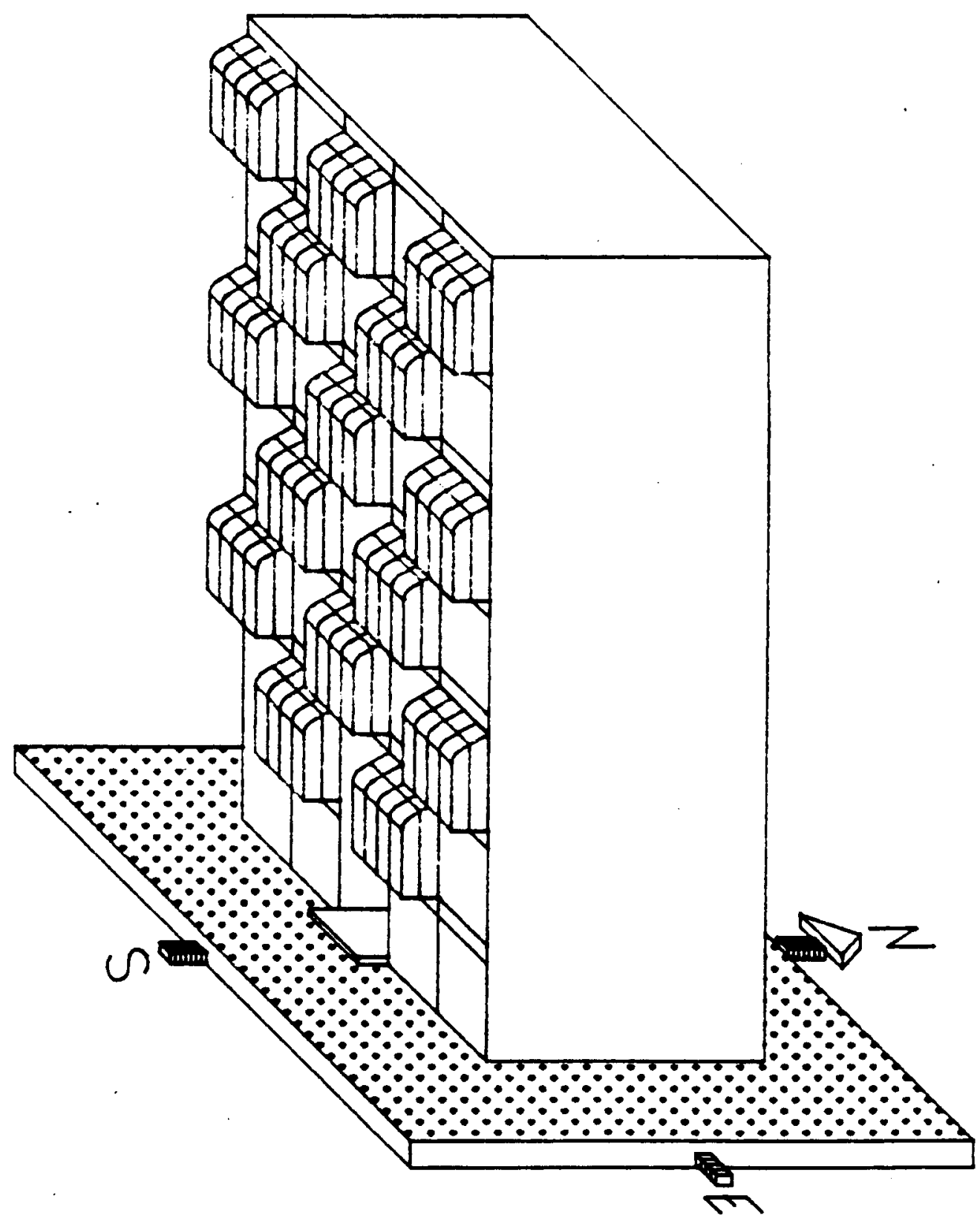

FIG.3.C.3:Highrise Buildings W/Checkerboard Configuration 
Sun porches can thus be placed one over the other in multi storied buildings extending, if so desired, along the whole facade of the building.

on the other hand a greenhouse, by definition, has a horizontal or sloping glazed "roof". If placed one on top of the other, the floor of the upper greenhouse will block the sun from the roof of the lower one. Therefore they cannot be placed one on top of the other in multi storied buildings. There is, of course, still the possibility to place the greenhouses, if they do not extend along the whole width of the facade, in a checkerboard pattern (FIG. 3.C.2). In this way there is a vertical distance of one floor between the floor of the upper greenhouse and the roof of the lower greenhouse at the same vertical "slice" of the facade.

\subsubsection{Sunspace/Building \\ Relationship}

Sunspaces can have different relationships to the building "proper" such as:

a) Attached outside the wall's line.

b) Semi enclosed: surrounded by rooms on two or three sides, with the southern glazed wall exposed.

c) Internal: surrounded by the building on all sides.

Atached Sunspaces.

Attached sunspaces share one wall with the rest of the building. They provide flexibility, for planning and construction, including retrofitting. In regions with favorable energy balance, they allow also the use of glazed end (eastern and Western) walls, for maximum utilization of morning or afternoon sunshine.

When the end walls and part of the southern glazing are openable they can be well ventilated and thus minimizing the likelihood of overheating. They also can provide good ventilation potential for the building behind, especially when the wind direction is oblique with respect to the south facade. On the other hand, in unfavorable climates, the end walls will have a negative energy balance, and therefore should be insulated.

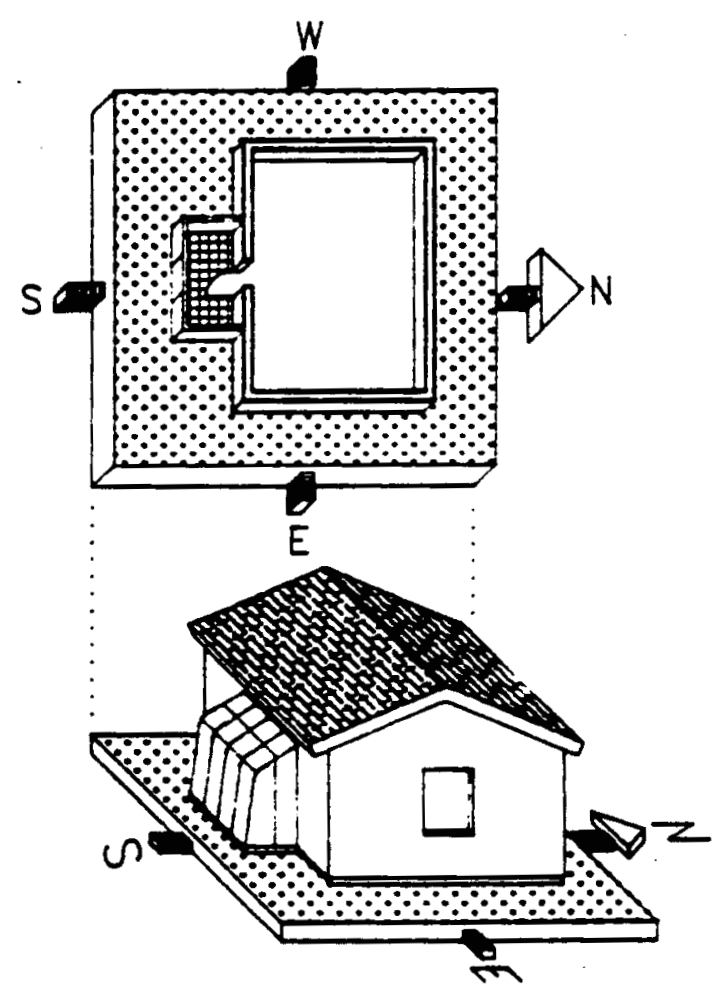

FIG.3.C.4: Attached Sunspace 
Having the greatest surface area exposed to the outside, attached sunspaces are subject to both the greatest heat loss and solar heat gain, and therefore may have large temperature swings. However, providing thermal mass within the sunspace can reduce its temperature swing. This subject is further discussed below $(3 \cdot 3 \cdot 7)$.

\section{Semi Enclosed Sun Spaces}

In this arrangement, when the sun space is indented into the building, it is protected from some of the potential heat losses, thereby increasing its usefulness as part of the usable space. There is a greater variety of possible connections between the surrounding rooms and the sun spaces. For a given size of glazing, both the efficiency of collection and of heat transfer to the habitable rooms are enhanced, compared with an attached sun space.

\section{Fully Enclosed Sun Spaces}

These are sometimes referred to as an atrium, patio or even as a "solar courtyard". As the southern glazing has to be above the roof, its size is limited, but the placement compensates for the lower heat gain potential by the greatest efficiency of distribution to the living spaces around them. They have obvious applications in deep plan forms, and with suitably designed openings and shading, may also be used to enhance summer ventilation of the main building.

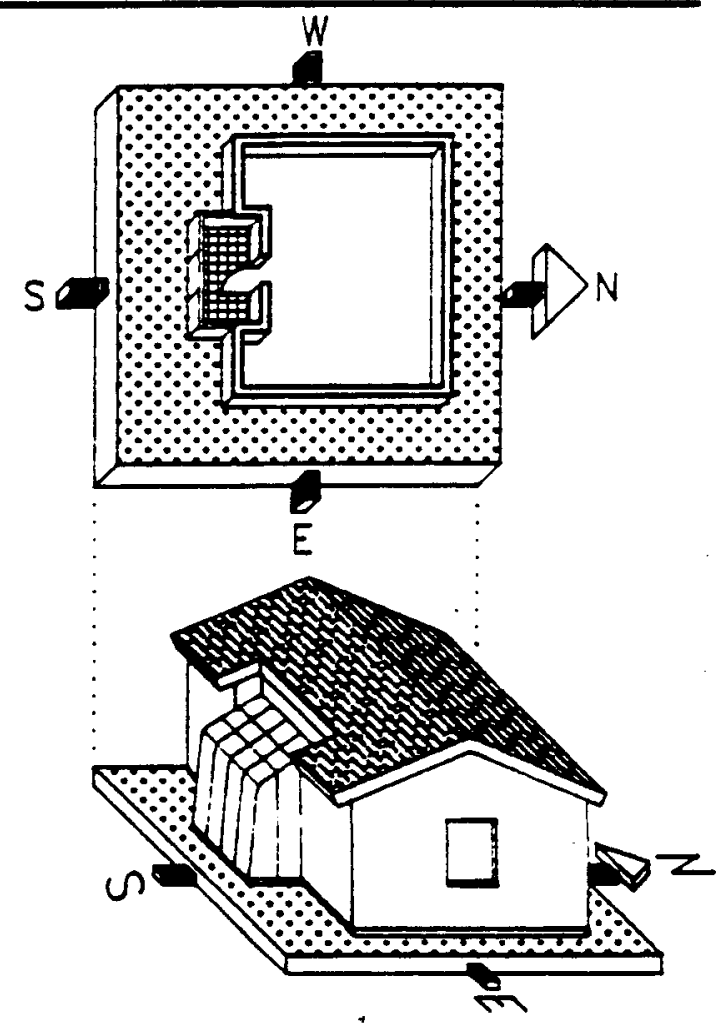

FIG.3.C.5: Semi-Enclosed Sunspace

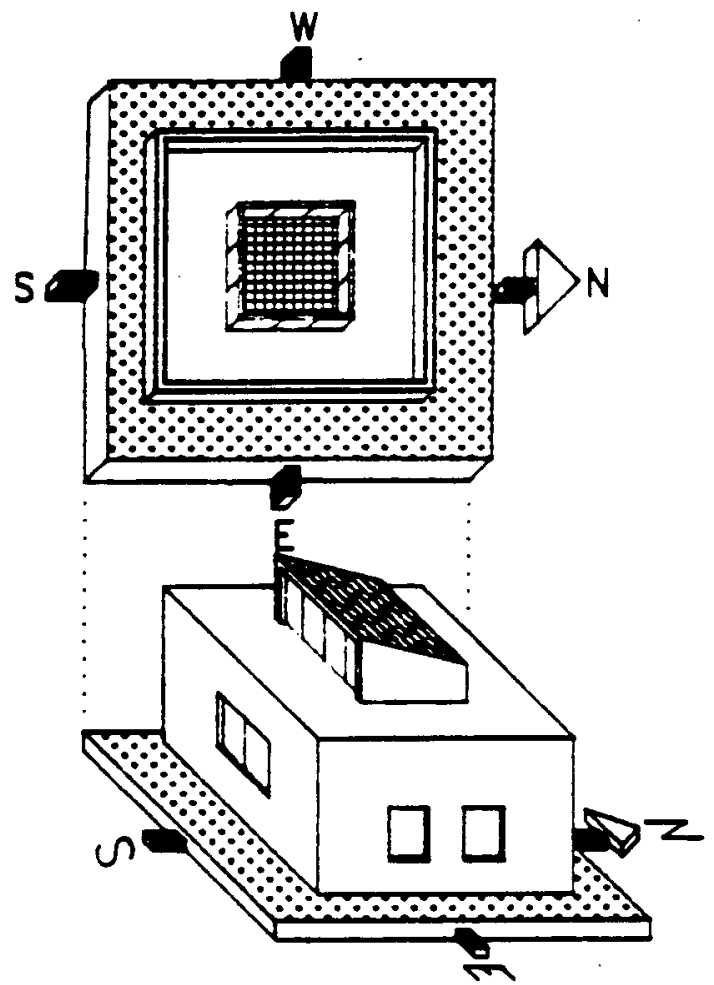

FIG.3.C.6: Fully-Enclosed Sunspace 


\subsubsection{The Connecting Wall}

The sunspace may be connected to the main building by a number of design solutions, singly or in combination. Each has differen effects on the amount and rate of heat transfer to the main spaces and on the indoor radiant and lighting conditions, as well as on the thermal environment of the sun space itself. The connecting wall may be one of the following:

a) Thermally massive, conductive wall

b) Large closable openings

c) Glazed wall

d) "Internal" Trombe wall (glazed massive wall)

e) Water wall

Thermally Conductive Mass Wall

The wall may be built of any of the conventional masonry materials. As in the case of the Trombe wall, it combines the functions of collection, transfer and thermal storage in one element, which usually is also an integral part of the building load bearing structure. According to its thickness and material, the wall determines the "time lag" between peak energy collectio at the outside face, and delivery of the heat to the interior. However, at night, most of the heat from the wall is actually given up to the sun space itself, thereby decreasing its efficiency as a source of useful heat for the interior.

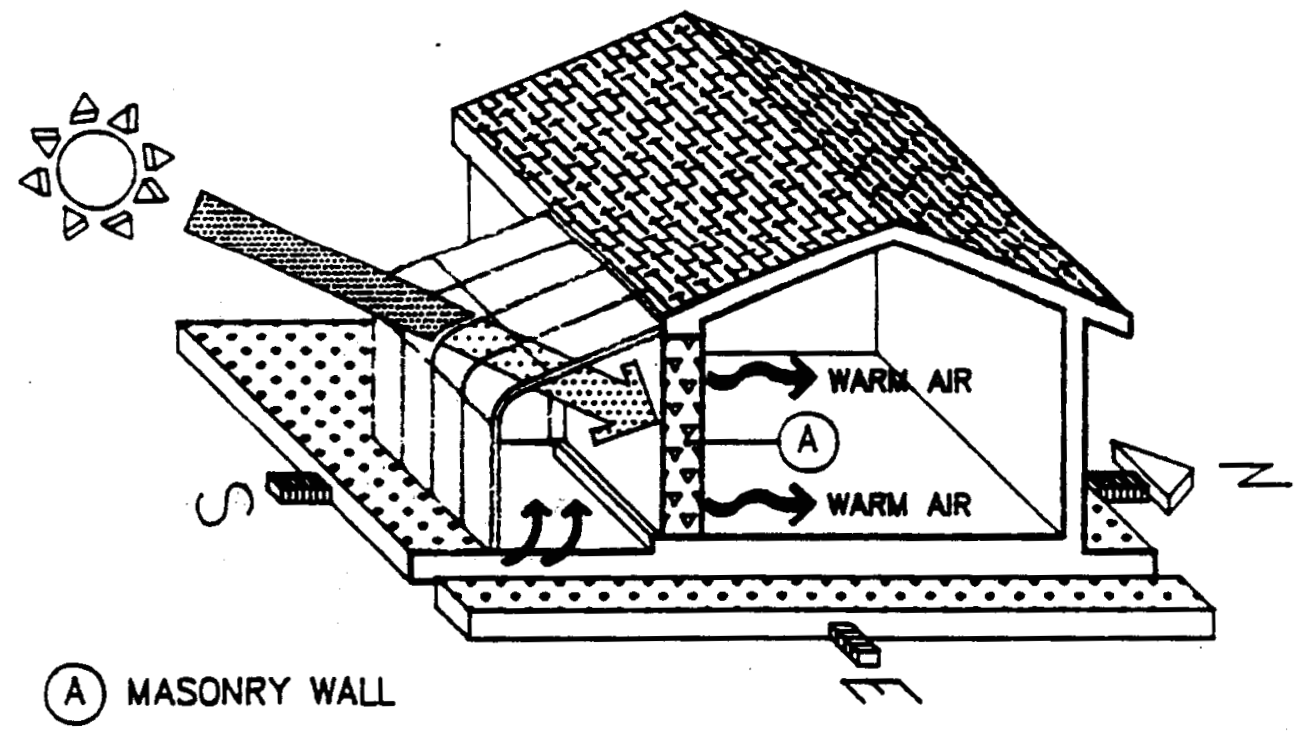

FIG. 3.C.7: Thermally Conductive Mass Wall 
In reality there always will be a door in the wall, to connect the sunspace to the room behind it and to provide daylight and ventilation. Heat transfer by natural convection will then supplement the conductive heat flow. The relative importance of the convective flow depends on the size of the door, relative to the wall, and whether the door is kept open during the sunny hours. Per unit area, however, the convective heat transfer through a door is much higher than the conductive flow across the wall (Balcomb).

\section{Glazed Storage Wall Within the Sunspace}

By placing an additional layer of glass over a massive conducting wall, an internal Trombe wall is created within the sunspace. While the solar energy penetrating the wall surface is somewhat reduced by the multiple glazing, other advantages compensate for it. First, the sun space protects the Trombe wall against its characteristic high heat loss to the outside, as any heat loss from the wall helps in maintaining higher temperatures in the sunspace.

Consequently, higher air temperatures are possible also in the gap between the glazing and the wall. This increases the efficiency of heat transmission through the wall itself. The hot air may be delivered by natural or forced convection to remote, north facing spaces in the building.

\section{(A) GLAZING \\ (B) MASONRY WALL}

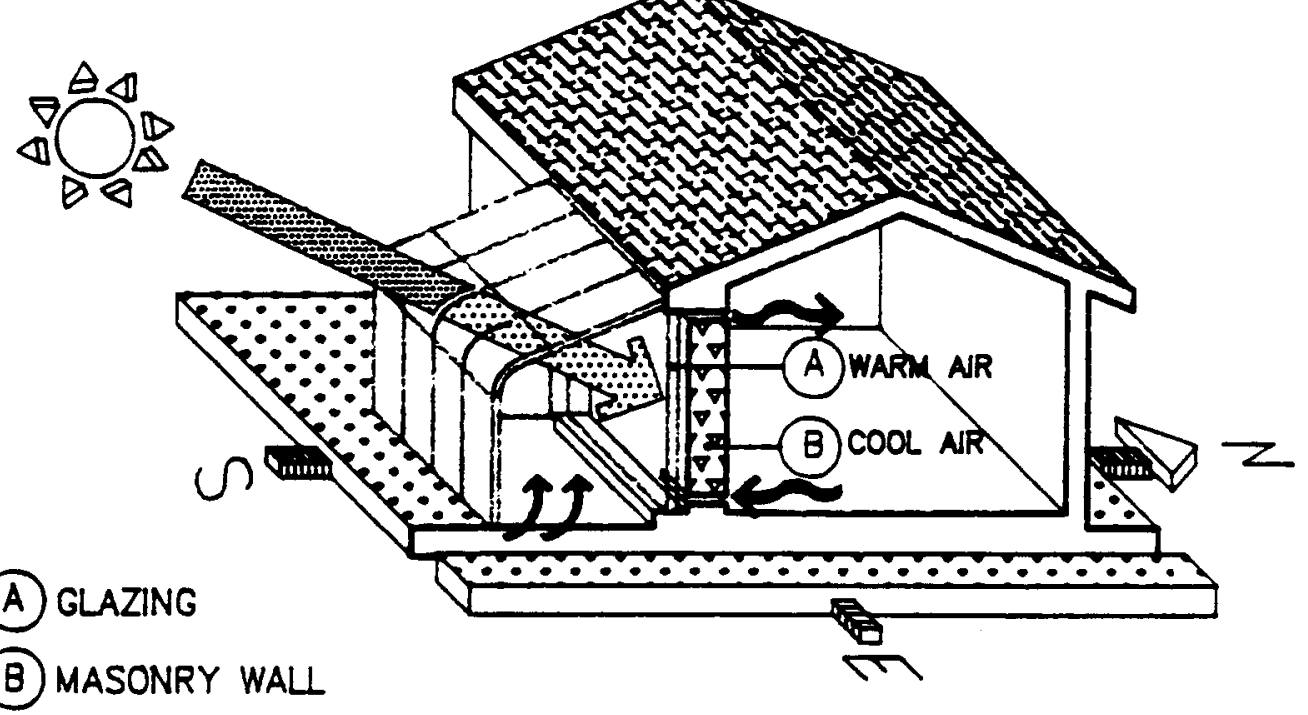

FIG.3.C.8: Glazed Storage Wall Within the Sunspoce 
Insulated Wall with Openings for Heat Transfer by Natural Convection

The separating wall may be insulated, with large doors in it connecting the sunspace with the rooms behind. Convective heat transfer typically takes place then by thermosyphonic air flow through conventional openings, such as doors and windows, leadin from the sun space to the rooms of the building.

The critical design features for insuring efficient natural air circulation are the area of the openings, the vertical distance between "supply" and return air paths, and the temperature difference between the sun space and the interior of the building. Air movement may be enhanced by the use of ceiling height door, rather than conventional doors.

In winter at night, when the connecting doors are closed, the insulated wall minimizes the heat flow from the interior, across the sunspace, to the outdoor. In summer during daytime, if the connecting doors are closed and shaded, the heat gain is minimized.

From these aspects this type of connecting wall is quite interesting.

On the other hand, because of the low heat capacity and thermal conductivity of the separating wall, in winter nights heat flow from the wall into the sunspace is negligible. Therefore the temperature in the sun space will be lower than in other types. In cold regions this may limit the use of the sunspace for plant growing, etc.

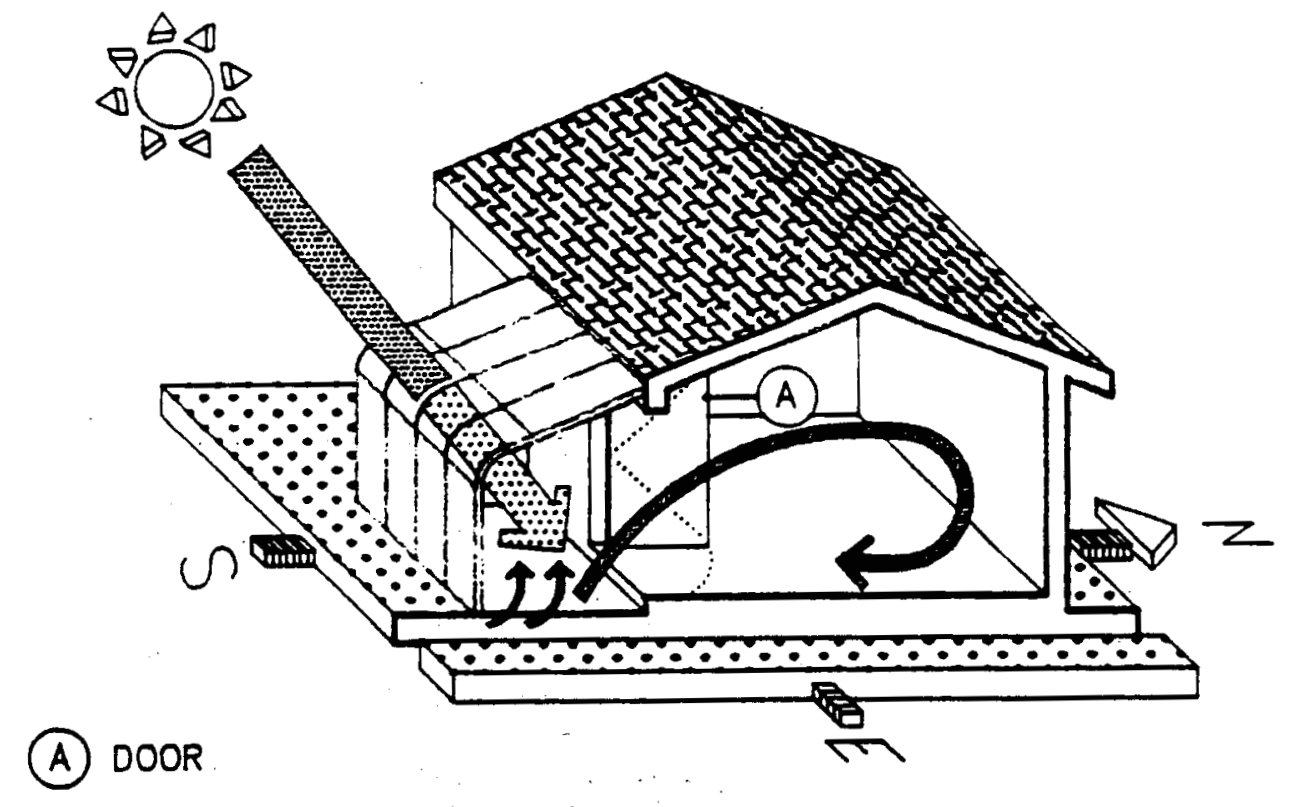

FIG.3.C.9:Convective LOOP 
Insulated Glazed Wall Within the Sunspace

An additional layer of insulated glazing may be placed in front of an insulated connecting wall. Since an insulated wall itself has no role in transmitting heat by conductance, the principal purpose of this arrangement is to supply air at temperatures higher than those with a conductive wall.

The hot air may then be used for quick heating of the adjacent occupied space. Typical applications might be schools and offices, where only daytime occupation need be considered, or the warm air may be routed through air channels in the structural ceiling, serving also as thermal storage, and to heat remote spaces, such as Northern rooms, by convection.

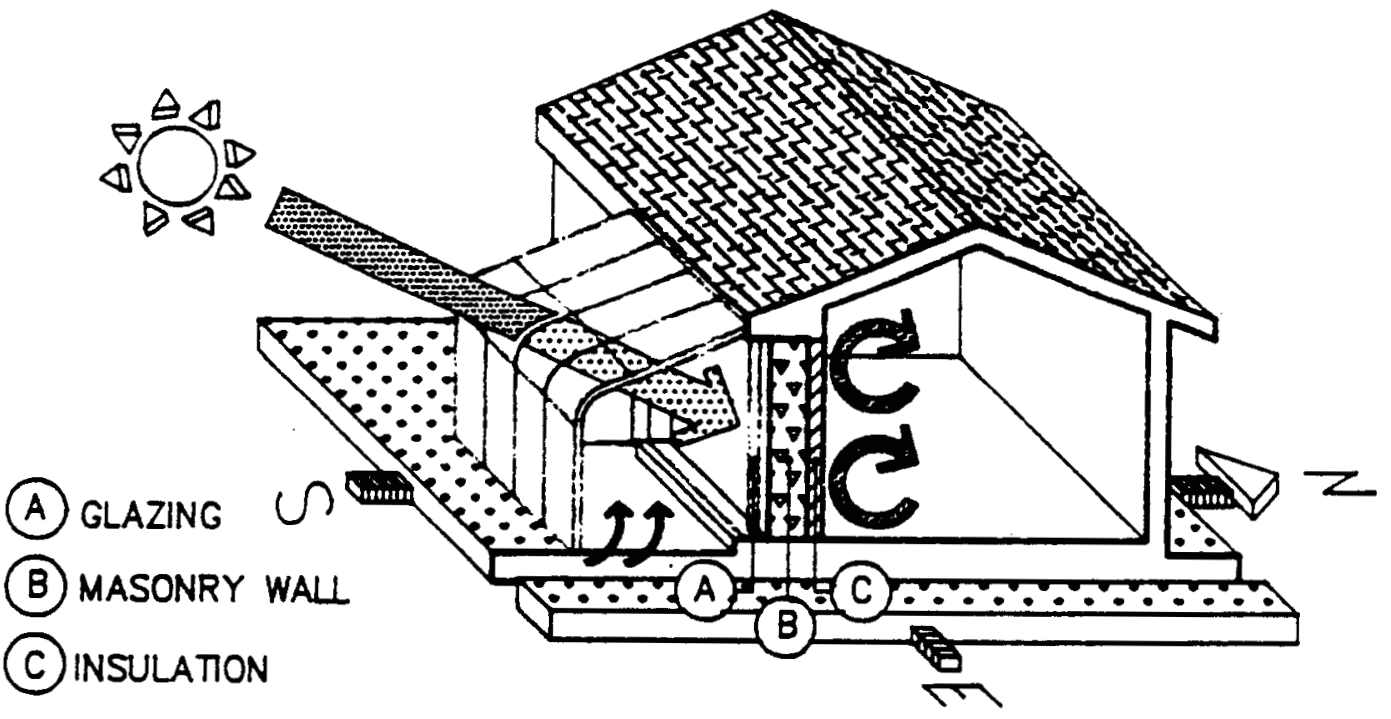

FIG. 3.C.10: Insulated Glazed Wall Within the Sunspace

\section{Glazed Wall as Connecting Element}

By having a glazed wall between the sunspace and the room behind it, including operable doors, the inhabited spaces may benefit from some direct gain, at a reduced rate compared with a Direct Gain system, while the control of the incoming radiation is, of course, much easier. For instance, controllable shading of the glazed wall, while external to the glazing, is within the protective environment of the sun space, and therefore structurally and functionally easy to provide.

As the glazing provides poor insulation against conductive heat loss (in winter) and heat gain (in summer), operable insulation may need, both against nighttime heat loss in winter, and heat 
gain in summer. Such insulation can be placed in the sun space where it is easily accessible and storable.

The principal benefit of a glazed connection, however, is the daylight transmitted to the interior and the view to the outdoor This design solution may be attractive in building types which need a lot of daylight.

Glazed and Insulated Glazed separating walls have not been applied and testec yet. The author recommends that the performance of such sunspaces will be studied.

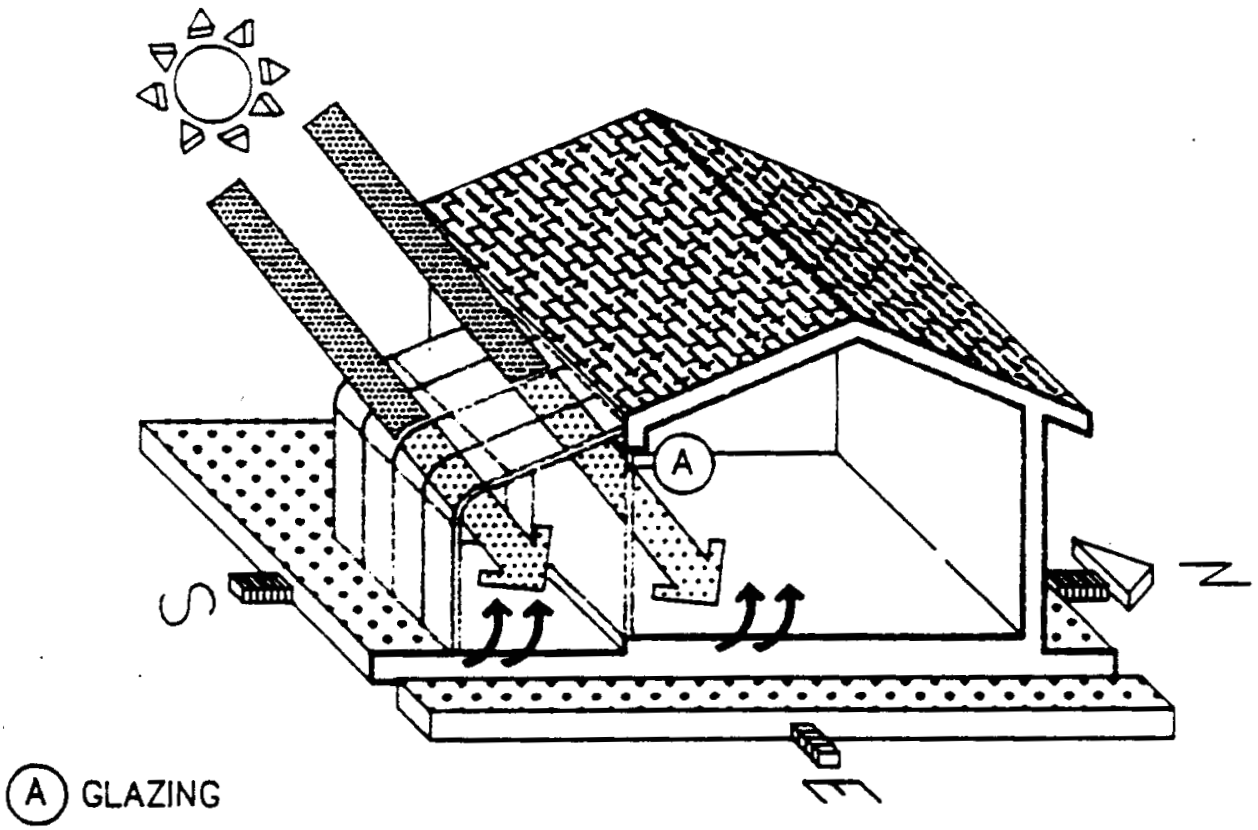

FIG. 3.C.11: Glazed Wall as Connecting Element

\subsubsection{Thermal Mass inside the Sunspace}

If the sunspace is to be used for anything else than for heating air, it must contain some thermal mass to moderate its temperature swings. Without thermal storage, diurnal temperature fluctuations of $30^{\circ} \mathrm{C}$ on clear, cold winter days, would not be unusual.

When the sunspace is at the ground floor the soil under the floor provides a thermal mass. At higher floors, or when additional mass is desired, the necessary storage mass may be provided in many forms, such as in the structural floor, connecting walls or other structural features, or it may not be part of the building structure, in the form of large planters, water containers, etc.

Such "additional" non structural mass should ideally be located at the base of the glazing. There it intercepts sunshine which would not, in any case, irradiate the connecting wall, and where the heat given off serves to set up favorable convection pattern within the sunspace. 
Because of the very large ratio of solar glazing to the volume of any practical sun space, relatively large temperature swing may still be experienced, even with appreciable thermal mass. As discussed previously in dealing with natural convection, such temperature elevation may actually be useful in enhancing air flow from the sun space to the main spaces, thereby reducing the temperature rise itself. 


\subsection{Remote Below-Floor Passive Collectors and Rockbed Storage}

Passive thermosyphonic solar water heaters based on convective loops were among the first applications of solar energy and they are very common in many countries. The collection principle involved in all solar convective loop systems, either for space heating or for passive domestic hot water systems, is that a fluid in contact with a collecting element is heated, expanded, and rises by natural thermosyphonic action to storage or for direct use, drawing cool fluid after it to the bottom of the collector.

For space heating, the circulating fluid is normally air, rather than water. Air is a poor heat transfer medium, having low heat capacity. But, far outweighing this shortcoming is the simplicit of constructing air collectors and distribution systems, in comparison with the difficulties of plumbing and fabrication of water systems and heat exchangers.

All air heating convective loops consist of a solar collector, through which air is flowing due to temperature difference. The collector consist of a layer of glazing covering a black (or dark) solar absorber. The absorber element can be a corrugated metal plate, expanded metal lath (in several layers), the external surface of a wall, etc. Depending on the type of the system, the heated air flows in front, behind or through the absorber.

Control of unwanted heat gain in summer is perhaps simplest with this system, if provision is made to vent off hot air from the glazed air space to the outside. By incorporating an air to water heat exchanger in the convective loop it is also possible to provide year-round hot water supply with air.heating collectors.

Systems for space heating by convective loops may be designed in two broad configurations:

- Remote below floor collectors (steve Baer / Scott Morris / Mark Jones systems)

- Insulated collecting walls (Trombe and Barra-constantini systems).

\subsubsection{Common Design Factors Affecting Performance of Convective Loops}

Thermal performance of all convective loop systems depends largely on delicate natural convection currents in the collectors. Air flow is low to nonexistent at times of little or no sun, but increases rapidly under sunny conditions. The slowly moving air must come in contact with as much surface area of the collecting element as possible, without being slowed too much. This is typically achieved by routing the airflow over, under or through corrugated or perforated metal surfaces.

The width of the air channel in the collector should be wide enough, to minimize the flow resistance within the collector. 
Steve Baer (1978) recommends a width of $1 / 15$ of the length of the collector.

Convective airflow is a result of temperature differences between two branches of the loop. The "chimney" effect governing the flow is proportional to the square root of the height of the collector times the temperature difference. To obtain the best air flow it is necessary to insure that air is supplied at the coolest available temperature, and to maximize the vertical distance between inlet and outlet.

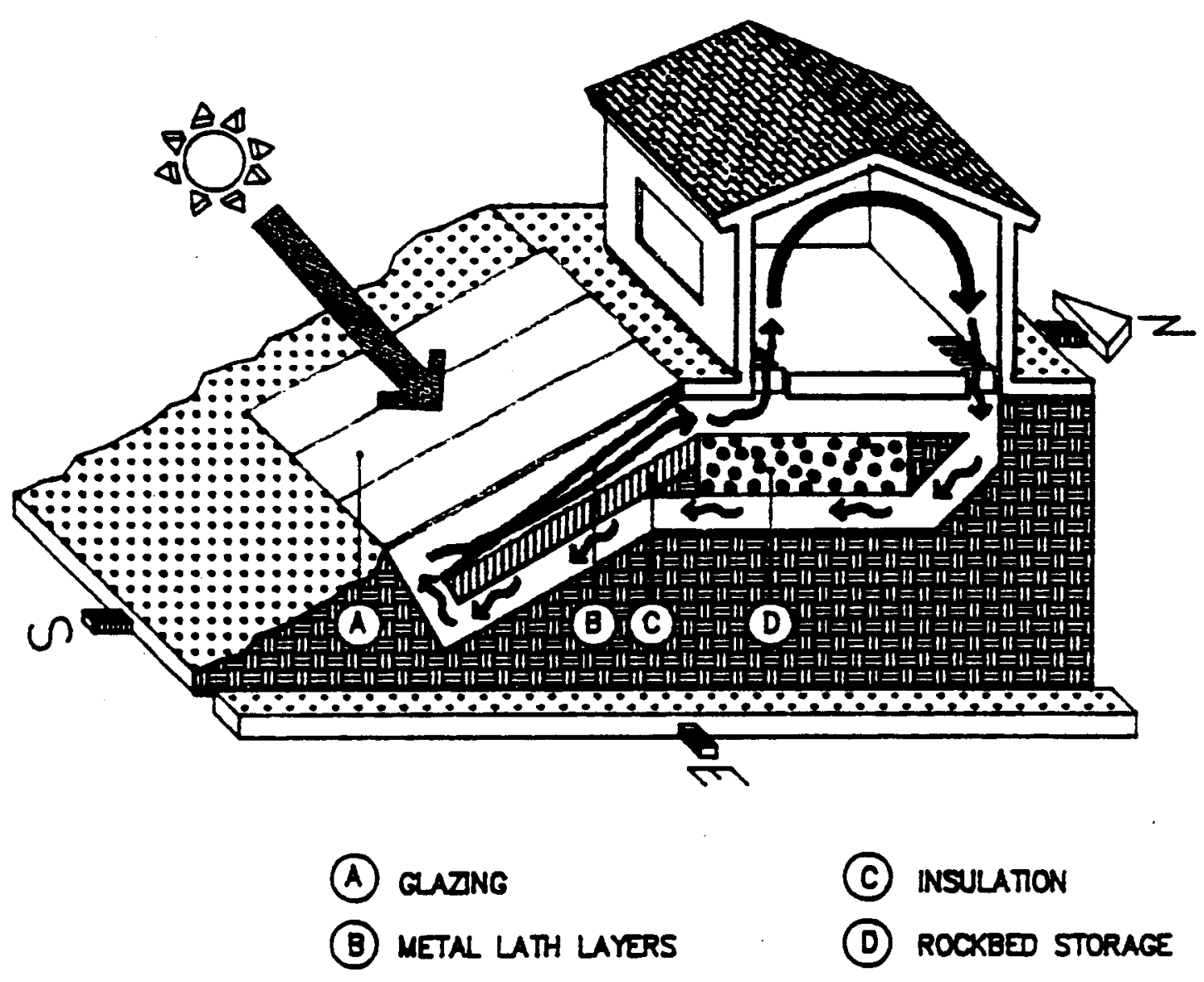

FIG. 3.D.1: Steve Baer System "Heating Mode"

In some situations, when a single story building is built on a southern slope, it is possible to locate the air collector of the convective loop below the level of the inhabited space which it serves. Such systems were developed originally by steve Baer and Scott Norris in New Mexico. Many solar building with this system (modified) were built in Santa Fe by Architect Mark Jones.

There is no thermal mass integrally associated with the energy collecting elements in this type of solar heating systems. It 
must be provided elsewhere, in a specialized storage space such as a rock bed.

The best known examples of application are the Steve Baer system (and modifications by Mark Jones) in New Mexico, where the hot air passes through a rock bed and heat is stored in an under-fl rock storage. A number of buildings utilizing this system have been built in New Mexico.

In the steve Baer system, as implemented in the Davis house in Albuquerque, NM, the collector consists of a number of metal lath layers, placed between the glazing in front and an insulation layer behind. The metal lathes are set diagonally in the air space, attached to the insulation at the bottom and to the glazing at the top.

With this configuration the air flows from the front of the absorber, at the inlet, and crosses it while flowing to the upper part of the collector, where the air is hottest. This flow pattern increases the efficiency of the collector by reducing heat loss outward from the hottest air at the top.

The rockbed storage space, $10^{\prime}$ wide and $4^{\prime}$ deep, accommodates 330 pounds of rocks per sqft of the collector. The rocks are fist size. In the Davis house it is located under a porch in front of the building.

From the collector the air flows over the rock's storage mass either in direct heating mode or in a storage mode. In the storage mode, when daytime heating is not needed, the air flows down through the rocks, heating them, and then back to the collector's inlet.

In the direct heating mode, when heat is needed during daytime, the air flows from the collector up to the building's space, and then "gravitates", through a duct under the building and the rockbed, back to the collector's inlet.

During the night the collector's inlet and outlet are closed and the warm air from the rockbed rises from the top of the rockbed to the building space and returns by the duct to the bottom of the rockbed.

There are several inherent potential advantages, as well as limitations, of this configuration:

\section{Advantages}

a) The collector, not attached to a conventional wall, may be tilted to a slope optimizing winter energy collection. Note, however, that non vertical glazing is more vulnerable to physica damage, (e.g., from hail) and to reduction of solar transmission due to dust settlement on the glazing.

b) A passive air flow through a large storage is possible. A specialized thermal storage, such as a rock bed, can conveniently be located above the collector and under the floor, enabling operation without fan power. With this configuration it is easy to provide a very large gross heat capacity even in low mass buildings.

c) Utilizing the floor for heating has some comfort advantages compared with the overhead storage elements associated with the Trombe and Barra-Constantini systems discussed below: lower 
temperature is needed for comfort and the indoor vertical thermal stratification is smaller.

d) Prevention of reverse convection is inherent in the geometry, the system supplies heat when the sun shines and the collector is warmer than the indoor air, but cannot introduce cool air to the interior at night, when the collector's heat balance is negative.

\section{Limitations and Applicability of Remote Below-Floor Collectors}

a) Remote below-floor collectors, with a rockbed thermal storage, can be applied only to single story buildings.

b) The system can be applied only to buildings located on a lot with a steep southern slop.

c) A tilted collector is more vulnerable to hail damage and dust settling. 


\subsection{Insulated Collecting Walls}

The simplest application of a convective loop may be by integrating it into a conventional vertical wall. Two different systems of space heating have been developed. One by $F$. Trombe in France (for offices) and the other by H. Barra in Italy (for residential buildings).

\subsection{The Trombe Insulated Collecting Wall}

The insulated collecting wall which has been developed by Trombe was designed specifically for office buildings. It provides ample daylight and at the same time heats the indoor air.

There are two main differences between the thermal storage wall, developed also by Trombe, and this system:

a) The wall collector consists of two horizontal strips: windows above and an air heating collector below. The collector extends

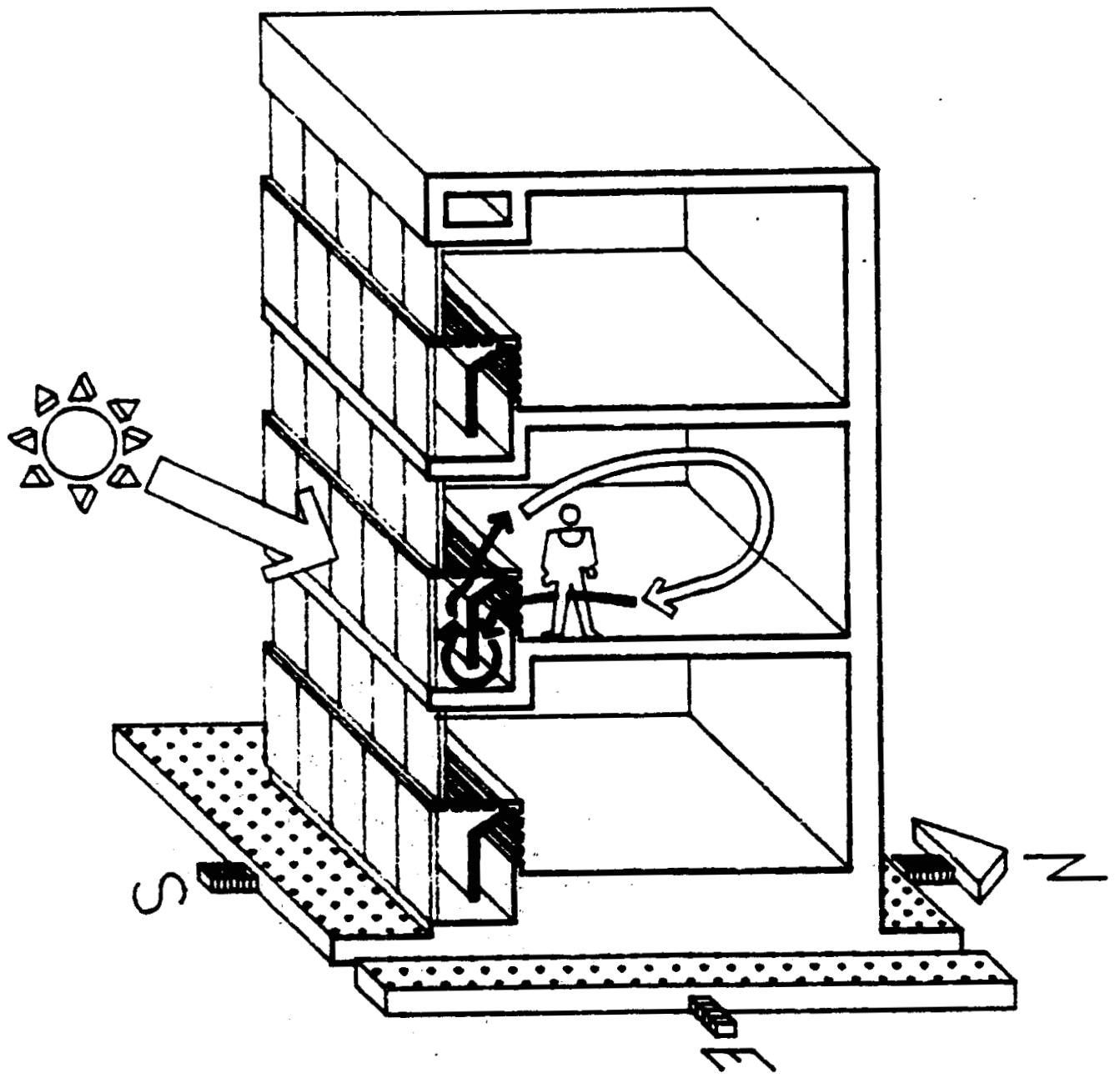

FIG. 3.E.1:Trombe Wall in Highrise Building 
down about 1 meter ( $\left.3^{\prime}\right)$ below the floor level. The window's strip provide ample daylighting which is essential in office buildings. The lower strip "sucks" the indoor air, circulates it around the U tube formed by the collector's absorbing plate, and back to the room.

b) The wall behind the collector's glazing is lightweight and insulated, and thus the collecting element in this system does not provide any thermal storage, besides the storage capacity of the structural mass within the building. However, as it was developed to heat office buildings, storage for nighttime use in this application is not needed.

The $U$ tube of the collector prevents back flow at night by "trapping the cold air below the floor level.

\subsubsection{The Barra-Constantini System - An Insulated Wall Collector and Concrete Ceiling Storage}

In the Barra-Constantini system (Barra et al., 1987) the southern wall can be any conventional wall, e.g. concrete, bricks, stud wall, etc., but it has to be well insulated externally. A solar collecting element is placed in front of the wall, (e.g. a number of metal lath layers or a corrugated metal sheet), covered by glazing.

With an insulated wall adjacent to a living space, unwanted heat losses in winter, especially during nights and cloudy periods, and heat gains in summer, are minimized, especially in comparison to the concrete Thermal storage walls.

This assembly forms a vertical air heating solar collector, which is architecturally integrated into the normal building's fabric. The verticality of the collector reduces, of course, its heating efficiency in winter but, on the other hand, reduces also the likelihood of overheating in summer.

The hot air emerging from the insulated collecting wall flows horizontally, within channels imbedded inside a concrete ceiling, and exits from these channels at the Northern part of the building. The air thus warms the Northern rooms first before flowing back through the building space, to the inlets at the lower part of the southern collecting wall. This insures more even temperature distribution through the whole house.

Because of its high operating temperatures, higher than in other passive systems, the collector is subject to large heat losses. The rear of the collector is insulated in any case, forming the wall of the interior. It is advisable to detail the collector to minimize exposed unglazed portions, especially at the upper parts. Polystyrene insulation should not be used, as collector temperatures may well exceed its melting point. Infiltration losses can be eliminated by good heat resistent sealing, but allowance should be made for substantial thermal movements, especially around the glazing.

windows in the southern collecting wall provide direct solar heating to the southern rooms, in addition to the radiant heating by the warm ceiling. The northern rooms are heated by the warm air exiting from the ceiling channels. 
The application of this system is not limited to single story buildings built on land with a southern slope, as is the case with the steve Baer system, but can be applied also to multi story buildings.. When the "front". facade of a building is not facing the south it is possible to use the rear or side southern facades as the collecting wall because the solar heat is transferred first by convection to the northern side of the building.

The system has been applied in numerous buildings in Europe.

If no measures are taken to prevent it, the air flow direction will reverse at night when the collector is cooler than the

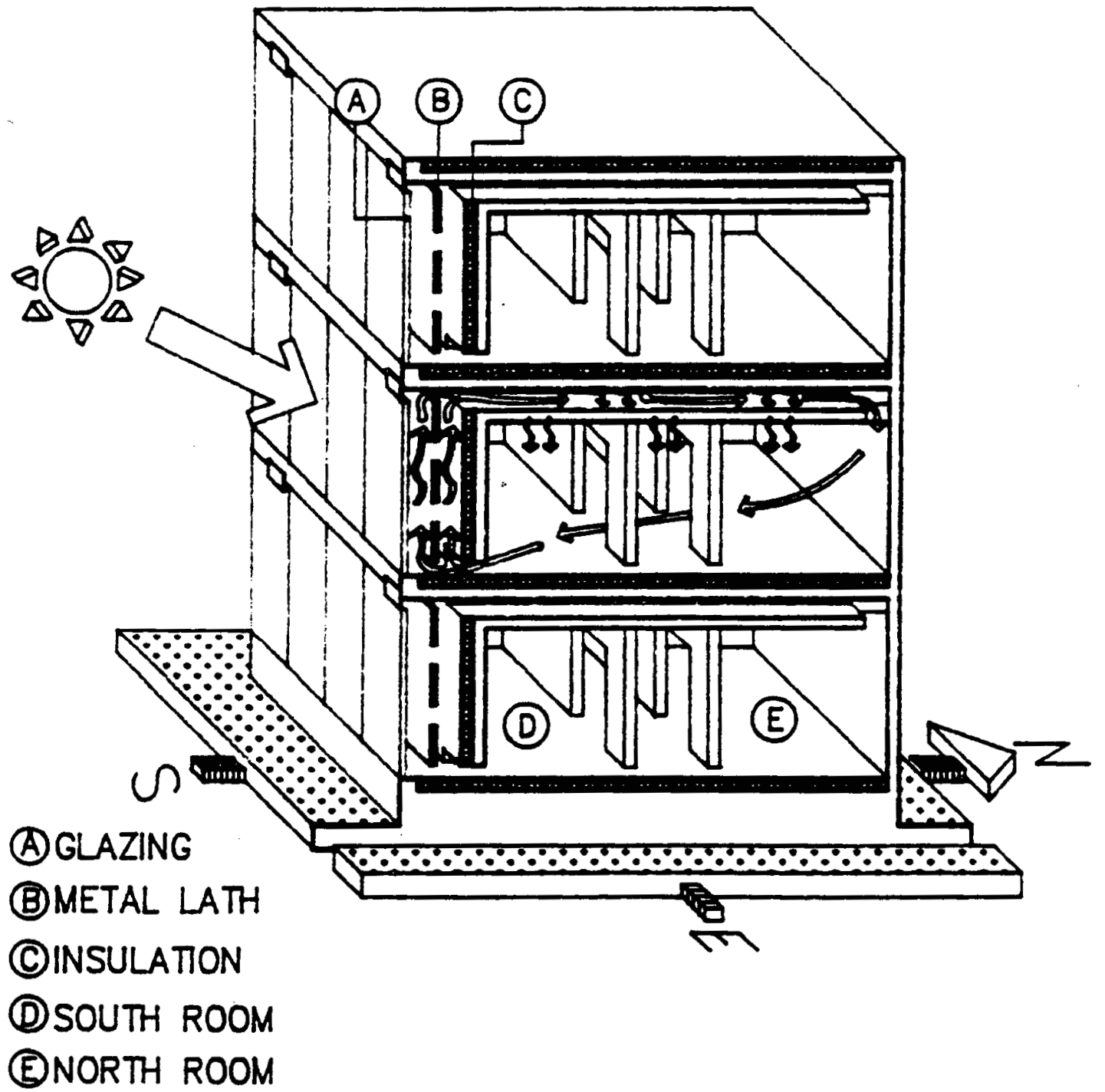

FIG. 3.E.2: Barra-Constantini System 
indoor air. This back flow can be prevented by back-draft dampers, ideally to both inlet and outlet vents. In their simplest form, they may consist of a light plastic film, acting as a one way valve preventing the reversed flow.

\subsection{References for Section 3}

-Anderson, B., Michal, C., Temple, P., Lewis, D. and Balcomb, D. (1980): "Passive Solar Handbook - Volume 1". NTIS.

-Balcomb, J.D., C.D. Barley, R.D. McFarland, J.E. Perry, Jr. W.O. Wray, and S. Noll (1980): "Passive Solar Design Handbook, Vol. 2". DOE/CS-0127/2. US Department of Energy, Washington, DC.

-Barra, O.A., G. Artese, L. Franceschi, R.K. Joels and A. Nicoletti (1987): "The Barra Thermosyphon Air System: Residential and agricultural Applications in Italy, UK and in the Sahara" Int. Conf. of Building Energy Management. Lausanne, France.

-Givoni, B. (1981): "Passive Solar systems - An Overview". Architectural science Review, Vol. 24, 2, pp.

-Givoni, B. (1983): "A Generalized Predictive Model for Direct Gain". Passive Solar Journal, Vol. 2,2 pp.107 - 115.

-Givoni, B. (1987): "The Effect of Heat Capacity in Direct Gain Buildings". Rassive solar Lownal, Vol. pp.

-Jones, R.W. (Ed.), J. D. Balcomb, C.E. Kosiewicz, G.S. Lazarus,

R.D. McFarland, and W.O. Wray, (1982): "Passive Solar Design Handbook, Vol. 3. DOE/CS-0127/3. Us Department of EnergY, Washington, DC.

-Mazria, E. (1979): "The Passive Solar Energy Book". Rodale Press.

-Moses, A. (1983): "Experimental study of Shaded Trombe Wall in Summer". Research Paper. Graduate School of Architecture and Urban Planning, UCLA.

-Watson, D. (1977): "Designing and Building a Solar House". Garden Way Publication. 
Section 4

\section{Design Guidelines for Solar Residential Buildings.}

This section provides condensed Guidelines for the design of solar buildings and neighborhoods. It is based on the more detailed discussion of the characteristics of the different passive solar systems presented in Section 3 . Specific Guideline are provided only for the main passive solar systems: Direct Gain, Trombe walls and sunspaces.

\subsection{Design Guidelines for Solar Neighborhoods}

Introductory Comments:

The application of solar systems, either active or passive (and especially in the case of passive), has direct impact on a numbe of aspects in the neighborhood design, for insuring solar access to the buildings, by such design elements as:

- street layout (impact on building's orientation)

- Sub-division patterns (impact on building's orientation and distances)

- Specifying building's size, height and types.

The following guidelines address these issues.

Objective: Providing Solar Access to the Buildings

SUBJECT: STREETS LAYOUT

Guideline: Orient residential streets mainly in the East-West direction.

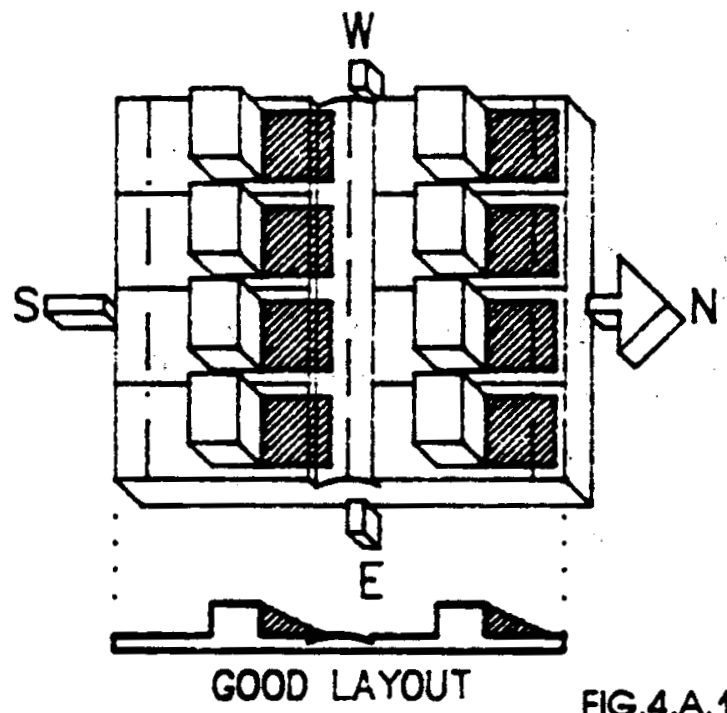

FIG.4.A.1: Street Layouts.

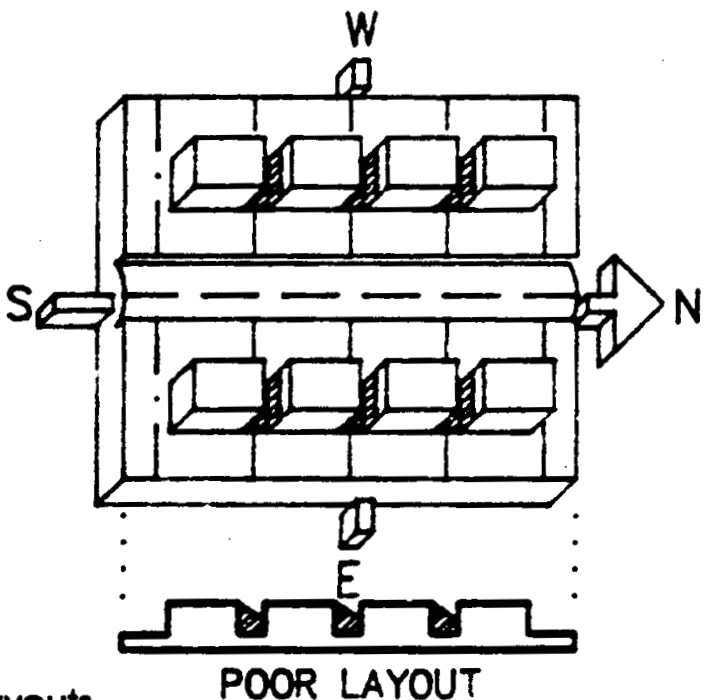


Reasons: Buildings tend to face the street, Fig.4.1, therefore this street orientation will enhance the potential of solar exposure of the buildings.

A street to the south of the building acts also as an open space, reducing the likelihood of shading by neighbors to the south.

\section{SUBJECT: SUBDIVISION LAYOUT}

Guidelinel For a given lot size required in the locality plan lots elongated in the North-South direction., Fig. 4.2

Reasons: This configuration of subdivision will enhance the potential of solar exposure of the buildings by increasing the distances between buildings in the North-south direction.

An example of a neighborhood's subdivision replanning to maximize solar exposure was implemented in the city of Davis, CA.

"Davis Energy Conservation Report", The City of Davis,1977

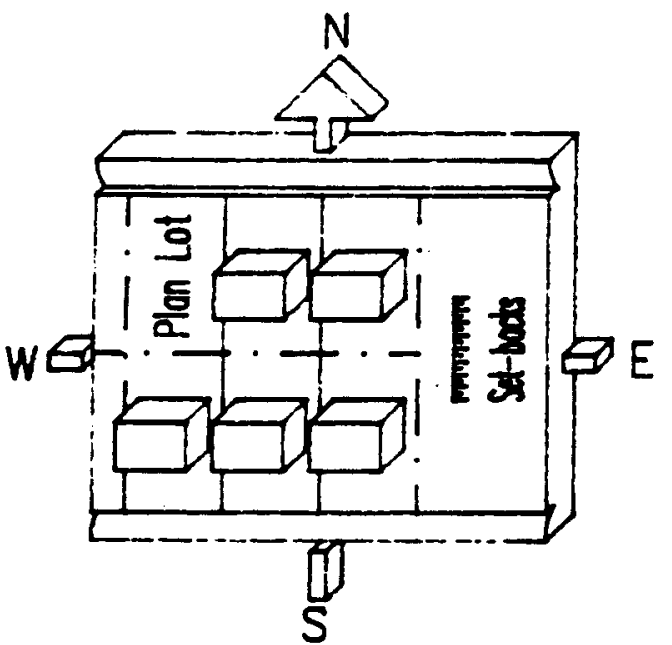

GOOD LAYOUT

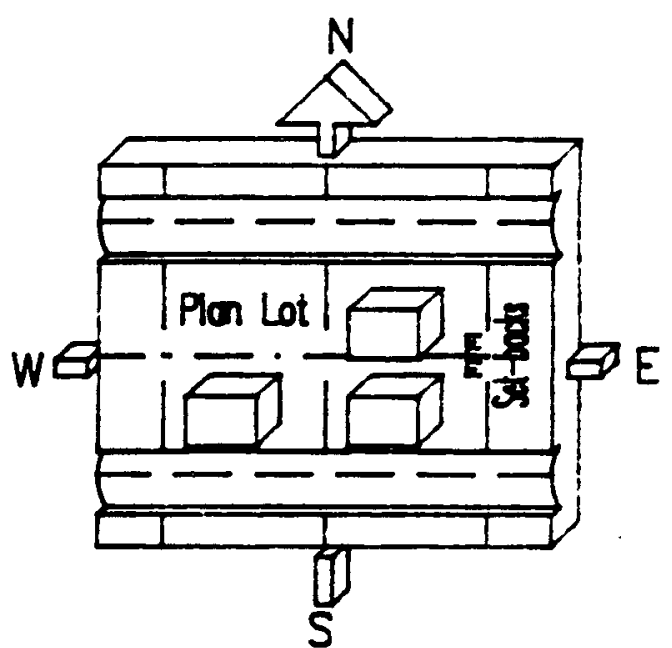

POOR LAYOUT

FIG.4.A.2: Set-Backs due to LOT Orientation.

SUBJECT: DISTANCES BETWEEN BUILDINGS

Guideline: Distances between buildings in the North South direction will be at least so that in December, between $10 \mathrm{a} . \mathrm{m}$. and 3 p.m. the shadow cast by the building to the south will not reach the building to the north of it.

Comment and criterion:The solar altitude at a given hour is a function of latitude. therefore the length of the shadow at that period, relative to the height of the "southern" building, depends on the latitude of the location. It can be determined from.
Shadow cost at:

(1) 10 p.m

(2) Noon

(3) 3 p.m

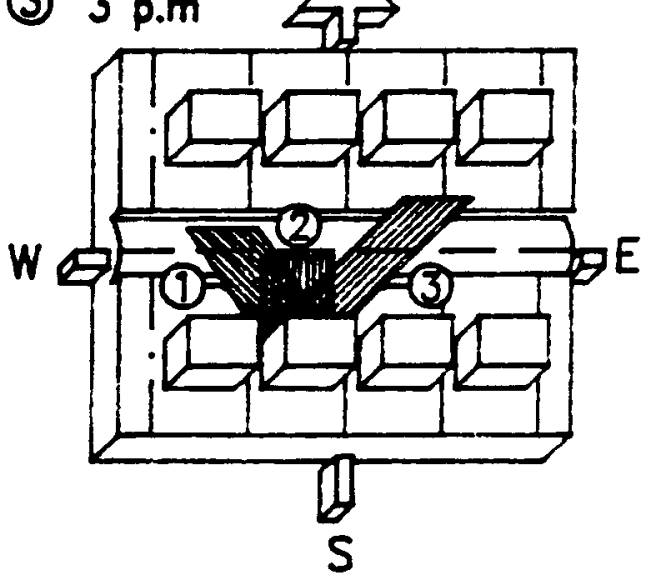

FIG.4.A.3: Shadow Cast. 
FIG. 4.A.4, which shows the relative shadow length as a function of latitude.

Reasons: Without insuring sufficient distances between buildings in the North-South direction the southern walls of some building may not have access to solar radiation as a source of heating by passive systems.

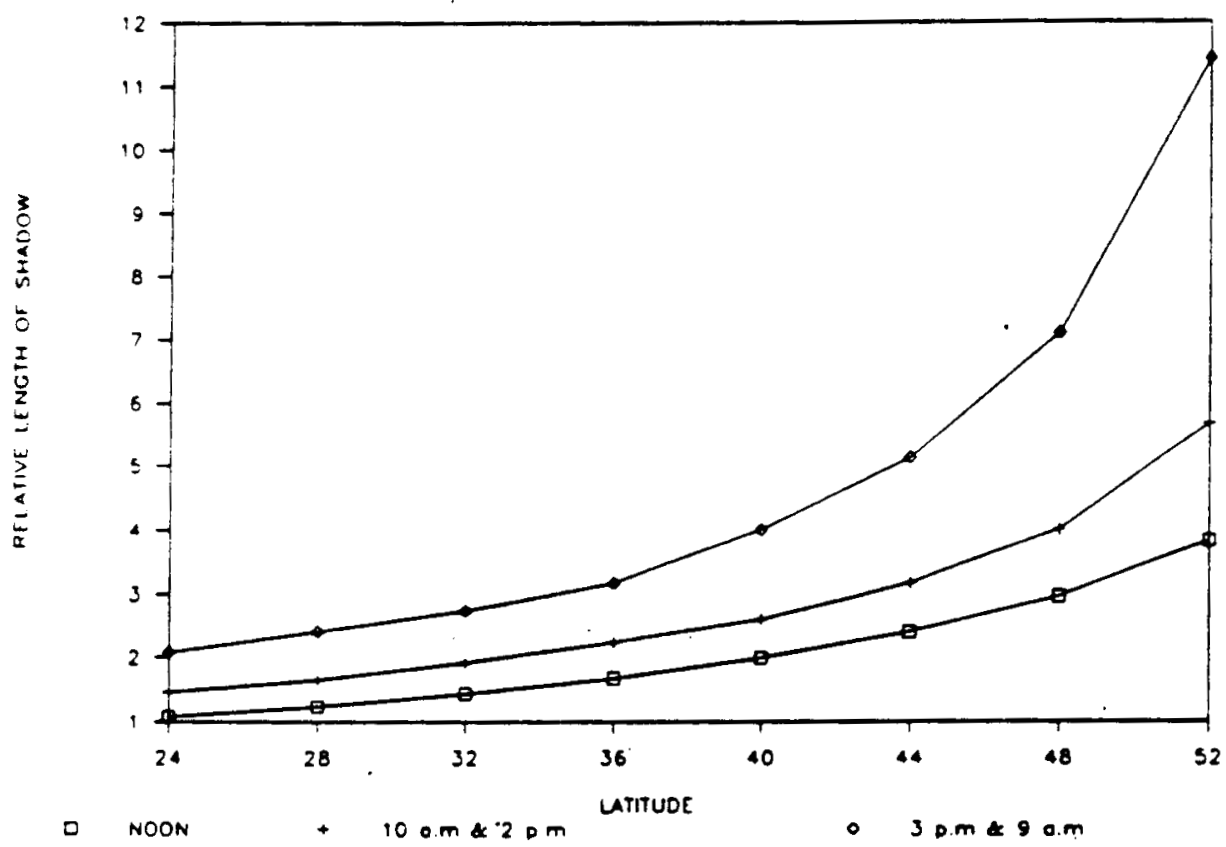

FIG.4.A.4: Shadow Castvs. Latitude.

\section{SUBJECT: SET - BACKS FOR BUILDINGS}

objectives: Setbacks for buildings could be so established that they will encourage extending the buildings in the East-West direction as well as enhancing solar exposure.

comments: To achieve these objectives the set backs should be permitted to be modified according to orientations and not by the different borders of the building's lots. A planning policy concerning set backs aimed at these objectives has been implemented in the city of Davis, CA, where zero foot side yards are permitted when it enhances solar exposure.

Site Planning Guidelines

Introductory Comments:

site planning, in the context of comfort, energy performance of the building and solar utilization, involves such items as the placement of the building. in the site (whenever the designer has different options in this respect), and the use of vegetatio as climatic control element. 
Proper site design can insure more effective utilization of solar energy for heating in winter, as well as better natural ventilation and shading in summer.

These aspects are addressed in the following guidelines. SUBJECT: PLACEMOENT OP THE BUTDING ON THE SITE

Guideline: Then deciding the location of the building on the site (the individual lot) take into account the following points: Placing the building on the northern part of the site gives the designer greater control over the solar exposure conditions of the building, due to his/her control of the treatment of the area to the south.

With this placement it is also less Iikely that the building will be obstructed by neighboring bulldings to the south.

SUBJECT: USE OP VEGETATION FOR CIMATIC CONTROL

Guideline: In planning the landscape of the site the designer should take into account the following points:

A dense belt of Evergreen trees to the North, Northeast and Northwest of the building can reduce greatly the speed of the wind from these directions.

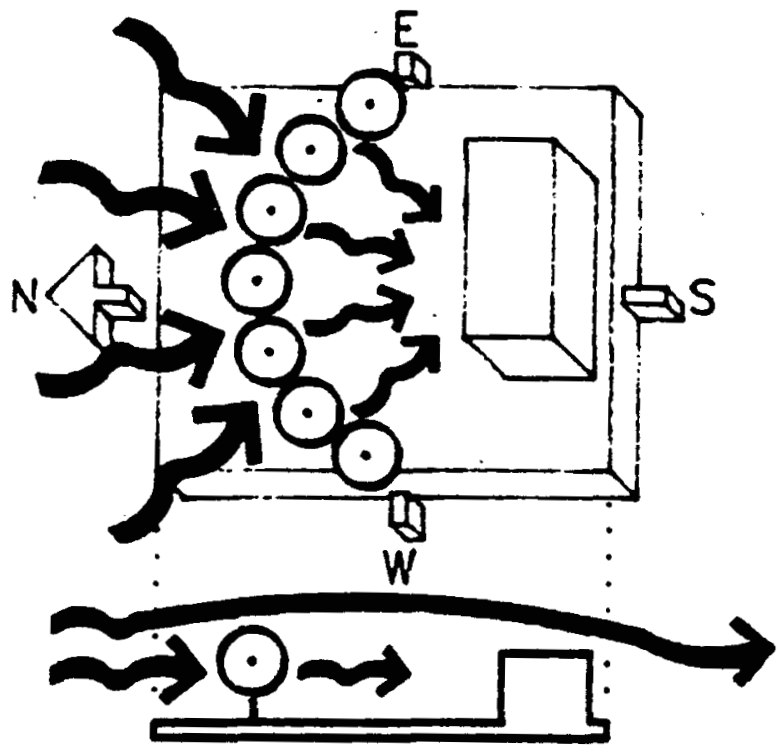

FIG. 4.A.5: Use of Vegetation

This point is of special interest in the East and Midwest regions of the country, where the winter winds are mainly from the north and northwest.

Reservation: In the Western states (e.g. California. Oregon, etc.) the dominant wind direction year round, including the summer months, is generally from the West (southwest to northwest). Trees to the west of the building can reduce greatly the potential for natural ventilation. 
Guideline: Trees with high trunk and wide canopy, or a high and wide pergola, in front and to the West of a building, can provid effective shading without blocking the westerly winds. This design detail is especially useful for providing shading to Eastern and Western windows, without obstructing the view.

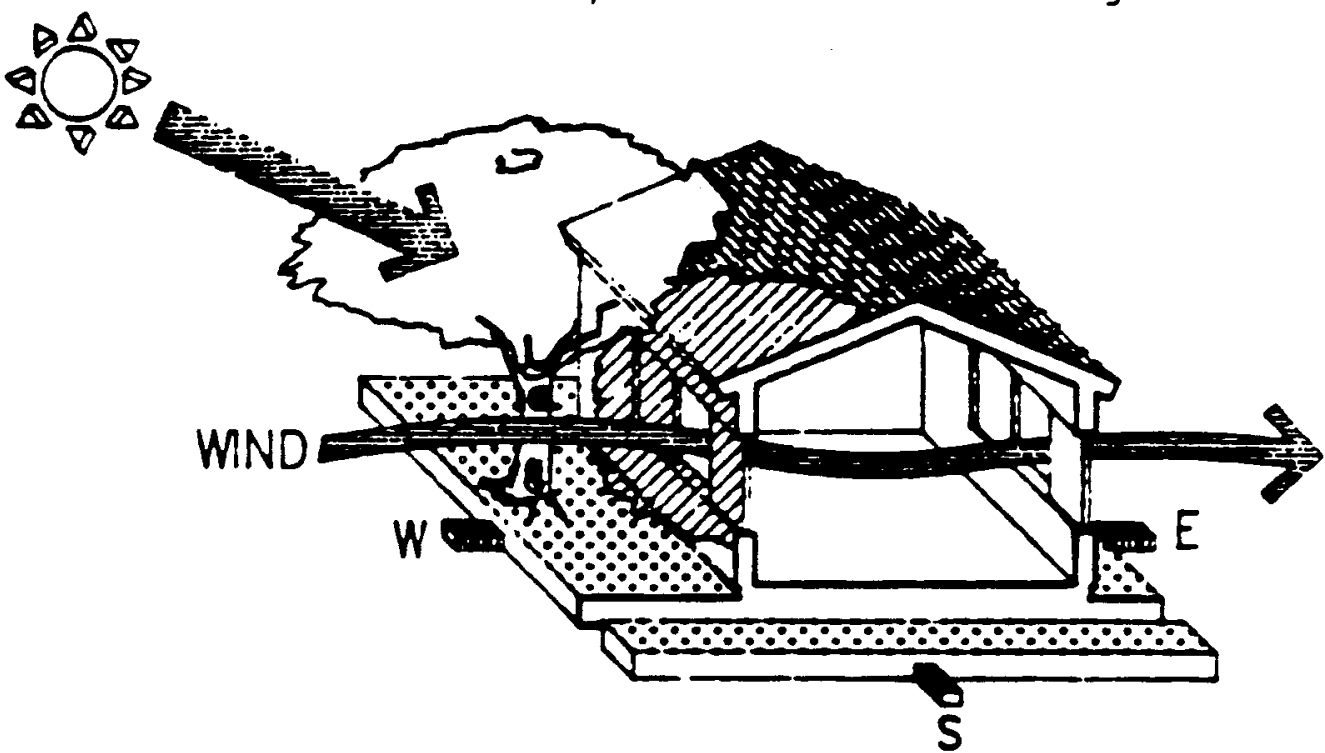

FIG. 4.A.6:High Trunk \& Wide Canopy on West Elevations

Guideline: Trees to the South of the building can block the sun in winter. Even deciduous trees reduce solar radiation significantly. Only deciduous trees with very high trunks and upwar growing branches (such as e.g. Jacaranda), placed near the wall of a single story building, can provide shade in summer without blocking the sun in winter.

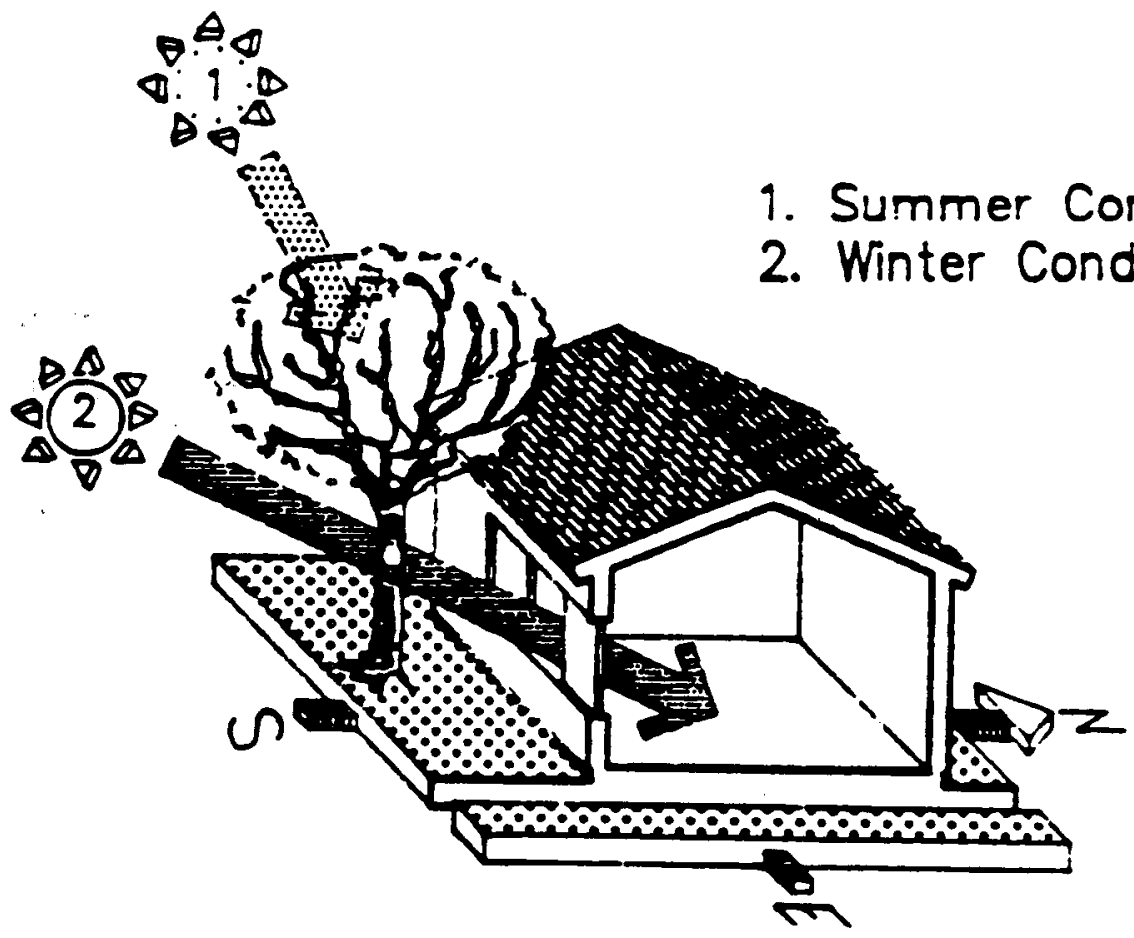

FIG. 4.A.7:Decidious Trees on South Elevations 
Guideline: Lawns and low vegetation around a building are very effective in reducing the reflected solar radiation impinging on the walls and windows of the building.

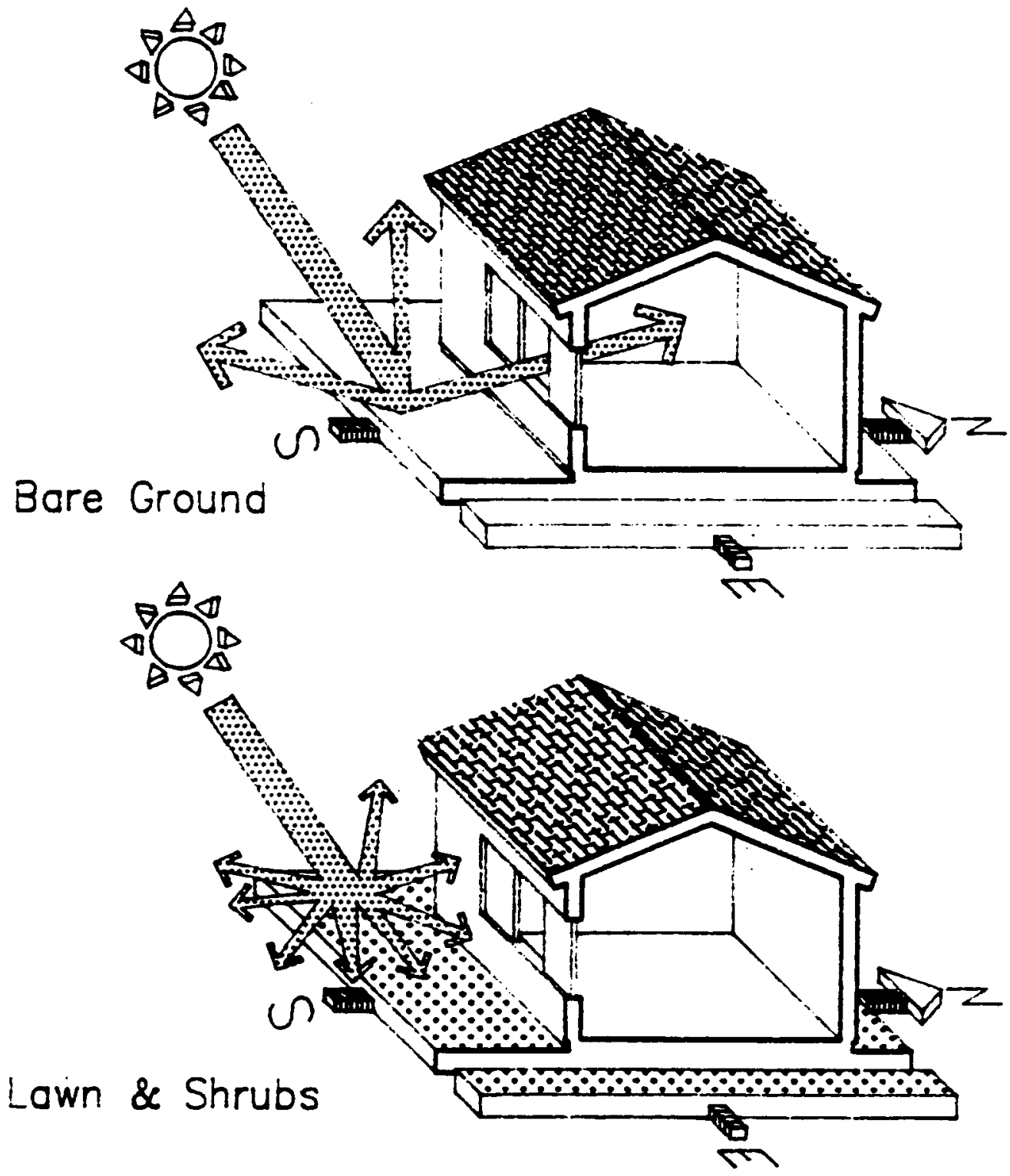

FIG. 4.A.8:Reducing Reflected Solar Radiation

Building Design Guidelines for Active Solar Heating Systems

Introductory Comments:

Application of active solar heating systems, either for space heating or for hot water supply, involves solar collectors, thermal storage, and a mechanical system and network for energy transfer. The Architect has to provide areas and spaces to accommodate all these components of the active system.

The most obvious architectural implication is the provision of area, exposed to the sun, for the collectors. Usually this will be on the roof, where orientation and tilt of the collectors 
can be optimized for annual or seasonal collection efficiency.

When the roof is flat the collectors can be tilted as desired without building design restrictions, although their orientation still has to be architecturaliy coordinated, during the design process, with the building's orientation.

on the other hand, when the roof is a sloped one, the collectors are practically at the same plane as that of one of the roof's surfaces. In this case the Architect has to take into account during the design stages both the orientation of the building and the slope of the roof, in order to enable satisfactory performance of the solar heating system. These considerations are reflected in the following guidelines.

Guideline: Whenever the building to the south is higher than the building in question, check to verify that the shadow cast by it in December is not reaching the roof of the building between $9 \mathrm{am}$. and $3 \mathrm{pm}$.

comment: If part of the roof is shaded collectors can be placed only over the unshaded part. If the roof does not get solar radiation in winter there is no potential at all for solar heating.

The shading of the roof by its neighbor to the south can be checked by using FIG.4.A.4, when the excess height of the southern building, $h$ ', (above the height of the northern building) is substituted for its actual height.

Subject: Options for Solar Collector's Location in Highrise Buildings

Introductory comments: In highrise buildings the area of the roof may not be sufficient, or too far from the dwellings, to accommodate all the collectors needed for solar heating systems. An additional optional location can be over the southern walls and parapets of balconies.

Walls are usually vertical and this determines also the position of collectors mounted on them. Parapets of balconies, however, can be tilted, to increase the amount of the impinging solar radiation.

When the walls and balconie's parapets are used as location for solar collectors each dwelling unit with a southern exposure can have its individual solar heating system.

When southern balconies are glazed and transformed into solar porches they provide very favorable location for solar collector and storage tanks. As the temperature in the sunporch during the night hours is significantly higher than the outdoors the heat loss from collectors located inside the glazed porch is lower and the collection efficiency is consequently higher than with exposed collectors.

Likewise, the heat retaining efficiency of storage tanks located inside sun spaces, e.g. behind tilted balconie's parapets, is enhanced.

collectors mounted on external walls of highrise buildings shoul be provided with structural support and with access for maintenance, cleaning and repairs. 
When the use of southern walls or balconie's parapets is desired for collector's location the following guidelines can help the designer to implement it:

Guideline: In highrise buildings provide blank areas of the southern wall suitable for accommodation of solar collectors.

Guideline: When considering mounting solar collectors over walls provide structural support for the collectors and means of access, e.g. narrow walking strip with safety railing, to enable easy installation, dismounting for repair or replacement.

comment: Note that the access strip cast shade under it. Do not extend the collectors array to the area shaded in winter.

Guideline: In highrise buildings you may tilt the parapets of southern balconies, so they can serve as location for solar collectors with a more favorable exposure to solar radiation

Guideline: When tilted parapets serve as location for water heating solar collectors the area behind them can be used as a location for the hot water storage tank.

\section{SUBJECT: BUIIDING SHAPE AND ORIENTATION}

Guideline: Whenever site conditions allow it elongate the building in the East-West direction.

Reasons: A building elongated in the East-West direction (with $S$ and $N$ walls longer than the $E$ and $W$ walls) maximizes solar exposure of the building in winter (and its potential for solar utilization) and minimizes solar radiation on the walls and windows (and the resulting solar heat load) in summer. 


\subsection{General Architectural Guidelines for Energy Conservation}

Introductory Comments:

High winter heat loss and summer heat gain increase the energy demand of the building. Increasing the overall effective thermal resistance of the building (against conductive and infiltration heat losses) reduces the heat demand of the building both in winter and in summer.

Guideline:The overall thermal conductance of the building envelope in a given location should follow the ASHRAE standard $20 A-1980$.

SUBJECT: Use of Buffer Areas for Energy Conservation

Introductory comments : Indoor spaces in which the range of acceptable thermal conditions is wider than the conventional "comfort zone", or rooms which are not used often and can be conditioned independently of the rest of the building, can be located on the periphery of the building. In such placement they serve as buffers, lowering the rate of heat exchange between the building as a whole and the outdoor.

In residential buildings such spaces as the entrance hall, bathrooms, storage areas, laundry, etc., can serve as buffer

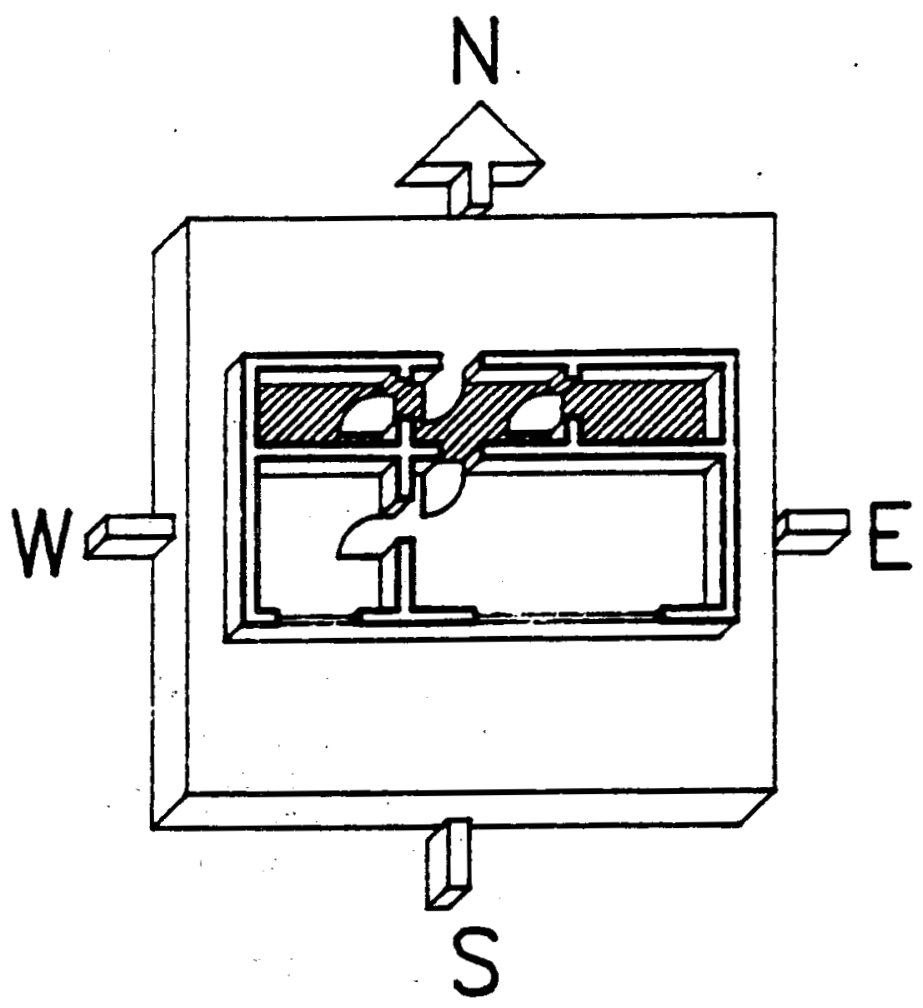

FIG. 4.B.1: Butfer Zone in Cold Region 
areas. In commercial buildings corridors and storage rooms are useful buffer areas.

Guideline: In cold regions, locate the buffer zones on the north side of the building. In this location they can reduce heat loss in winter from the building as a whole, without interfering with solar exposure of the main spaces.

Guideline: In hot regions buffer areas on the west side of the building, and to a lesser extent also on the east side, can reduce solar heat gain and overheating of the main areas of the building.

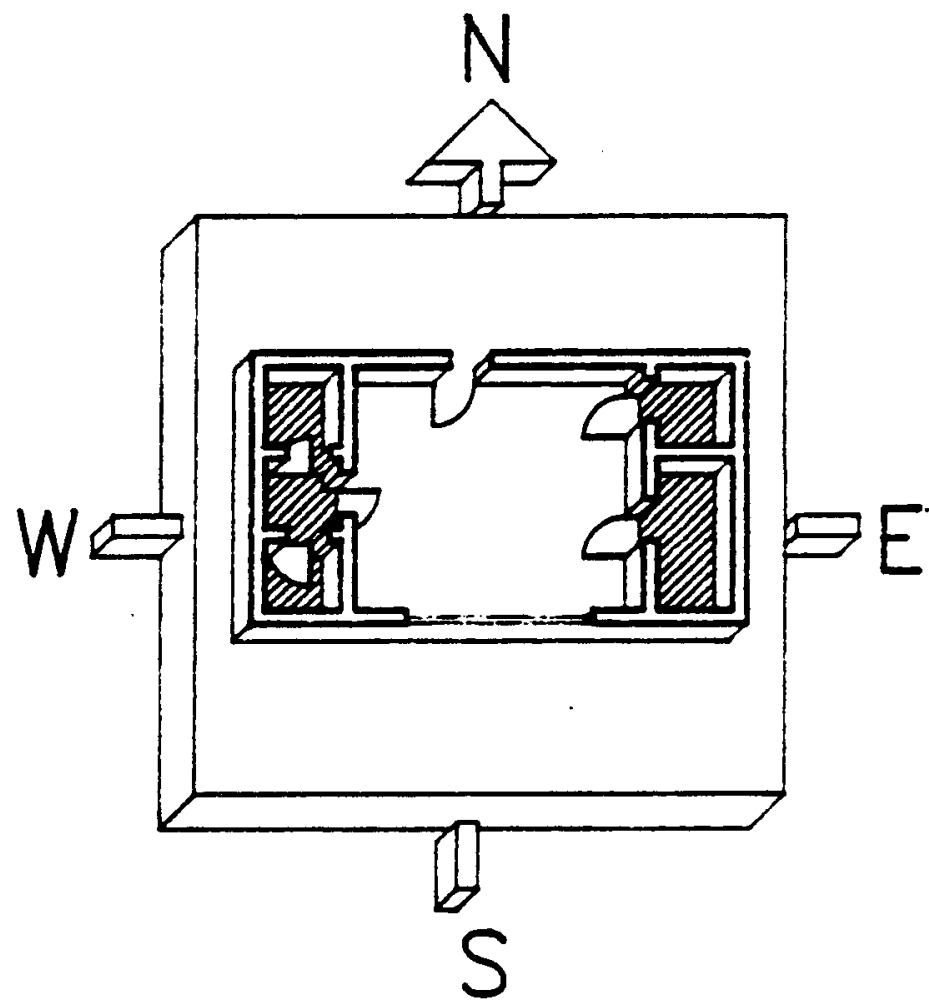

FIG. 4.B.2: Buffer Zone in Hot region

Guideline: In regions where the main direction of the summer winds is from the west or the east, make sure that buffer areas do not prevent effective ventilation of the main rooms of the building.

\section{SUBJECT: SUMMER COMFORT AND ENERGY CONSERVATION}

Introductory comments: Indoor comfort in summer often can be obtained by natural ventilation or by minimizing the rate of indoor temperature rise during the daytime hours. Satisfactory performance of the building in these parameters can minimize, or even eliminate, the need for mechanical cooling.

These features of the indoor climate depend mainly on the architectural and structural design details. The following guidelines address these issues. 


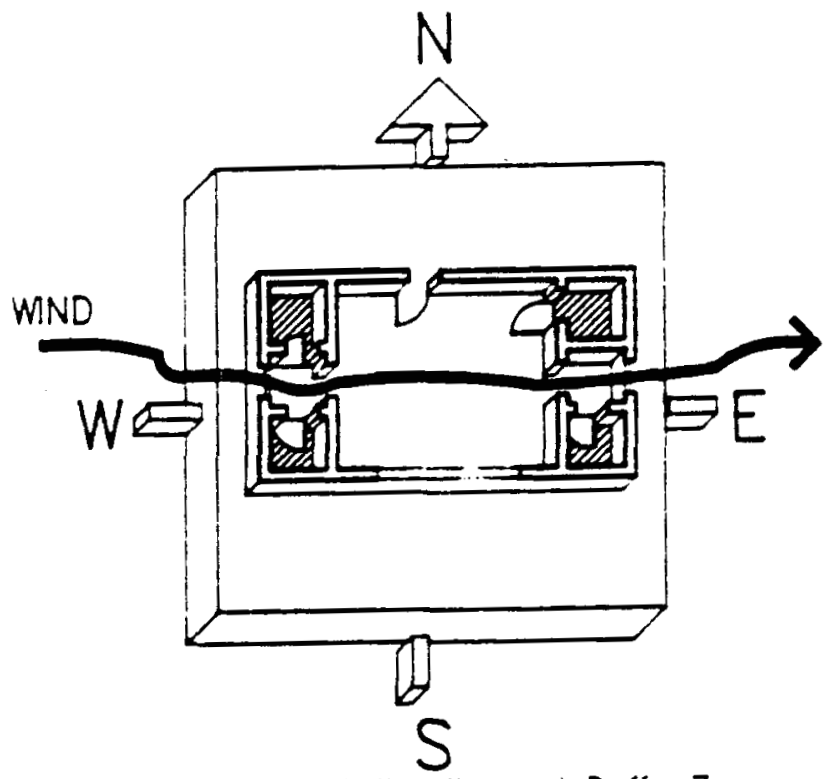

FIG. 4.B.3: Ventilation through Buffer Zone

\section{SUBJECT: Providing Natural Ventilation in Summer}

Guideline: Provide openable windows to all rooms. Whenever possible have at least two windows to every rooms which is close at night, with one of them facing the wind direction.

Reasons: In summer natural ventilation is important for comfort in all regions of the country and can minimize or even eliminate the need for mechanical cooling.

Comments: Some rooms, e.g. Living rooms, Dining and Kitchen, can be kept with open doors all day and therefore can be cross ventilated by air flow inlets at one room and outlets in another room.

on the other hand other rooms, such as Bedrooms and children rooms, are usually kept closed at night or at other times, for privacy or noise reduction. In such rooms cross ventilation can be insured, when the door is closed, only if the rooms have at least two windows.

\section{SUBJECT: Shading of Windows}

Guideline: Provide shading in summer to all windows. Choose type according to climatic region and orientation of window as detailed in General comments below.

Reasons: In summer any solar penetration through windows may cause overheating and discomfort, and therefore should be preventable.

In regions with different summer conditions, and in different orientations of windows, different shading devices (external vs. internal, fixed vs. operable) would be effective. 

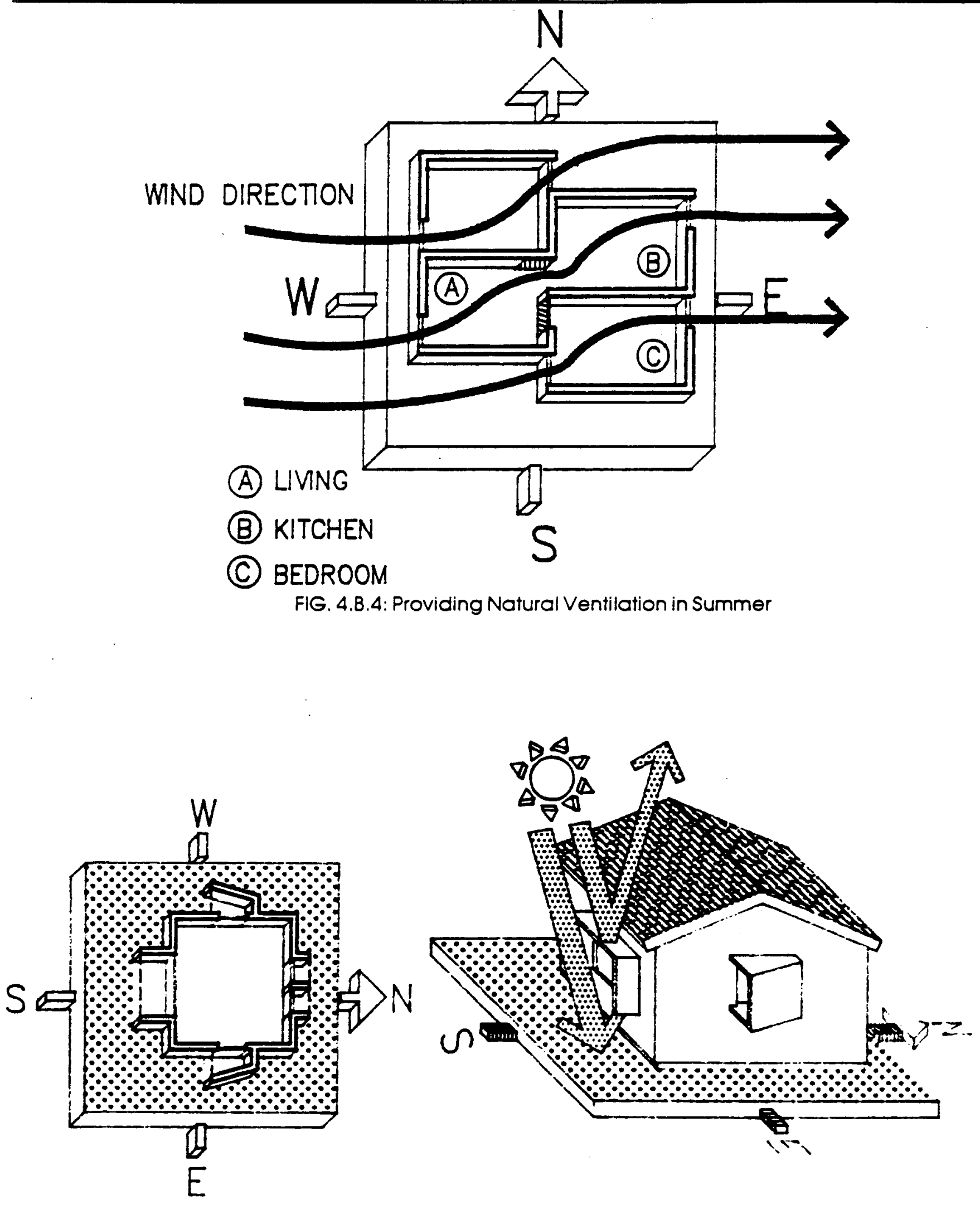

FIG. 4.B.5: Shading Devices Configuration 
General Comments on Fixed Shading Devices

Guideline: For southern windows fixed horizontal overhangs of appropriate depth can provide sufficient shade, except in very hot regions (e.g. Arizona, Nevada, Louisiana).

Guideline: In hot regions the glazing should also be protected from solar radiation reflected from the ground. There is also a need to minimize conductive heat gain through the glazing, which may make the provision of insulated operable shading desirable.

Guideline: For northern windows fixed vertical "fins" are effective in blocking the low north-western sun in the afternoon

Guideline: Eastern and western windows can not be shaded effectively by fixed shading devices perpendicular to the wall. only the special combination of vertical fins turned about 45 degrees to the south and horizontal plates can block the summer sun while enabling penetration of the sun in winter (FIG. 4.B.5)

Guideline: In hot regions with easterly or westerly summer winds the oblique fins can be open to the wind while blocking the morning and afternoon sun by suitable design details. 


\subsection{General Guidelines for Passive Solar Heating}

SUBJECT: IMPACT OF SOLAR SYSTEM ON SUMMER COMFORT AND COOLING

LOAD

Guideline: A passive solar heating system shall not adversely affect the indoor comfort conditions in summer or the cooling load on the air-conditioning system.

Comments: Solar heat gain through passive heating elements may continue to heat the building also in summer, although at a lower rate than in winter, if appropriate measures are not taken such as shading the solar element, ventilation of a sunspace, etc.

A given amount of solar energy, absorbed at the "solar element" in summer, results in a higher heat gain for the building than the same amount in winter, because the temperature difference to the outdoor is much smaller, causing a higher thermal "efficiency" of the passive system.

Therefore heat gain in summer from passive solar elements may cause heat discomfort and higher cooling load in regions with hot summers.

\section{SUBJECT: SOLAR EXPOSURE OF THE BUILDINGS}

Guideline: Insure unobstructed solar radiation over the southern wall of the building.

Reasons: Most passive solar heating systems use the southern. wall as the energy collecting element.

Comment: An exception to this "rule" can be in the case of a single story buildings, where roof monitors can be used for solar collection.

\section{SUBJECT: PLACEMENT OF MAIN ROOMS}

Guideline: Place the main rooms to the south side of the building.

Reasons: With most passive solar systems (except the Barra - Constantini system and one story buildings heated by Direct Gain from roof monitors) effective heating extends only to one room depth.

Consequently, only southern rooms can be heated by simple passiv systems.

\section{SUBJECT: LOCATION OF WINDOWS}

Guideline: Place most of the windows on the SOUTH side of the building. In other orientations limit the window's area to the size needed for daylighting and for natural ventilation.

Reasons: Southern windows get maximum solar energy in winter and a minimum in summer. For solar heating a larger area is usually needed than for lighting. For ventilation, relatively small windows, properly located, are sufficient.

Comment: Western windows in most regions are effective for natural ventilation. Western and Eastern windows often need operable shading. 
Design Guidelines for Various Passive Solar Systems

Guideline: All rooms for which passive solar heating is intended should have an unobstructed South exposure (plus/minus 30 degrees).

Reasons: In winter the south wall receives the highest solar radiation. Deviating from the recommended orientation for the solar heated rooms would decrease the thermal performance of the system.

Eception: In the case of a single story building or an upper story of a multi- story building, solar energy can be received through roof monitors with the glazing facing south.

Therefore: For single-story buildings and/or upper stories:

Vertical southern "skylights" (or roof monitors) can provide heat and daylight also to rooms without southern exposure. 
4.4 System: Direct Gain

Subject: Applicability of Direct Gain to Different Buildings

Guideline: When solar heating is provided by Direct Gain there is no limit on height of the building and number of stories, provided that the structural design can handle the load imposed by the mass needed for thermal storage.

Explanation: Solar windows can serve as energy collection elements, for any height of a building and a number of stories. comment: With new concepts of lightweight thermal storage by Phase Change Materials incorporated in conventional building materials the load issue may be bypassed in the future. (see Appendix B).

\section{Subject: Transfer of Excess Heat from Solar to Non-Solar Rooms}

Guideline: Provide closeable openings or fans between the "solar" and the non solar rooms.

Explanation: Appreciable temperature gradients can exist between "solar" and "non-solar" rooms when auxiliary heat is not provide to the non solar rooms. The non solar rooms will be appreciably cooler and uncomfortable.

To maintain comfort, occupants may use auxiliary heating even when excess heat is available in the solar rooms, unless it can be transferred to the cooler rooms. Large open doors enable effective passive convective heat transfer from the solar to the non solar rooms. An alternative method to transfer the exces

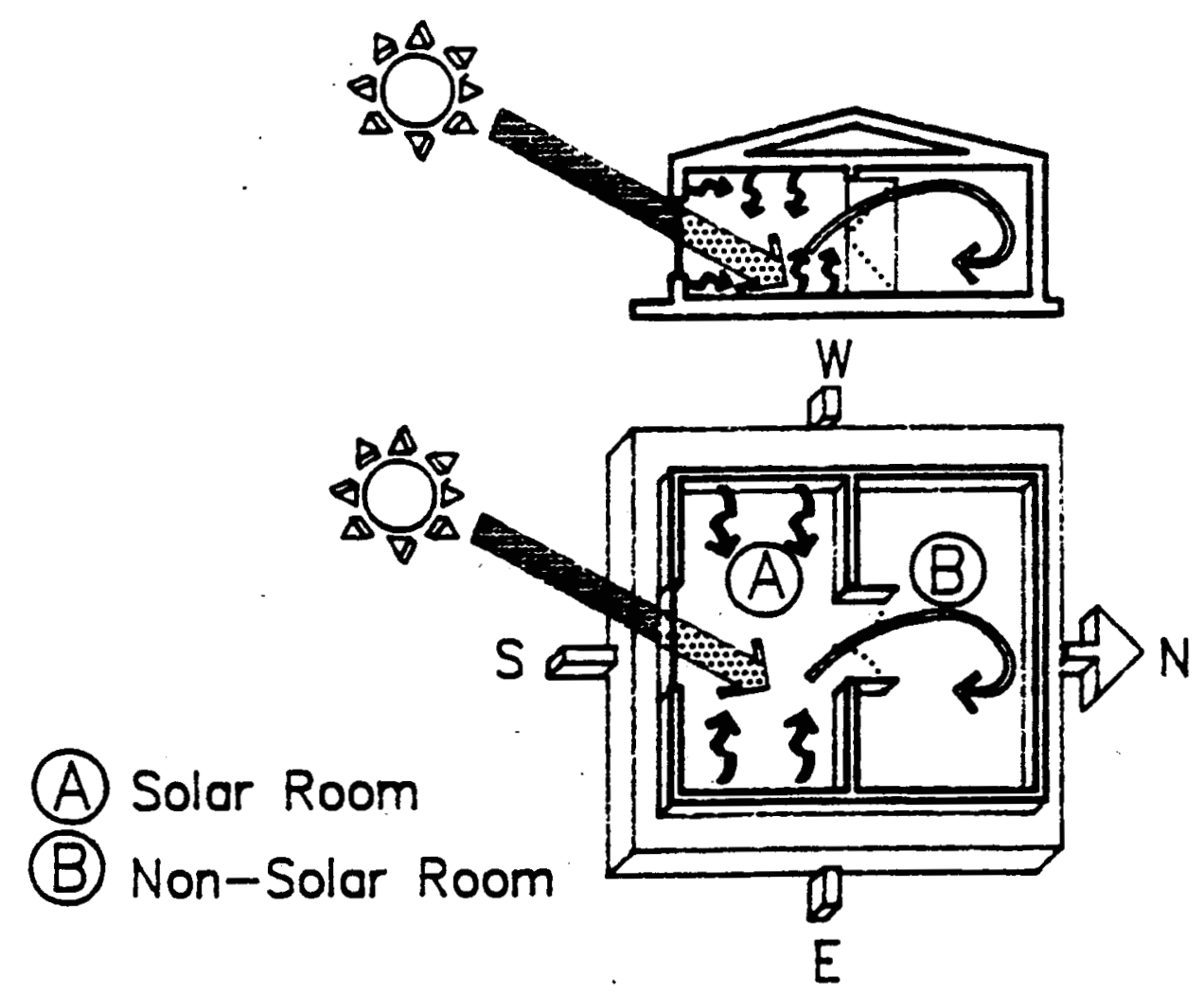

FIG.4.D.1: Heat Transfer from Solar to Non-Solar Rooms 
solar heat is by means of a fan, placed between the two rooms.

Subject: Size of Solar Windows in Direct Gain Buildings.

Comments: Direct Gain is the most efficient method to collect solar energy because the energy is collected at the lowest usable temperature, besides the benefits of daylight and view offered by southern glazing.

Guideline: It is recommended that in all solar buildings direct gain will be included with glazing area up to a certain limit, e.g. about 10-15\% of the floor area of the heated space Increasing the glazing area beyond this limit will often cause overheating of the interior of the building. In this case excess heat will be vented out or the glazing will be shaded. Excessive sunlight also causes too much glare, deterioration of the materials of furniture, fabrics, etc. These factors limit the practical size of Direct Gain glazing.

Comment: The size of the solar glazing is also related to the amount of the available thermal storage, which stores excess heat in daytime and releases it at night.

Comment: When large glazing areas are provided in cold regions, where night insulation is needed to prevent excessive heat loss, care should be exercised in their design details to insure trouble free daily operation.

- Some options of night insulation:

a-Insulated curtain with velcro strips

b-Folded insulated panels (Concertina type)

c-Insulated hinged shutters

\section{Thermal Storage Issues in Direct Gain}

Subject: Thermal Storage for Direct Gain with Conventional Materials.

Functions:

a) to maintain indoor daytime temperature within the comfort range by reducing rate of temperature rise.

b) To store excess solar energy during daytime and release it to the indoor space at night

\section{Materials which can be Used for Thermal Storage}

Three types of materials can be used for thermal storage in Direct Gain buildings:

a-Conventional cementious materials (concrete, bricks, etc.).

$b$-Water in specialized containers.

c-Phase Change Materials (PCM). See appendix for details.

Thermal Storage by Conventional Building Materials

Guideline: For each sqft of solar glazing provide thermal storage elements made of high mass materials, with a surface area of at least 6 sqft. The walls, floor and ceiling of the space can be used for thermal storage. Disregard any surfaces 
covered by rugs, carpets, paintings, etc., and any materials behind insulation.

Guideline: Interior plaster boards (gypsum boards) of stud walls can also contribute to the storage, in spite of their small thickness, due to their large area.

Subject: Concrete Floors as Thermal Storage Elements.

Guideline: When a concrete floor is taken into account as a storage element the following limitations should be taken into account:

- carpets insulate the concrete floor from the radiation.

- furniture intercept the radiation.

Because of the common interior conditions in Living rooms, Bedrooms, etc., the actual, practical, effective storage capacity of floors may be much smaller than what is calculated on the basis of the "gross" floor area. This factor should be taken into account in evaluating the available thermal storage in Direct Gain rooms.

Subject: Colors of Interior Surfaces of Thermal Storage Elements

Guideline: The internal colors of the energy storing elements have no significant effect on the storage efficiency, provided that sufficient surface area of the storage elements is availabl

(at least 8 times the solar glazing area).

Explanation: In considering the effect of colors of interior surfaces it should be remembered.that light colors cause inter reflections between all interior surfaces. A larger area of the internal materials participates in the energy storage, compensating for the smaller fraction of energy which is absorbed at each impingement by reflection.

\section{Water as a Thermal Storage Material in Direct Gain Buildings}

\section{Introductory Comments:}

Water has much higher specific heat (about 4.5 times that of masonry materials). Therefore also the volumetric heat capacity of water is higher than that of the denser conventional building materials (more than twice).

Water in suitable containers, placed within the heated space, can provide the required storage capacity. The containers can be either opaque or transparent (or translucent). The surface area of the containers may by the limiting factor in the transfe of heat in and out of the containers and the effective storage capacity of the water.

Common containers used in solar buildings are vertical cylinders made of steel or plastics. The water can be clear or colored by a dye. Treatment against fungi growth is recommended.

Subject: Location of the Water Containers in the Heated Space

Guideline: Place the water containers in an area exposed to the penetrating solar radiation.

Reasons: The surface area of water containers is usually mach smaller than the area of the room surfaces utilized when thermal storage is in conventional building materials. The whole mass 
Design Guidelines for Solar Buildings

System: Direct Gain

of the water is participating in the storage of the energy upon its absorption. Direct exposure to the solar beam maximizes the absorption and storage efficiency. 
ShortDescription:

A high mass southern wall, made of conductive material and havin a dark color, with glazing in front of it, serves as a combined collecting and storage element. The heat wave passes the wall with a time lag of several hours so that the interior is heated mainly in the evening and night hours. Lowest temperatures occur in the morning hours. Indoor temperatures in rooms heated by thermal storage walls are very stable.

For detailed description and analysis see section 3 .

Subject: Materials for Thermal Storage Walls

Guideline: The heat from the wall can be utilized only in the rooms adjacent to the wall. Therefore only southern rooms can apply a thermal storage walls heating systems.

Explanation: The heating effect of such walls extends only to about 1.5 times the height of the wall. Therefore rooms with thermal storage walls can not be as deep as rooms with Direct Gain.

Excess solar heat is usually not available in rooms with thermal storage walls.

Guideline: For daylighting and early morning heating some Direct Gain should accompany Thermal storage walls. Eastern windows can be very effective, provided they can be shaded in the summer

Reason: The lowest indoor temperature in rooms heated by a Thermal storage wall occurs in the morning. Also, such walls do not provide, of course, any daylighting.

Subject: Applicability of Thermal Storage Walls.

Comments: If structural load is not a limiting factor then thermal storage walls can be applied also to high rise buildings However, access for maintenance of the glazing would be needed. It can be provided by e.g. balconies, which may serve also as horizontal overhead shading for the glazing in summer.

Subject: Convection Vents in Thermal Storage Walls (Trombe Wall)

Comment: openings for thermosyphonic ventilation (vents), at the top and the bottom of the wall, can increase the collection efficiency by about 10\%, if they are opened every day and closed every evening. otherwise the thermal efficiency of "vented" (Trombe) walls would be lower than that of unvented thermal storage walls.

Comment: The need for daily operation of the vents is considered a nuisance by many occupants. The vents may also interfere with arrangement of furniture. Most recent passive buildings with thermal storage walls apply solid walls without vents.

Comments concerning provision of Night Insulation for Thermal Storage Walls

- Night insulation can be located either on the inside of the glazing (within the air-space), or external to the glazing. 
- Night insulation can be located either on the inside of the glazing (within the air-space), or external to the glazing.

- Practically, external insulation can be applied only to single story buildings. It should withstand wind force.

- External night insulation can be, inter alia, in the following forms :

a-Hinged panel with horizontal hinges

b-Rolled-up insulated curtain with reflective coating facing

the glazing.

- When night insulation and/or summer shading is placed in the air-space between the mass-wall and the glazing it should be accessible for maintenance and repair, even when the daily operation is from the interior.

- Practically it means that a space of about 2 feet wide is needed between the wall and the glazing, with access to the space.

- Such a space can provide also possibilities for cleaning the interior side of the glazing.

- If part of the glazing is openable then the space can be ventilated in summer. The opening can enable cleaning also the outside of the glazing.

- Insulation within the air-space is protected from wind and rain. Consequently, less expensive materials and design details can be applied. 


\subsection{System: Sun-Spaces}

Introductory Comments:

Sun spaces comprise an intermediate environment between the interior of the building and the outdoors, thus buffering the main spaces from extremes of exposure. Solar energy impinging on and absorbed in the floor of the sunspace is released at night back to the sunspace air. Consequently the sunspace night temperature is significantly higher than the outdoor's.

The sunspace area itself can constitute an additional living space in the winter and the transitional seasons. With appropriate provision of shading and ventilation in summer such spaces may be pleasant environments year round.

From the viewpoint of design, thermal characteristics and climatic applicability, two types of sun spaces may be distinguished:

a) Modified Greenhouses, with a glazed roof and often also with tilted glazed walls.

b) Sun Porches, with opaque and insulated roof and the glazing only in vertical position.

Sunspaces can have different relationships (configurations) to the building "proper" such as:

1) Attached sunspace: outside the building's wall Iine.

2) Semi enclosed: surrounded by rooms on two or three sides, with the southern glazed wall exposed.

3) Internal: surrounded by the building on all sides.

The main design issues affecting the performance of sunspaces are:

- The choice of the type of sunspace (greenhouse or solar porch)

- The configuration: relationship to the building.

- Type of the wall separating the sunspace from the rooms behind

- Thermal storage within the sunspace.

- Provisions for ventilation in summer.

- Applicability to different building types.

Detailed discussion of these subjects is presented in section 3.5 .

The following guidelines deal with them.

Subject: Choice of the Sunspace Type in Different Climates.

Comments: In choosing a sunspace type the following characteristics of the two types should be considered:

- In regions with mild winters and hot summers a greenhouse (glazed roof) may cause overheating. Solar porch (opaque and insulated roof) minimizes this drawback and also shades the separating wall. Therefore a solar porch would be preferable in such regions even though it is less efficient in collecting solar energy in winter. 
- In regions with cold winter and mild summer a greenhouse with glazed roof would provide more heat (for the same vertically projected area) than a solar porch. Provisions for ample natural ventilation of the greenhouse can be adequate to minimize overheating in summer. In such regions the greenhouse type would be preferable.

- In regions with cold winter and hot summer the designer should decide which season is more critical and chose the sunspace type accordingly.

A"compromise" might be the optimal solution by which a strip of the roof next to the separating wall would be opaque, with a width sufficient to shade the wall from April through August. The rest of the roof can be glazed. Cross ventilation of the sunspace in summer in essential in such regions.

Guidelines for sunspaces in Different Climates

Regions with Cold winters and Mild summers

Guideline: All glazing in the sunspace should be double glazing.

Guideline: The end walls should be well insulated, to reduce heat loss from the warm sunspace.

Guideline: In such regions the roof of the sunspace should preferably be glazed, except for an opaque and insulated overhang strip for summer shading of the southern wall of the building.

Regions with Hot Summers and Mild Winters.

Guideline: In regions with hot summers and mild winters the sunspace should be designed with openable end walls, as well as some openable parts of the southern glazing. This will enable cross ventilation of the sunspace, thus minimizing the likelihood of overheating.

Guideline: Glazing in the sunspace can be either single or double. In view of the higher transparency of a single glazing

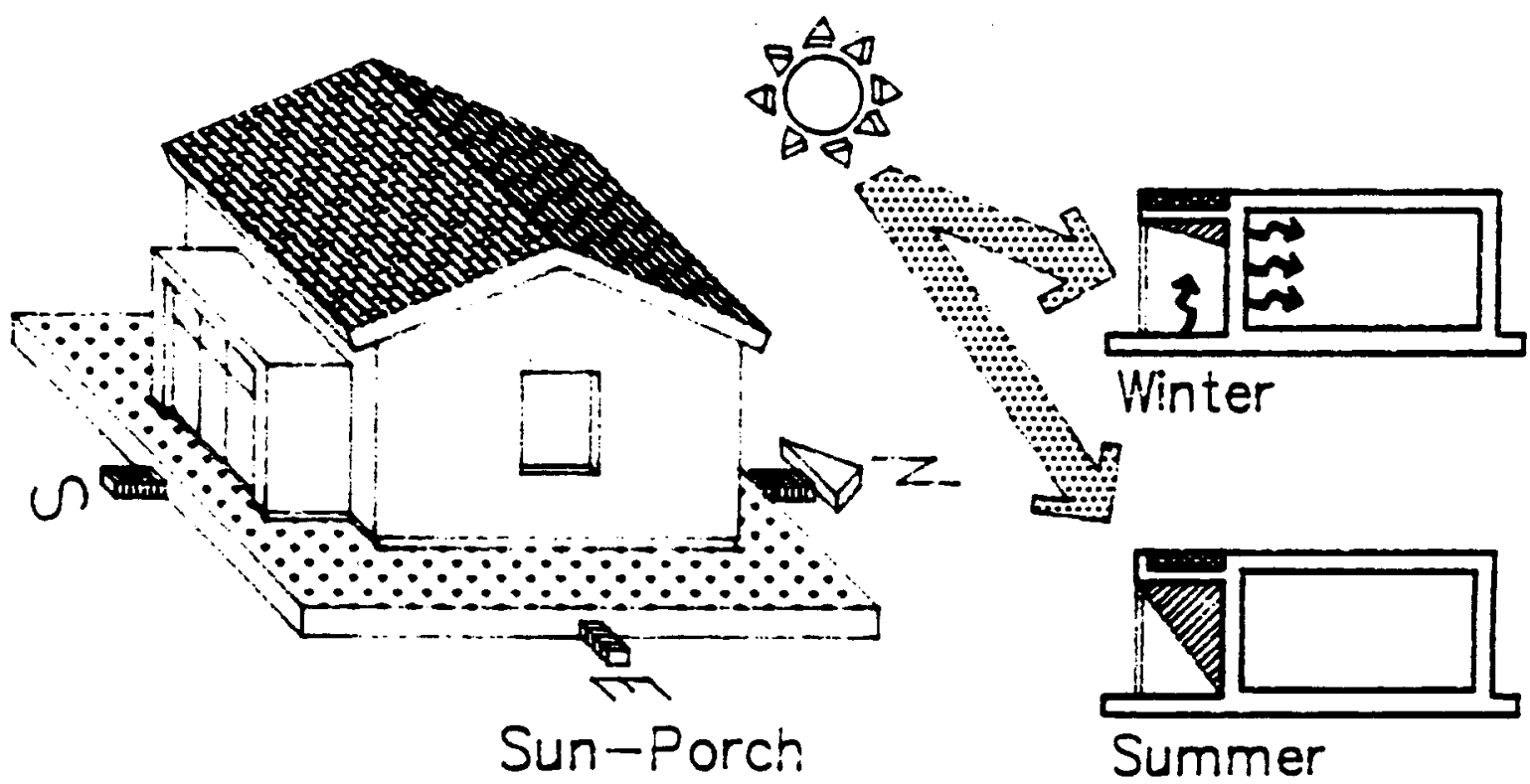

FIG. 4.F.1: Sunspace for Mild Winter \& Hot Summer 
(by about 10\%) and the mild winter temperatures in such regions the expected effect on performance is not very large.

Guideline: In buildings which are not air-conditioned the roof should preferably be opaque and insulated, (the solar porch type). This will minimize summer everbeating of the building and indoor discomfort which may result from solar radiation transmitted through a glazed roof. This recommendation is suggested although it will cause somewhat reduced solar heat gain in winter.

Guideline: In buildings which are air-conditioned summer discomfort can, of course, be prevented by the air-conditioning, counteracting the extra heating from the sunspace by additional energy expenditure. In this situation the issue of the sunspace roof type (glazed or insulated) could be decided by the designer by comparing the electrical energy cost of the additional coolin caused by a glazed roof with the additional solar heat it provi in winter.

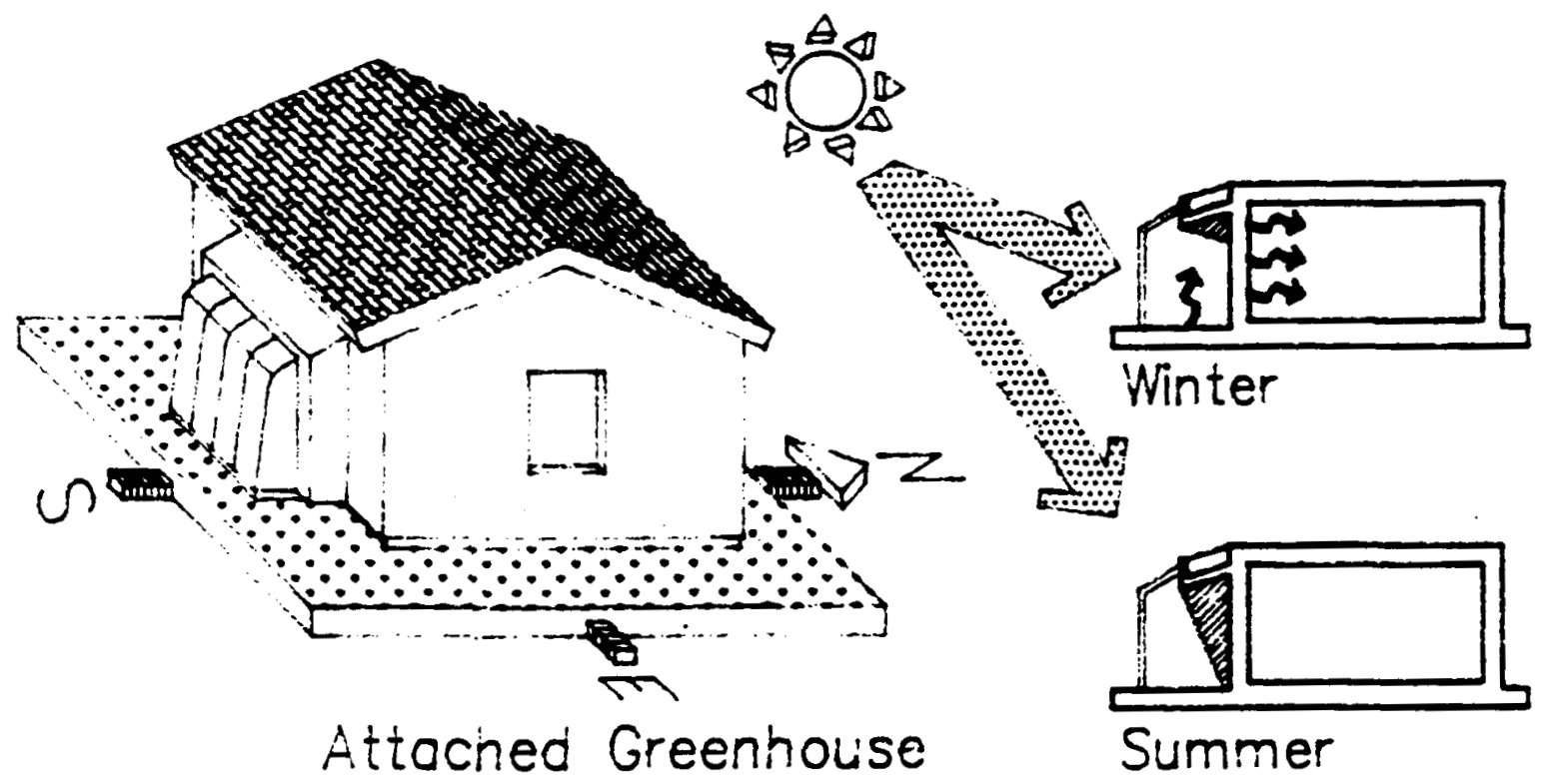

FIG. 4.F.2: Sunspoce for Cold Winter \& Hot Summer

Subject: Sunspace Configuration: Relationship to Building.

Guideline: In deciding the relationship between the sunspace and the building the designer should consider the following functional aspects of the different types of sunspaces:

- Attached sunspaces share one wall with the rest of the buildi They provide flexibility, for planning and construction, including retrofitting.

- When the sun space is indented into the building (semienclosed), there is a greater variety of possible connections between the surrounding rooms and the sun spaces.

Comments: Internal sunspaces are sometimes referred to also as atria or as a "solar courtyard". The glazing has to be above the roof, and therefore its size is 1 imited. The lower heat gain potential is partly compensated by the greatest efficiency of distribution to the living spaces around the sunspace. With 
suitably designed openings and shading (above the building's roof level), internal sunspaces may enhance summer ventilation of the main building.

Subject: The Wall Separating the Sunspace from the Rooms Behind.

Comments: The sunspace may be connected to the main building by a number of design solutions, such as:

a-Thermally massive, conductive wall

b-Large closable openings

c-Glazed wall

d-Internal "Trombe" wall (glazed storage wall)

In considering the choice of the separating wall the designer should take into account the following characteristics of the different walls.

\section{Thermally Conductive Mass Wall}

The wall may be built of any of the conventional masonry materials. At night, most of the heat from the wall is given up to the sun space itself, reducing its rate of cooling but also decreasing its efficiency as a source of useful heat for the interior.

Heat transfer from the sunspace to the rooms behind can be accomplished mainly by natural convection through large doors in the separating wall. The convective flow depends on the size of the door, and whether the door is kept open during the sunny hours.

Guideline: When the separating wall is built of masonry materials the main heat flow to the interior would be by convection. Therefore all conventional masonry materials, such as concrete, bricks, stones, Adobe, etc., would be appropriate, regardless of their conductivity.

Guideline: The thickness of the separating wall would be between 12 and $16^{\prime \prime}(30$ to $40 \mathrm{~cm}$.)

\section{Glazed Storage wall Within The Sunspace}

By placing an additional layer of glass over a massive conducting wall, an internal Trombe wall is created within the sunspace. The sun space protects the wall against high heat loss to the outside, increasing the heat flow to the interior.

Higher air temperatures are maintained also in the gap between the glazing and the wall. The hot air may be delivered by natural or forced convection to remote, north facing, spaces in the building.

Insulated Wall with Openings For Heat Transfer By Natural Convection

The separating wall may be insulated, with large doors in it connecting the sunspace with the rooms behind. Convective heat transfer typically takes place then by thermosyphonic air flow 
through the openings, from the sun space to the rooms of the building. The convective heat flow may be enhanced by the use of ceiling height doors, rather than doors of conventional height.

In winter at night, when the connecting doors are closed, the insulated wall minimizes the heat loss from the interior. In summer during daytime, if the connecting doors are closed and shaded, the heat gain is minimized.

on the other hand, because of the low heat capacity and thermal conductivity of the separating wall, in winter nights heat flow from the wall into the sunspace is negligible. Therefore the temperature in the sun space will be lower than in other types.

\section{Insulated Glazed Wall Within The Sunspace}

An additional layer of glazing may be placed in front of an insulated connecting wall. The principal purpose of this arrangement would be to supply air at temperatures higher than those obtained with a conductive wall. The hot air may then be used for quick heating of adjacent or remote spaces.

\section{Glazed Wall As A Separating Element}

By having a glazed wall between the sunspace and the room behind it, including operable doors, the inhabited spaces may benefit from some direct gain, at a reduced rate compared with a Direct Gain system:

The principal benefit of a glazed connection, however, is the daylight transmitted to the interior and the view to the outdoor

As the glazing provides poor insulation against conductive heat loss (in winter) and heat gain (in summer), operable insulation (e.g. insulated curtains) may be advisable, both against nighttime heat loss in winter, and heat gain in summer.

Subject: Thermal Mass Inside the Sunspace

If the sunspace is to be used for anything else than for heating air, it must contain some thermal mass to moderate its temperature swings. When the sunspace is at the ground floor the soil under the floor provides a thermal mass. At higher floors specialized mass would be needed.

Guideline: The necessary thermal mass may be provided in the sunspace in many forms, such as in a structural floor, connectin walls or other structural features, or by planters, water containers, etc.

Guideline: Thermal storage mass could be located at the base of the glazing. There it will intercept sunshine which would not, in any case, irradiate the connecting wall.

Subject: Applicability of Sunspaces to Different Building Types.

Sun porches can be applied to the south facade of any building, regardless of its height, because all the glazing is vertical: Sun porches can thus be placed, one over the other, in multi storied buildings and extending, if so desired, along the whole facade of the building. 
On the other hand a greenhouse, by definition, has a horizontal or sloping glazed roof. If placed one on top of the other, the floor of the upper greenhouse will block the sun from the roof of the lower one.

There is, of course, still the possibility to place the greenhouses, if they do not extend along the whole width of the facade, in a checkerboard pattern (FIG.3.C.2).

4.6 Bibliography: Books with Guidelines for Solar Buildings.

-Anderson, B., Michal, C., Temple, P., Lewis, D. and Balcomb, D. (1980): "Passive Solar Handbook - Volume 1". NTIS.

-Balcomb, J.D., C.D. Barley, R.D. McFarland, J.E. Perry, Jr. W.O. Wray, and S. Noll (1980): "Passive Solar Design Handbook, Vol. 2". DOE/CS-0127/2. US Department of Energy, Washington, DC.

-Jones, R.W. (Ed.), J. D. Balcomb, C.E. Kosiewicz, G.S. Lazarus,

R.D. MCFarland, and W.O. Wray, (1982): "Passive Solar Design Handbook, Vol. 3. DOE/CS-0127/3. US Department of Energy, Washington, DC.

-Mazria, E. (1979): "The Passive Solar Energy Book". Rodale Press.

-Watson, D. (1977): "Designing and Building a Solar House". Garden way Publication. 


\section{Results of Previous Experimental Studies}

The following Reports on monitored residential buildings will be summarized and their results evaluated in this Appendix:

-Jones, R. (1982): "Monitored Passive Solar Buildings". Los Alamos National Laboratories.

-Haskin, D. and R.P. Stromberg (1979): "Passive Solar Buildings"

-SANDIA Laboratories.

Comment: Some particular solar buildings are reviewed in both of the above reports. One of them (SANDIA-79) will serve as basis for the summary. Reviews of the same building in the other report will not be included, unless different evaluations, or performance parameters, are presented in the two reports.

-AIA Research Corporation, (1978): "Passive Solar Design: A survey of Monitored Buildings".

Comment: This report is a collection of various articles, by different authors, which evaluate different solar buildings. While all the authors gave evaluation of the performance of the buildings only few of them provided data which would enable independent quantitative evaluation of the performance of the solar systems. Only these additional buildings will be reviewed in this publication.

-SERI (1983): "Passive Solar Performance: Summary of 1981-1982 class B Results".

-SERI (1884): "Passive Solar Performance: Summary of 1982-1983 Class B Results".

comment: These two SERI reports deal mostly with different buildings, but distributed in the same climatic regions of the country. Some buildings, however, were monitored in both studies. The climatic conditions were different in the years of the two stages. The performance of these buildings will be given separately for each year. The summary, analysis and evaluation will deal with the two stages as one study.

-Duffy, J. and D. Odegard (1986): "Solar Load Ratio Design Tool Predictions Compared to Level B Monitoring Data". Passive Solar Journal, V 3, No 1, pp.77-98.

Comment: This paper contains comparison between the measured auxiliary energy and predictions by the SLR model, developed at the Los Alamos National Laboratories. Duffy and Odegard have found that the predicted and measured average values did agree very well, with average difference of 0.15 of the measured mean. However, there were significant deviations of measured from predicted values of individual buildings. Balcomb (1987) suggests that errors in estimating the heat loss coefficient of the buildings caused these deviations. 


\section{A.1 Summary of AIA Research Corporation Report.}

The survey consists of a collection of articles describing buildings using various passive solar systems and, in some cases, also reporting performance, in different climatic regions of the USA. Additional information about the buildings was collected and the performance evaluated by the authors of the Report.

In this summary general conclusions are drawn first. Then several individual articles from which lessons of general interest can be learned are summarized separately.

Applicability of passive solar techniques to different climates.

It was concluded that the "feasibility of passive design techniques has been demonstrated in all eight climatic regions where monitoring results have been reported". In particular the results obtained in the North-East region are of interest because this region is relatively cloudy. Some of the buildings achieved more than $50 \%$ solar contribution to the heating energy needs (59\% in February and $76 \%$ in March in Massachusetts, and $65 \%$ during the heating season in Connecticut).

A more significant measure of the potential of passive solar systems in a given region is the solar energy collected per unit area of the solar glazing. This potential in the North-East was also impressive. Some calculated results are:

- 154,000 Btu/sqft per year in Manchester, NH.

- 165,000 Btu/sqft. per year in Royalton, VT.

- 19,207 Btu/sqft per month in February and 21,350 in March, in Cambridge, MA.

Applicability of Passive Solar Systems for Different Building Types.

The Report concludes that "both residential and commercial (non residential) buildings show solar fraction as high as 95-100\%". It should be pointed out that the performance of monitored buildings did not show such high SHF.

The application of solar energy to non residential buildings was studied in much more details in other studies. See section 2 .

\section{Combinations of Different Passive Solar Systems.}

The authors of the Report observe that "Higher solar fractions" tend to be obtained when two or more passive techniques are employed in the same building. Four of the monitored buildings combine three or more techniques and average 75\% (solar) contribution. of thirteen buildings combining both sunspace and a direct gain approach, all but three reported solar fraction of at least $75 \% "$. 
Performance of some Individual Buildings.

As this Report provides information on the performance of solar buildings in different climatic regions it would be useful to summarize some details of the performance of some individual buildings from which general lessons can be learned.

\section{Green Mountain Homes in Royalton, Vermont}

This building is of two stories and has Direct Gain solar heatin and convective night ventilation cooling. The floor area is 1264 sqft and the south glazing (windows and a door) 120 sqft and the east windows 58 sqft. The collector to floor area ratio in this building was 0.095 The windows were equipped with internal insulating shutters (R7). Thermal storage was in a ventilable slab, consisting of a combination of concrete, concrete blocks and gravel. A fan circulated air between the two floors, or through the storage slab, as needed. The performance of one building was monitored over one year (1977).

The solar contribution of the heating has ranged from $25.7 \%$ in January to $81.4 \%$ in september. No heating was needed from May 11 to september 13th. The annual solar contribution (SHF), calculated separately by two persons in two papers, was between 0.34 and 0.37 . The unit area annual solar gain was 124 Kbtu/sf.Year. The percent solar insulation. The results were:

Gain KBtu/sgft-year : without NI with NI

South window : $31.4 \quad 62.8$

It seems that several features of the solar system in this building have contributed to its very high relative performance. The building has Direct Gain to all the habitable rooms and the glazing is equipped with internal insulated shutters for night insulation. However, it seems that the main feature of the building contributing to its performance was its thermal storage

With the storage system of this building overheating was prevented and excess heat was stored and utilized instead of being vented out. The same storage can be used in summer to store night coolness and serving as daytime heat sink.

MIT Solar Building \# 5, Cambridge, MASS.

Timothy Johnson (1978) has applied polymer concrete/PCM ceiling tiles for thermal storage in the MIT solar building \# 5 (a studio-classroom): The tiles were $2^{\prime}$ square and $1^{\prime \prime}$ thick. Their chemical core ( $1 / 2$ ") was Glauber salt, fumed silica, borax and sodium chloride, wrapped in waterproof membrane. The core was bounded by two layers of polymer concrete. The phase transition temperature of this PCM is 73 oF. The PCM ceiling tiles are discussed in more details in Appendix $B$.

The solar system is a Direct Gain. Incoming insolation was reflected to the dark colored ceiling tiles by movable reflectin louvers, thus also eliminating glare from the large windows, as sunlight is reflected over the occupant's heads to the ceiling. Auxiliary energy was baseboard electrical heating. 
Performance: The building was monitored from Feb. 5 to April 3, 1978. The temperature swing of the PCM ceiling on sunny days was from 82 to 70 oF. The indoor air temperature, in sunny days, was about 10 of below the ceiling temperature. The indoor temperature swing was about $10 \mathrm{OF}$. even in very sunny days. The solar heating contribution was $52.9 \%$ in February and $75.9 \%$ in March.

\section{A.2 Summary of the SANDIA and JONES Reports.}

Haskin and Stromberg (SANDIA 1979), AIA Research Corp. (1978) and Jones (1982) have evaluated the performance of passive solar houses, mainly in NM but also in other climatic regions. The information on the individual buildings in the SANDIA Report is more detailed than in the AIA and the Jones reports. Therefore the SANDIA data will serve as a basis for the summary, with supplemental data from the AIA and Jones Reports, when needed. The SANDIA report provides data on the performance of the buildings in terms of the "net" load, the auxiliary heating and the SHF, as well as on the solar glazing area. From the net load and the auxiliary use it is possible to calculate total and unit area solar gain. The Report does not provide data on the solar radiation impinging on the collecting elements. Therefore, for these buildings, it is not possible to calculate the "efficiency" of the buildings, as defined above (Introduction).

Table A-1 gives original and additional performance data for the buildings covered by the SANDIA report.

Five of the houses reviewed in this report are located in northern New Mexico, with similar climatic conditions. This is the only report with data on performance of solar buildings in NM. Other three residential buildings discussed in this report are: one in Virginia (One Design), one in New Jersey (Kelbough) and one in Vermont (Green Mountain Homes). This last building is discussed also in the AIA Research Corp. Report.

Two of the buildings in NM have Direct Gain, one is with a sunspace and an "active" rock bed, one with a combination of a water wall and Direct Gain, one with an under-floor passive collector and an air loop and one building with a combination of a Trombe wall and Direct Gain. The solar heating fraction of the six buildings ranged from 0.57 to 0.84 .

The best performance of a building with Direct Gain (Shankland) was a solar gain per unit area of glazing of $170 \mathrm{Kbtu} / \mathrm{sf} . \mathrm{Y}$. With solar glazing to floor area ratio of 0.14 it provided a computed SHF of 0.66 . In reality the owner did not use the auxiliary system, except for a wood stove, but when the outdoor temperature was $-15 \mathrm{~F}$ the indoor was very cool, $44 \mathrm{~F}$.

Review of the building's plans shows very direct connection between the solar glazing and the rooms where heat is needed. This architectural design feature should be stressed because, it is one of the main factors which determine the performance of passive solar buildings.

The other building with Direct Gain (Williamson) has a much higher collector to floor area ratio, 0.25 . In comparison to 
the first building the SHF increased only to 0.72 and the solar gain per unit area has dropped to $153 \mathrm{Kbtu} / \mathrm{sf}$.Year.

The building with the Trombe wall. (Hunn) had a solar glazing to floor area ratio of 0.2 . The solar gain per unit area was 153 Kbtu/sf.Year and the SHF 0.57! In the Jones Report the performance of the Trombe wall in this building was reported separately. The total incident radiation on the wall (with 250 sf), from November through April, was 58.0 Mbtu and the heat transmitted to the building was $11.6 \mathrm{Mbtu}$. This yields an overal efficiency of 0.2 .

Comparing the field performance of the Direct Gain with a Trombe wall demonstrates the lower efficiency, per unit collection area, of the TW. The measured lower collection efficiency of the TW as compared with a DG results apparently from the higher collection temperature (surface temperature) of the Trombe wall.

\begin{tabular}{llllllll}
\hline \multicolumn{7}{c}{ Table A-1: Summary of SANDIA Performance Data } \\
\hline Location & Owner & System & $\begin{array}{c}\text { Solar } \\
\text { Saving } \\
\text { (MBtu/Yr) }\end{array}$ \\
\hline NM Santa Fe & Balcomb & SS & 55.64 & 84 & 0.18 & 135 \\
\hline NM Santa Fe & M. Jones & Loop & 78.33 & 84 & 0.20 & 147 \\
\hline NM Santa Fe & Williamson & DG & 47.33 & 72 & 0.25 & 153 \\
\hline NM WhiteRock & Shankland & DG & 63.58 & 66 & 0.14 & 170 \\
\hline NM Los Alamos Hunn & TW & 53.01 & 57 & 0.20 & 136 \\
\hline VA Star Tannery & WW\&DG & 25.11 & 80 & 0.48 & 46 \\
\hline NJ Princeton & Kelbaugh & TW\&SS & 36.50 & 83 & 0.50 & 39 \\
\hline VT Royalton & Green Mount DG & 27.43 & 34 & 0.10 & 165 \\
\hline
\end{tabular}

The performance of the Balcomb building, with the sunspace, was monitored more extensively than maybe any other solar building and is documented in several, more recent, publications. This solar system is a hybrid one: a fan circulates hot air from the top of the sunspace through rockbeds underneath the floors of the living and the dining rooms, and back to the sunspace.

The building has a glazing to floor area ratio of 0.18 . The total annual unit area solar gain was $135 \mathrm{Kbtu} / \mathrm{sf} . \mathrm{Y}$ and the SHF 0.84 . Although the SHF was higher than in the DG buildings, reflecting perhaps the much lower net heating load per unit floor area, the solar gain per unit area of solar glazing was lower.

The owners have commented that the temperature control requires opening and closing of the doors between the sunspace and the rooms according to the indoor comfort conditions and there is nothing critical about it. the temperature in the house was relatively stable and comfortable.

The $M$. Jones building has an under-floor passive collector and a passive thermosyphonic air loop between the collector and a rock bin storage. The circulation between the storage and the 
building is driven by a fan. Detailed analysis is presented in the LANL Report on the performance of the collector/rock bin subsystem.

The building had glazing to floor ratio of 0.20 , solar gain of $147 \mathrm{Kbtu} / \mathrm{sf} . Y$ and SHF of 0.84 . The overall system efficiency as cited in the SANDIA report, was $31 \%$. Significant losses (40\%) were from the rock bin, mainly by reverse thermosyphonic flow at night. It was concluded that with effective dampers and duct insulation this system could be very effective.

The owner has commented that the indoor temperature was stable and comfortable, and was kept within 65 to $70 \% \mathrm{~F}$ with very little use of auxiliary heating.

The building with the water wall and Direct Gain (Gunderson) has complex orientation of the glazing so that the "solar" glazing area could not be defined clearly. Consequently also the solar glazing to floor area ratio and the unit area solar gain could not be computed.

The annual SHF calculated in the SANDIA Report was 0.72 .

The water walls has operable insulation which is closed in summer. The owner has commented that the hottest indoor temperature occurs in the fall but excess heat can be vented out by opening the doors and windows.

\section{Buildings in the Other Regions}

Only three residential buildings in regions other than NM were evaluated in these Reports: one in Virginia (One Design), one in New Jersey (Kelbough) and one in Vermont. (Green Mountain).

The house in Virginia (One Design) had water walls and Direct Gain through clerestories. The solar glazing to floor area ratio was 0.48 , the solar gain per unit area was $46 \mathrm{Kbtu} / \mathrm{sf}$. Year and the SHF 0.80 .

The house in NJ (Kelbough) had a Trombe wall as the main solar element, and a greenhouse attached (without closeable doors) to the living area. The solar glazing to floor area ratio was 0.50 , the solar gain per unit area was $39 \mathrm{Kbtu} / \mathrm{sf}$.Year and the SHF 0.83 .

It is of interest to note that the unit area solar gain in these two buildings, with the mildest climates (VA and NJ), were the lowest, and their collector to floor area ratio was the highest, of all the buildings reported in this Report. As information on the incident solar radiation is not available in the SANDIA report it is not possible to compare the performance of these buildings to other solar buildings in these regions reported in the SERI Reports and to determine the relative effects of the climatic conditions and the design details.

The performance of the solar building in Royalton, VT, (Green Mountain Homes) has been discussed above, in the summary of the AIA Research Corp. Report. 


\section{A. 3 Summary of the SERI Reports}

A total of 58 solar buildings are covered in the two SERI repor with quite a few monitored twice, during the two years of the project. The description of the buildings is very short but their performance data includes the incident solar radiation, internal and auxiliary measured energy gain and calculated solar gain. From the reported data it is possible to calculate the unit area solar gain as well as the efficiency of the solar building, as defined above.

Duffy and Odegard (1986) have compared and reported the measured auxiliary energy use and the values calculated by the Los Alamos correlational model, for each building. This information enabled graphic analysis indicating the relative performance of the different solar systems and to analyze the factors associated with deviations of performance of individual buildings from the average performance.

Tables $A-2$ and $A-3$ show some design and performance data for all the monitored building in the two SERI Reports (1981-1982, 1982-1983), respectively.

The performance data was analyzed graphically, to see correlations between different performance and design parameters. The plans of buildings with either higher or lower performance than the average trend were analyzed to see the paths of probable heat flow from the energy collecting elements (windows, sunspaces, Trombe wall) to the various rooms of the building.

In some buildings the flow path was direct. for instance in buildings with southern windows to all rooms. Some of these buildings had the highest performance, in particular when the area of the windows was about 10-13\% of the floor area.

In many buildings, however, not all the rooms had southern exposure. In some plans it was clear that these rooms were heate only by the auxiliary system. The building's system efficiency, as defined above, could be quite high if the windows were sized to heat only the adjacent rooms (about 15-20\% of the area of the adjacent rooms), although the SHF for the building as a whole could be low.

In some buildings large solar glazing area was provided without clear heat flow paths between the collection points and rooms which did not have southern exposure. This was often the case in buildings with sunspaces. In some buildings the heat flow from a large sunspace to the rest of the building had to pass through a particular room which, of course, had to keep the doors open all day. Some of these buildings had the poorest performance.

In general, the observed differences in performance among the individual buildings were quite large. The conclusion which can be drawn at this stage is that these differences are caused either by uncertainties in the measured heat loss coefficients of the buildings, as Balcomb (1986) suggests, or as a results of the "operation" of the solar buildings, for instance closing and opening doors to insure convective flow from the points of solar collection to rooms, etc. 


\section{A.4 Summary of: SERI (1986): "PASSIVE SOLAR HOMES: A National Study".}

The Report summarizes the findings on thermal comfort and livability of 335 passive solar homes. The evaluation of the buildings was based on audits and occupant's questionnaires, coupled with utility bills (class $C$ by DOE monitoring levels classification). All the buildings have been occupied at least one full year.

The surveyed homes were distributed among 43 states, in different climatic regions: the Northeast, South, Mid-America and the West. Most of them (76\%) were of the Direct Gain type, including buildings with sunspaces connected to the main rooms by large openings, and $18 \%$ were with different types of thermal storage walls.

Passive cooling was applied to almost all the buildings, by means of night ventilation, shading, floor directly on the ground, etc. Air conditioning was used in the south by $48 \%$ of the homes, in the Mid-America by $22 \%$, in the Northwest by $21 \%$ and in the west by $9 \%$ of the homes for which data was available. The main findings of the study are summarized below.

\section{Overall Satisfaction Level.}

All the occupants surveyed were "very satisfied" (89\%) and "satisfied" ( $11 \%$ ) with their solar homes. No respondent was "not at all satisfied".

When asked specifically about the thermal comfort provided by the passive solar systems $71 \%$ were "very satisfied and $11 \%$ "somewhat satisfied".

Comment: Apparently the question dealing with satisfaction with the solar systems was perceived to be concerned only with the provision of heat. In fact, as is shown below, there were many complaints about overheating caused by the solar systems.

\section{Overheating Complaints.}

overheating of the buildings, due to the solar systems, was cited as a problem by $46 \%$ of the respondents to the questionnaire. overheating has occurred during all seasons but mostly in the summer and the winter.

Comments: In summer the outdoor temperature is highest so that even modest excess heat from the solar elements may cause overheating. In winter the sun intensity on the solar glazing is highest so that on clear, but not so cold, days overheating is likely.

The phenomenon of overheating depends to a great extent on the climatic conditions prevailing in the location of the building. Unfortunately the data on overheating were not classified by distribution in the different climatic regions. 


\begin{tabular}{|c|c|c|c|c|c|c|c|c|c|}
\hline $\begin{array}{l}\text { BLDG LOCATION } \\
\text { CODE }\end{array}$ & $\begin{array}{l}\text { Floor } \\
\text { Area }\end{array}$ & $\begin{array}{l}\text { Glazing } \\
\text { Area }\end{array}$ & $\begin{array}{l}\text { Incident } \\
\text { Radiation } \\
\text { Btu/Saft/Dav }\end{array}$ & $\begin{array}{l}\text { Load } \\
\text { KBtudDay }\end{array}$ & $\begin{array}{l}\text { Solar } \\
\text { Gain } \\
\text { KBtu/Day }\end{array}$ & SHF & $\begin{array}{l}\text { Ag/Af } \\
\text { Ratio }\end{array}$ & $\begin{array}{l}\text { Sg/Ag } \\
\text { Btu/ } \\
\text { SafidDay }\end{array}$ & $\begin{array}{l}\text { System } \\
\text { Effic. }\end{array}$ \\
\hline DMA BOULDER, CO. & 1832 & 279 & 1210 & 358 & 208 & $0.58 \%$ & 0.15 & 746 & 0.62 \\
\hline DMC LAFAYETIE, CO. & 1360 & 167 & 1320 & 313 & 189 & $0.61 \%$ & 0.12 & 1132 & 0.86 \\
\hline DMD GOLDEN, CO. & 3291 & 365 & 1360 & 512 & 309 & $0.61 \%$ & 0.11 & 847 & 0.62 \\
\hline DME ARVADA, CO. & 3236 & 436 & 1360 & 615 & 307 & $0.50 \%$ & 0.13 & 704 & 0.52 \\
\hline DMF ARVADA, CO. & 1873 & 286 & 1220 & 324 & 116 & $0.36 \%$ & 0.15 & 406 & 0.33 \\
\hline DMG NORTHGLENN, CO. & 2851 & 307 & 1060 & 428 & 208 & $0.49 \%$ & 0.11 & 678 & 0.64 \\
\hline DMH DENVER, CO. & 1088 & 191 & 1450 & 181 & 101 & $0.56 \%$ & 0.18 & 529 & 0.36 \\
\hline DMI DENVER, CO. & 2766 & 264 & 1370 & 363 & 105 & $0.29 \%$ & 0.10 & 398 & 0.29 \\
\hline DMJ AURORA, CO. & 1298 & 140 & 1270 & 236 & 116 & $0.50 \%$ & 0.11 & 829 & 0.65 \\
\hline DMK AURORA, CO. & 2037 & 339 & 1400 & 289 & 160 & $0.55 \%$ & 0.17 & 472 & 0.34 \\
\hline DML AURORA, CO. & 1739 & 161 & 1520 & 337 & 170 & $0.51 \%$ & 0.09 & 1056 & 0.69 \\
\hline MBA BOULDER, CO. & 2150 & 292 & 1280 & 402 & 259 & $0.65 \%$ & 0.14 & 887 & 0.69 \\
\hline MAB CEDARRAPIDS, 10. & 1225 & 109 & 920 & 291 & 108 & $0.37 \%$ & 0.09 & 991 & 1.08 \\
\hline MAC EAU CLAIRE,WS. & 1812 & 343 & 1090 & 342 & 89 & $0.26 \%$ & 0.19 & 259 & 0.24 \\
\hline MAM LINCOLN, NB. & 2897 & 413 & 950 & 429 & 102 & $0.24 \%$ & 0.14 & 247 & 0.26 \\
\hline MBB SPENCER,WS. & 1007 & 85 & 1310 & 310 & 106 & $0.34 \%$ & 0.08 & 1247 & 0.95 \\
\hline HAMILTON, MS. & 2100 & 403 & 830 & 426 & 101 & $0.24 \%$ & 0.19 & 251 & 0.30 \\
\hline ORANGE,MS. & 1342 & 208 & 810 & 213 & 100 & $0.47 \%$ & 0.15 & 481 & 0.59 \\
\hline TOLAND, CN. & 1740 & 224 & 690 & 403 & 117 & $0.29 \%$ & 0.13 & 522 & 0.76 \\
\hline NEWPORT. VR. & 1400 & 89 & 1030 & 233 & 48 & $0.21 \%$ & 0.06 & 539 & 0.52 \\
\hline TOPSHAM, MN. & 1540 & 193 & 1090 & 256 & 103 & $0.40 \%$ & 0.13 & 534 & 0.49 \\
\hline SOUTHROYALTON, VR. & 1460 & 152 & 990 & 250 & 54. & $0.22 \%$ & 0.10 & 355 & 0.36 \\
\hline JAMESTOWN. RI. & 1182 & 174 & 890 & 163 & 75 & $0.46 \%$ & 0.15 & 431 & 0.48 \\
\hline NORTHWOOD. NH. & 1925 & 308 & 1220 & 239 & 89 & $0.38 \%$ & 0.16 & 289 & 0.24 \\
\hline EDMOND.OK. & 2400 & 440 & 210 & 663 & 190 & $0.28 \%$ & 0.18 & 432 & 2.06 \\
\hline MANNING, SC. & 2899 & 391 & 510 & 429 & 129 & $0.30 \%$ & 0.13 & 330 & 0.65 \\
\hline BLACKMOUNIAIN, NC. & 927 & 88 & 860 & 197 & 70 & $0.36 \%$ & 0.09 & 795 & 0.92 \\
\hline CARRBORO,NC. & 1632 & 244 & .470 & 323 & 93 & $0.29 \%$ & 0.15 & 381 & 0.81 \\
\hline RICHMOND.VR. & 1236 & 261 & 760 & 203 & 91 & $0.45 \%$ & 0.21 & 349 & 0.46 \\
\hline DAVIS, CA. & 1273 & 283 & 820 & 213 & 131 & $0.62 \%$ & 0.22 & 463 & 0.56 \\
\hline COLTON, CA. & 1664 & 207 & 1120 & 163 & 56 & $0.34 \%$ & 0.12 & 271 & 0.24 \\
\hline COLTON.CA. & 1660 & 50 & 1120 & 158 & 56 & $0.35 \%$ & 0.03 & 1120 & 1.00 \\
\hline YREKA, CA. & 1375 & 338 & 880 & 231 & 110 & $0.48 \%$ & 0.25 & 325 & 0.37 \\
\hline TRUCKEE, CA. & 1159 & 271 & 650 & 303 & 150 & $0.50 \%$ & 0.23 & 554 & 0.85 \\
\hline SANTABARBARA, CA. & 842 & 275 & 1000 & 137 & 79 & $0.58 \%$ & 0.33 & 287 & 0.29 \\
\hline RIOLINDA, CA. & 1215 & 135 & 860 & 189 & 52 & $0.28 \%$ & 0.11 & 385 & 0.45 \\
\hline WSK SACRAMENTO. CA. & 1420 & 170 & 640 & 126 & 32 & $0.25 \%$ & 0.12 & 188 & 0.29 \\
\hline WSL RIOLINDA, CA. & 1199 & 40 & 860 & 139 & 8 & $0.06 \%$ & 0.03 & 200 & 0.23 \\
\hline WSM SEBASTOPOL, CA. & 1493 & 228 & 1170 & 226 & 170 & $0.75 \%$ & 0.15 & 746 & 0.64 \\
\hline
\end{tabular}




\begin{tabular}{|c|c|c|c|c|c|c|c|c|c|c|}
\hline $\begin{array}{l}\text { BLDG } \\
\text { CODE }\end{array}$ & LOCATION & $\begin{array}{l}\text { Floor } \\
\text { Area }\end{array}$ & $\begin{array}{l}\text { Glazing } \\
\text { Area }\end{array}$ & $\begin{array}{l}\text { Incident } \\
\text { Radiation } \\
\text { Btu/SaftDay }\end{array}$ & $\begin{array}{l}\text { Load } \\
\text { KBtu/Day }\end{array}$ & $\begin{array}{l}\text { Solar } \\
\text { Gain } \\
\text { KBtu/Day }\end{array}$ & SHF & $\begin{array}{l}\text { Ag/Af } \\
\text { Ratio }\end{array}$ & $\begin{array}{l}\text { Sg/Ag } \\
\text { Btu/ } \\
\text { Saft/Day }\end{array}$ & $\begin{array}{l}\text { System } \\
\text { Effic. }\end{array}$ \\
\hline DMD & GOLDEN, CO. & 3291 & 365 & 1190 & 461 & 205 & $0.45 \%$ & 0.11 & 562 & 0.47 \\
\hline DMF & ARVADA.CO. & 1873 & 286 & 1190 & 324 & 87 & $0.27 \%$ & 0.15 & 304 & 0.26 \\
\hline$\overline{D M H}$ & DENVER, CO. & 1088 & 191 & 1300 & 144 & 64 & $0.44 \%$ & 0.18 & 335 & 0.26 \\
\hline DMM & NEDERLAND, CO. & 2350 & 538 & 1310 & 250 & 133 & $0.53 \%$ & 0.23 & 247 & 0.19 \\
\hline$\overline{D M N}$ & GOLDEN.CO. & 1282 & 60 & 1020 & 155 & 20 & $0.13 \%$ & 0.05 & 333 & 0.33 \\
\hline DMT & GOLDEN.CO. & 1007 & 75 & 131 & 203 & 51 & $0.25 \%$ & 0.07 & 680 & 5.19 \\
\hline MBA & BOULDER. CO. & 2150 & 292 & 1170 & 370 & 220 & $0.60 \%$ & 0.14 & 753 & 0.64 \\
\hline$\overline{\mathrm{MAD}}$ & BRAINERD. MN. & 1916 & 316 & 780 & 237 & 95 & $0.40 \%$ & 0.16 & 301 & 0.39 \\
\hline$\overline{\mathrm{MAE}}$ & DULUTH, MN. & 1188 & 108 & 1360 & 189 & 51 & $0.27 \%$ & 0.09 & 472 & 0.35 \\
\hline$\overline{\mathrm{MAl}}$ & INDIANAPOUS, ID. & 2964 & 278 & 730 & 416 & 167 & $0.40 \%$ & 0.09 & 601 & 0.82 \\
\hline$\overline{\text { MAN }}$ & NORTHFIELD. MN. & 1280 & 281 & 670 & 198 & 68 & $0.34 \%$ & 0.22 & 242 & 0.36 \\
\hline$\overline{\mathrm{MAP}}$ & PLYMOUTH, MN. & 1640 & 205 & 870 & 260 & 35 & $0.14 \%$ & 0.13 & 171 & 0.20 \\
\hline $\mathrm{MBD}$ & FARGO.ND. & 1695 & 128 & 830 & 247 & 103 & $0.42 \%$ & 0.08 & 805 & 0.97 \\
\hline NEA & HAMILTON, MS. & 2100 & 403 & 700 & 400 & 103 & $0.26 \%$ & 0.19 & 256 & 0.37 \\
\hline NED & NEWPORT, VT. & 1400 & 89 & 870 & 212 & 52 & $0.25 \%$ & 0.06 & 584 & 0.67 \\
\hline NEH & TOPSHAM, ME. & 1440 & 172 & 900 & 205 & 89 & $0.43 \%$ & 0.12 & 517 & 0.57 \\
\hline NEI & BOLTON.MS. & 1850 & 167 & 640 & 311 & 67 & $0.21 \%$ & 0.09 & 401 & 0.63 \\
\hline NEJ & LEXINGION. MS. & 2200 & 274 & 390 & 164 & 24 & $0.15 \%$ & 0.12 & 88 & 0.22 \\
\hline NEK & S-ROVALTON, VT. & 1460 & 152 & 1000 & 249 & 55 & $0.22 \%$ & 0.10 & 362 & 0.36 \\
\hline NEL & JAMESTOWN, RI. & 1182 & 174 & 820 & 197 & 59 & $0.30 \%$ & 0.15 & 339 & 0.41 \\
\hline NEM & NORTHWOOD.NH. & 1925 & 308 & 1170 & 289 & 148 & $0.51 \%$ & 0.16 & 481 & 0.41 \\
\hline NER & BRAINTREE, MS. & 520 & 126 & 640 & 112 & 42 & $0.38 \%$ & 0.24 & 333 & 0.52 \\
\hline SSF & SUWANEE. GA. & 2200 & 158 & 440 & 279 & 68 & $0.24 \%$ & 0.07 & 430 & 0.98 \\
\hline SSG & ATLANTA, GA. & 2965 & 164 & 260 & 481 & 112 & $0.23 \%$ & 0.06 & 683 & 2.63 \\
\hline SSJ & MANNING.SC. & 2899 & 391 & 570 & 338 & 130 & $0.38 \%$ & 0.13 & 332 & 0.58 \\
\hline SSK & B-MOUNIAIN, NC. & 927 & 88 & 810 & 202 & 60 & $0.30 \%$ & 0.09 & 682 & 0.84 \\
\hline SSL & STEVENS CITY, VA. & 1200 & 210 & 860 & 165 & 36 & $0.22 \%$ & 0.18 & 171 & 0.20 \\
\hline$\overline{S S N}$ & RICHMOND,VA. & 1236 & 261 & 710 & 196 & 76 & $0.39 \%$ & 0.21 & 291 & 0.41 \\
\hline$M B G$ & RICHMOND.VA. & 1180 & 185 & 940 & 97 & 58 & $0.60 \%$ & 0.16 & 314 & 0.33 \\
\hline WSK & SACRAMENTO. CA. & 1420 & 170 & 430 & 154 & 62 & $0.40 \%$ & 0.12 & 365 & 0.85 \\
\hline
\end{tabular}

Table A.3: Summary of SERI Report 1982-1983 
Appendix $B$.

\section{Technological Developments in PCM Thermal Storage.}

Factors Presently Limiting the Thermal Storage Capacity

The typical pattern of solar energy utilization in residential buildings shows diminishing return, in terms of the utilized energy, with increasing size of the collectors. The problems are specific for the various solar systems but, in general, they are related to the characteristics of the presently available thermal storage systems:

a) The rate of heat flow into the storage elements (mainly in buildings with Direct Gain and sunspaces) limits the amount of instantaneous solar gain to that level which will not cause severe overheating. Excessive heat gain has to be discarded, e.g. by venting it out, or prevented by shading the glazing.

b) With sensible heat storage materials the temperature of the storage elements rises as more heat is stored. In active solar systems this factor reduces the efficiency of the collection. In passive systems it is associated with a higher indoor radiant temperature, so that higher levels of storage may cause heat discomfort and lead to venting out the collected heat.

c) With conventional thermal storage in passive solar systems it is practically not possible to store solar energy for more than one cloudy day.

It seems that in residential buildings one of the main factors limiting the use of solar energy is the difficulty of storing heat, with the present storage technologies, for a sequence of several cloudy days.

It can be suggested, therefore, that if sufficient storage capacity (for several cloudy days) would be available at reasonable cost, a much higher fraction of the heating needs could be provided by solar energy.

A second, related, requirement is that this storage capacity would be achieved through a relatively small temperature change of the storage, without greatly affecting the indoor temperature and comfort (in passive systems), and the collection efficiency (in active systems).

In the case of "core-dominated" nonresidential buildings cooling is often a major consumer of electrical energy. In addition to the amount of energy the cooling load during hot days exaggerate the peak load problem. 'Developing practical methods for storing "cold energy" during the off-peak night hours, utilizing either nocturnal convection or low-cost night electricity, can be helpful in this respect. 
Thermal storage elements based on PCM can be used to store solar heat, as well as "cold energy", both in residential and in commercial buildings. For storing coolness the PCM should be formulated to have a lower phase transition temperature than the PCM intended for the storage of solar heat.

New developments in thermal storage by Phase Change Materials (PCM), as described below, can open the way to developments of thermal storage systems with much higher capacity than is presently practical. This Appendix deals with these new developments in PCM, which at present are not applied in buildings, at least on a commercial scale, but which may have a significant impact on the use of solar energy for heating and cooling of buildings.

\section{B.1.1 Thermal storage potential of PCM.}

Phase Change Materials (PCM) absorb and store heat while changing their state from solid to liquid (melting) and release it back when they solidify (freezing). The energy density (on weight basis) of the PCM material itself is very high in comparison with sensible heat storage materials with the temperature range common in passive solar applications. On the basis of the volumetric heat storage the difference is smaller but still significant.

Thus, for example, the latent heat of wax, a low cost and inert PCM, is about $40 \mathrm{cal} / \mathrm{gr}$. Sensible heat capacity of concrete, with a temperature swing of $5{ }^{\circ}\left(9{ }_{F}\right)$, is only about $1 \mathrm{cal} / \mathrm{gr}$. on a volumetric basis the heat capacity of wax (density of .78 $\mathrm{gr} / \mathrm{Cc}$ ) is about 31 . and that of concrete (density of 2) is about $2 \mathrm{cal} / \mathrm{cc}$.

The main problem with the use of PCM in passive, as well as in active, solar buildings is that of containerization, and this issue has "bugged" the application of PCM till now. Most PCM are inexpensive but the current "vessels" packaging them are expensive or not durable. Eutectic salts PCM (such as Glauber salt) are corrosive and have to be contained in expensive vessels. With inert PCM, such as waxes, the corrosion problem does not exist and less expensive containers can be used, but even in this case the cost of durable containers may be the main cost item.

Another major issue with PCM is that of the slow rate of heat transfer into and out of the PCM, as their thermal conductivity is low. As a result the thickness of panels containing PCM is

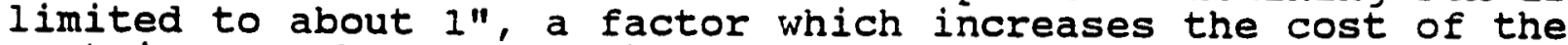
containers. The volumetric heat capacity of containerized PCM is smaller, of course, than that of the material itself.

\section{B.2 Experience with PCM in Solar Buildings}

MIT Building \# 5 in Cambridge, MASS.

Timothy Johnson (1978) has applied polymer concrete/PCM ceiling tiles for thermal storage in the MIT solar building \# 5 (a studio-classroom). The tiles were 2' square and 1" thick. Their 
chemical core $\left(1 / 2^{\prime \prime}\right)$ was Glauber salt, fumed silica, borax and sodium chloride, wrapped in waterproof membrane. The core was bounded by two layers of polymer concrete, which have functioned as the containers for the PCM.

The phase transition temperature of this PCM is $73^{\circ} \mathrm{F}\left(23^{\circ} \mathrm{C}\right)$. The tile weighs $11 \mathrm{lb} / \mathrm{sqft}$ and stgres about $220 \mathrm{Btu} / \mathrm{sqft}$ ( 600 $\mathrm{Kcal} / \mathrm{sqm}$ or $690 \mathrm{Wh} / \mathrm{sqm}$ ) over a $10 \mathrm{~F},(5.5 \mathrm{C}$ ) swing (latent and sensible heat). This is about ten times the sensible heat capacity of a concrete tile of the same thickness with the same temperature swing $(.025 * 2000 * .22 * 5.5)$.

Johnson mentions that aging problems were overcome by packaging the thickened salts in two adjacent 1/4" layers, thin enough to approximate the long dimension of Glauber salt crystals. After 2400 freeze-thaw cycles no signs of aging were observed.

The solar system was a Direct Gain. Incoming insolation was reflected toward the dark colored ceiling tiles by movable reflecting louvers. The temperature swing of the PCM ceiling on sunny days was from 82 to $70 \mathrm{~F}$. The indoor air temperature was about 10 of below the ceiling temperature. The indoor temperatur swing was about 10 oF., even in very sunny days.

According to Johnson (personal communication), the PCM tiles were used not only as ceiling but also as floor tiles in many buildings. Their cost was about $\$ 13 /$ sf, out of which only $\$ 3$ was for the PCM and its pouch and the rest for the containerization. The manufacturing of the tiles in the USA ceased about a year ago although they are still manufactured in Japan and in Sweden.

\section{A Building In Annot, France.}

Jaffrin (1986) of the CNRS has measured the performance of an $80 \mathrm{sqm}$ (about $900 \mathrm{sqft}$ ) solar house with PCM and concrete flogr thermal storage in a cold region of France, Annot, (minus $10{ }_{\mathrm{C}}$ average minimum in January).

Southern windows provided direct gain, but during periods when the house was not occupied the windows were converted into solar air heating collectors by installing insulation panels behind them.

The thermal storage consisted of a $20 \mathrm{~cm}$ (8") concrete floor in which 80 PVC tubes (10 cm. diameter and $2 \mathrm{~m}$. Iong), filled with CaCl PCM, were embedded.

Solar heated air from the vertical collectors was blown by a 300 watts fan through small PVC tubes $(5 \mathrm{~cm})$ inside the PCM tubes. Electric wires in the concrete floor provided the auxiliary heating, which was operating only during the night hours.

The performance of the house was monitored during two winters (1985 and 1986). The average efficiency of the "window air collectors" in January was about $30 \%$. The stored solar energy by itself was able to keep indoor stable temperature about 10 OC above the outdoors average even during a cloudy period of 10 days. 
PCM in Thermal Storage Walls in a Test Cell in Odeillo, France

Benard et al. (1980) have measured the performance of a 1 sqm thermal storage wall, $8 \mathrm{~cm}$ thick, made of glass blocks, $20 * 20 * 8$ cm. $\left(8 * 8 * 3.2^{\prime \prime}\right)$ filled with 65 liters $(52 \mathrm{~kg})$ paraffin wax, in a test cell at the Odeillo laboratory in france. This PCM wall was compared with a concrete thermal storage wall, $40 \mathrm{~cm}$ thick weighing $800 \mathrm{~kg} / \mathrm{sqm}$.

The thermal performance of the two walls was similar. The total weight of the PCM wall was less than one-tenth, and the thickness one fifth as that of the concrete wall. This experiment has demonstrated the potential of reducing the volume. (by a factor of five) and weight, (by a factor of more than ten) by the PCM, as compared with concrete, for a given required thermal storage. In this particular experiment the overall heat capacity was about the same as that of a conventional Trombe wall. But, potentially, a PCM thermal storage wall can have a much greater thickness, and heat capacity, if the problem of the heat transfer rate could be solved.

\section{B.3 PCM Incorporated in Conventional Building Materials and New Packaging Technologies}

Till recently, Phase Change Materials, or PCM, were "packaged" in specialized containers, such as tubes, shallow panels, plastic bags, etc. The MIT ceiling tile is an example of a packaged PCM. Recently, however, research and development is oriented towards combining, or integrating, PCM with conventional building materials and/or elements, and thus developing new "packaging" technologies.

Examples of such developments, and discussion of various options for their application in solar systems, are given below.

PCM can be incorporated into conventional building materials and elements in different ways, suitable for different applications and having different effects on the indoor temperatures and energy use for heating and/or cooling.

PCM in the newly developed forms can serve as thermal storage elements in solar passive, active and hybrid applications. The PCM can be mixed with concrete, plasterboard, expanded Perlite, etc.. The mixture can also be used as a filling in concrete blocks, etc.

The main design variables in considering incorporation of PCM in conventional building materials are:

- The medium with which the PCM is mixed (mainly its conductivity),

- The thickness of the layer incorporating the PCM,

- The location of the PCM containing element within the building.

- The method of heat transfer into and out of the PCM.

In most passive and hybrid applications, when the PCM is incorporated in any type of buildings boards, its effective volumetric heat capacity, latent as well as the sensible heat associated with the temperature swing of the element containing 
the PCM material, is the relevant indicator of its potential for thermal storage.

\section{Examples of PCM Incorporated in Common Building Elements}

Shapiro et al. (1987) from concordia University in Quebec have developed and tested wallboards impregnated with organic fatty acids. No exudation of Iiquid PCM occurred below 25\% (by weight) of the PCM. The wallboards, 1/2" thick, had a total heat capacit of about $30 \mathrm{Btu} / \mathrm{sf}$ with temperature swing of $4 \mathrm{OC}$ ( $7 \mathrm{OF}$ ), namely about three times the heat capacity of concrete tiles of the same thickness. The organic PCM have been diffused into conventional wallboard's materials such as gypsum (30\% by volume).

Salyer and his colleagues (1985) from the University of Dayton, Ohio are developing, under a contract with the DOE, and have applied for patents, passive storage systems incorporating PCM into such materials and building elements as cement, concrete, plaster, plasterboard, tiles, etc. The PCM they are recommending are mainly crystalline alkyl hydrocarbons (paraffin waxes).

These PCM are by-products of oil refining, readily available and quite inexpensive. They can be formulated to melt and freeze at any desired temperature, from about $50 \%\left(10^{\circ} \mathrm{C}\right)$ up to 120 ${ }_{F}\left(50{ }_{C}\right)$. For passive solar applications a transition temperature of about $77^{\circ} \mathrm{F}\left(25^{\mathrm{C}}\right)$ would be the most likely.

The waxes have heat of fusion of $70-110 \mathrm{Btu} / 1 \mathrm{~b}$. $(40-60 \mathrm{cal} / \mathrm{gm})$. Salyer and Milier mention that the waxes can be applied to the building materials in various ways, for example:

- Adding directly to the wet mix of the cementious materials up to about $5 \%$ in weight. However, in this form of application the strength of the concrete is reduced considerably.

- Wax PCM in liquid state can be directly percolated into the open spaces of porous building materials, such as concrete, plaster, bricks, etc.. This form of application also waterproofs the material.

- The PCM can be processed into small hard expanded pellets, containing about $80 \%$ PCM. These pellets can be incorporated into the wet mix, as aggregates, with minimum reduction in strength.

Salyer and his colleagues (1985) have reported that they succeeded in producing hard pellets containing $80 \%$ wax PCM, imbibed into high density polyethylene (HDPE), which store and release the energy at about the same temperature as the pure PCM. They suggest several applications of these pellets:

- Using them as aggregates in the mix of concrete.

- Incorporation into other media such as polystyrene bead foam insulation.

- Incorporation into thermosetting or thermoplastic composites. - A PCM pellets bed heat exchanger, with air or liquid circulation. 


\section{B.4 Perlite Impregnated with PCM}

Another approach to the incorporation of PCM into conventional materials is that of William A. Cordon (Patent applicationprivate communication). He has applied for a patent for "energy storing insulation", which is obtained by mixing Iiquid PCM, such as sodium sulfate (Glauber Salt) or calcium chloride, with expanded perlite. Expanded perlite is a porous volcanic material with a very large number of tiny pores, usually serving as insulation material. The expanded perlite particles serve as a carrier for the PCM.

The liquid PCM is absorbed within the pores of the perlite, which can absorb more liquid than its awn weight and stili remain surface dry. This leaves the perlite particles moist but not wet.

Cordon suggests that the perlite/PCM mixture can be used to fill in the air space between the sheeting and the wall board in stud-walls. Another suggested application is as loose insulation over a ceiling, with a sealant sprayed over the entire surface.

Two problems have to be solved, in my opinion, for this form of PCM application to be practical. The first is that of the heat transfer rate in and out of the Perlite/PCM volume. The conductivity of Perlite (an insulating material) is very low and may be the limiting factor of the performance when the energy input is from the indoor space into the PCM, as is the case in Direct Gain solar heating or in night ventilation cooling.

The second problem is that of the need for "absolute" prevention of vapor flow in and out of the PCM, as its properties are highly sensitive to the water content.

\section{B.5 Comments on Potential Applications of PCM}

\section{Containerized PCM Ceiling Tiles}

The PCM tiles tested in the MIT building are in effect shallow containers with about one half of the total volume filled with "pure" PCM. The problem of cost of the containers with such tiles stili exist.

The project of the MIT building has demonstrated that it is possible to produce conventional building elements with PCM storage capacity. In this case these were containerized PCM tiles but other "integrated" thin elements, like e.g. PCM impregnated ceiling panels or wallboards, may also perform a similar function. Other PCM materials can also be used in ceiling tiles or other surfacing elements, like waxes.

In the MIT case the "charging" of the storage was by reflection of direct penetrating solar radiation to the ceiling tiles. This mode of heat transfer enables charging the PCM with a small temperature difference between the indoor air and the tiles. But the area of the PCM ceiling is limited to the area onto which the solar energy is reflected in practice, an area which 
changes every month. This factor limits the potential for therma storage in PCM ceilings.

An alternative method of "charging" ceiling PCM tiles can be by convection, with hot air from a wall collector flowing above the tiles, as in the Barra-Constantini system (see section 3). It seems that with appropriate details of a modified "Barra ceiling" it may be possible to provide a high heat storage capacity without a risk of overheating.

\section{Comparing "Containerized" and "Incorporated" PCM "}

containerized" PCM, like e.g. the MIT tiles, can have a higher volumetric heat capacity than PCM incorporated within conventional building materials. The total heat capacity is a function of the PCM fraction in the composite element. The PCM containers can have a high fraction of their volume (above 50\%) filled with the "pure" PCM.

Impregnated building materials, e.g. a plasterboard, can contain less than $10 \%$ PCM.

on the other hand the potential cost of packaging the PCM within conventional materials may be much lower than the cost of the containers which have been applied to PCM elements up to now. If a large portion of the building surfaces could be PCM elemen

then even with low volumetric fraction of PCM the total heat capacity could be higher than that of conventional building materials.

\section{Adding PCM to Concrete}

Concrete/PCM material can find applications only in passive solar systems. Different considerations may be relevant to different passive heating systems.

The effective heat capacity of concrete is the product of its specific heat (about $0.2 \mathrm{cal} / \mathrm{gr} . \mathrm{C}$ ) and density (about $2 \mathrm{gr} / \mathrm{cc}$ ) times the average diurnal temperature swing of the material, which is different in various systems.

The effect of adding the PCM, with latent heat of about 40 cal/gr.C to concrete, depends on the temperature swing of the storage element. The larger the swing the smaller is the relativ contribution of the PCM. With this background the different ways of applications of the PCM to concrete can be evaluated. Some examples of such applications are discussed below.

\section{Use of Concrete/PCM in Direct gain Buildings}

In Direct Gain buildings the acceptable temperature swing can be assumed to be up to 5 oc. Thus the total effective heat capacity of the concrete by itself is about $2 \mathrm{cal} / \mathrm{gr} / \mathrm{day}$.

Adding $5 \%$ of PCM with latent heat of 40 (cal/gr) would increase the total heat capacity of the material to about $4 \mathrm{cal} / \mathrm{gr} / \mathrm{day}$ $(0.05 * 40+2)$, namely approximately doubling the heat capacity of the concrete element serving for thermal storage.

When the PCM is added to the wet mix of the concrete the increas in heat capacity should be weighted against the "penalty" of 
the significant reduction in the strength. It is the opinion of the author that in considering the weakening of the concrete and the modest gain in the heat capacity it is doubtful whether there might be many application for the PCM in this form.

\section{Using PCM Pellets as Aggregates in Concrete Blocks}

No data was given in the paper of Salyer on the density of the pellets, and on the maximum fraction that the pellets can fill in concrete. The density of the PCM material is about 0.78 . still, even with the Iimited available information it is possible, with some assumptions, to estimate the properties and the outcome of several ways of application.

A simple use for thermal storage might be to incorporate the pellets in non-structural solid concrete blocks used exclusively for thermal storage, where strength is not a factor, and where the pellets can be packed at the maximum volume fraction. Assuming it would be possible to have about $50 \%$ pellets (by volume) and that the PCM fills $80 \%$ of the pellets, the heat capacity of the block's material would be about $15.8 \mathrm{cal} / \mathrm{gr} / \mathrm{day}$ $(0.78 * 0.5 * 40+0.5 * 2 * 0.2)$, namely about 8 times the specific heat capacity of concrete in a direct gain situation $(2 * 0.2 * 5)$.

However, it should be noted that the limiting factor which will determine the actual heat storage capacity of such walls might be not the intrinsic capacity of the wall but the rate of heat flow into and out of the PCM in the wall, a factor depending on the thermal conductivity of the material. The conductivity will, in effect, determine the useful thickness of such walls. The design details of the "assembly" of blocks can also determine the effective heat capacity of the PCM.

Concrete/PCM solid "thin" blocks could be used in Direct Gain buildings as non bearing partitions, as well as lining of load bearing walls. As the heat input into the wall is from the interior, and.the acceptable indoor temperature swing is rather small, the "usable" thickness of the wall would be quite limited. Concrete/PCM pellets blocks could also be used as thermal storage (Trombe) walls. In this application, with common thickness of a thermal storage wall $(20-40 \mathrm{~cm}$.), the wall will have a very high thermal time constant with a long time lag of few days. The thermal conductivity of the composite material may be the limiting factor determining the maximum useful thickness of such walls.

After a sequence of several cloudy days it might take several sunny days till the new heat wave will "cross" a wall with conventional thickness of concrete blocks, e.g. $20 \mathrm{~cm}$. Therefore, provisions for fast heat gain, e.g. by southern and/or western windows providing direct solar gain, would be advisable.

on the other hand, after a sequence of several sunny days, with the melting of all the PCM, the wall will contain many times more heat than a conventional concrete wall. The latent heat capacity of the PCM in a wall $30 \mathrm{~cm}$. thick of $50 / 50 \mathrm{mix}$, for example, is $0.5 * 30 * 10,000 * 0.78 * 40=4680 \mathrm{Kcal} / \mathrm{sqm}$. The sensible heat capacity of the concrete, with 5 oc temperature swing (the melting-freezing temperature difference) is $0,5 * 30 * 10,000 * 2 * 0.2 * 5=300 \mathrm{Kcal} / \mathrm{sqm}$. The combined heat capacity is $4980 \mathrm{Kcal} / \mathrm{sqm}$. For comparison, a $30 \mathrm{~cm}$. water wall, undergoing 
$5^{\circ} \mathrm{C}$ temperature change, exhibits a heat capacity of 1500 $\mathrm{Kcal}$ /sqm.

The fraction of the stored heat which will actually be utilized would depend on the ratio of the interior heat transfer coefficient times the wall to indoor temperature difference, to the external conductance times the wall to outdoor temperature difference. The wall's temperature depends on the phase transition of the PCM.

With fixed heat transfer conditions (which depend mainly on availability of night insulation), elevating the transition temperature of the PCM will significantly improve this ratio and increase the indoor gain, although it will reduce somewhat the efficiency of solar energy collection by the wall.

This effect can be estimated by the following example. Jet assum indoor temperature of $20^{\circ} \mathrm{C}$ and outdoor average of $0{ }_{C}$, indoor surface coefficient of $8 \mathrm{~W} / \mathrm{sqm} * \mathrm{C}$ and external conductance, of double glazing without night insulation, of $3 \mathrm{~W} / \mathrm{sqm}$. C.

with transition temperature of 30 oc the above ratio would be: $(8 *(30-20) / 3 *(30-0)=80 / 120=0.89$,

The indoor heat gain would be $4980 *(80 /(120+80))=1992 \mathrm{Kcal} / \mathrm{sqm}$.

With transition temperature of 40 oc the ratio would be:

$(8 *(40-20) / 3 *(40-0)=160 / 120=1.33$,

The indoor heat gain would be $4980 *(160 /(160+120))=2846$ $\mathrm{Kcal} / \mathrm{sqm}$.

However, it should be noted thaf the energy collection efficienc would be lower with PCM of $40^{\circ} \mathrm{C}$ transition temperature because of the higher heat loss to the outdoor during the "charging" time.

\section{Containerized PCM Pellets in Water}

PCM pellets can be immersed in water in various containers in the form of water walls, opaque or translucent cylindrical tubes centralized thermal storage (for active solar systems), etc.

The combination of PCM pellets and water exhibits different thermal properties and application possibilities than the $\mathrm{PCM} / \mathrm{concrete} \mathrm{mix}$. The high convective heat transfer of the water will keep the whole mass of the PCM and the water at about the same temperature. Thus, in the case of a water wall, no significant time lag exist between a temperature change at the external and the internal surfaces.

The effective heat storage capacity of the water/PCM is somewhat higher than the concrete/PCM. The volumetric heat capacity of water is more than twice that of concrete, but the overall contribution of the sensible heat storage is relatively small.

For example, assume a 50/50 mixture (by volume) of PCM pellets and water, in a gontainer $30 \mathrm{~cm}$. deep, with the PCM melting/fre ing range of $5 \mathrm{C}^{\mathrm{C}}$. The latent heat storage capacity of one sqm of the PCM will be $4680 \mathrm{Kcal} / \mathrm{sqm}(0.5 * 30 * 10,000 * 0.78 * 40)$. The water heat storage capacity, with 5 C swing, will be $750 \mathrm{Kcal} / \mathrm{sqm}$ $(0.5 * 30 * 10,000 * 5)$. 
The combined heat capacity is $5430 \mathrm{Kcal} / \mathrm{sqm}$, disregarding the sensible heat capacity of the PCM, compared with 4980 for the $\mathrm{PCM} /$ concrete wall.

A water/PCM combination is easily applicable to passive, active or hybrid solar systems, while the application of concrete/PCM to an active system, although not impossible, would require complex detailing for the heat transfer in and out of the material.

In contrast with the thermal advantages and application flexibility of the PCM/water combination it should be pointed out that in passive solar buildings the construction and maintenance of a concrete wall seems to be much simpler than the water wall. These two aspects should be weighted by the designer.

\section{Combining heat and Cold Storage in One Element}

It is possible to mix two types of PCM pellets, with two phase transition temperatures, e.g. 20 and $30^{\circ} \mathrm{C}$., either with concrete or with water. The effective latent heat capacity of the material will be only one half of a mix with a single PCM type but the same element could serve to store solar heat in winter and night coolness in summer.

\section{Effect of PCM Carrier Matrix and Method of Application}

The carrier matrix with which the PCM are mixed and the form of application in the building can have significant effects on its potential uses and performance. The following comments deal with the use of perlite (as well as other insulating materials) as carriers.

PCM impregnated perlite is a composite material which may combine high specific heat with low thermal conductivity. Although no experimental data was provided on the actual conductivity, it can be assumed that it is somewhere between the conductivities of the two individual components.

When filling an air space of a wall, the combination of high thermal resistance and high heat capacity provides a high Thermal Time constant (TTC) for the wall. Such a wall, although a lightweight one, will perform as a high mass wall. It is very effective in suppressing the effect of the temperature swing of the external surface on the interior swing and in stabilizing the indoor temperature.

In fact, a building with lightweight stud walls filled with perlite/PCM mixture can perform in this case as a very high mass building. The indoor temperature in the building will be stabilized around the melting/freezing temperature range of the PCM, provided that the outdoor temperature swings well above and below the PCM range. A concrete/PCM wall of a given thickness will perform thermally in a similar climate as a much thicker concrete wall.

In such applications, as a filling of stud wall's cavity or forming a layer over the ceiling, the combination of high insulation value of the carrier medium and the storage capacity of PCM would act together in suppressing the indoor temperature 
swing. This stabilization effect can be very useful in regions and seasons with large diurnal temperature swings above and below the comfort zone, where it improves indoor comfort and reduces the need for both heating and cooling.

on the other hand the rate of heat exchange between the indoor air and the PCM, at a given depth of the layer of perlite/PCM mixture, is reduced by the thermal resistance of the perlite layer. Therefore it can be assumed that if applied in passive solar building, or a building cooled by night ventilation, the effect of the wall will be limited.

For example, if the function of the perlite/PCM mixture would be to provide thermal storage within the space of a stud wall in a Direct Gain solar building, namely to absorb heat from penetrating solar radiation during daytime and to release it back to the room at night, only a very limited thickness of the perlite is likely to participate in the diurnal thermal storage process.

The same will happen when the indoor space is ventilated at night, with the objective of storing night coolness for the next day, even when the night temperature is cool enough to "charge" the PCM.

The same problem may be expected to exist when PCM is mixed with concrete in walls, or any other building element, of a depth exceeding about 2". The thermal resistance of the concrete /perlite mixture may limit the effective depth in which the PCM can serve as a thermal storage medium.

\section{Issues with Interior Surfacing Elements Incorporating PCM}

When PCM is incorporated in interior plasterboard or tiles and used as thermal storage in Direct Gain solar heating, and/or cooling by night ventilation, an issue which should be considere is the indoor air temperatures which are needed to effectively melt the PCM during the day and to freeze it during the night. This issue is also related to the temperature range between the melting and the freezing of the PCM.

The required temperature gradient between the indoor air and surfaces, and the resulting heat flow, would depend also on the thickness and thermal conductivity of the material containin the PCM. As the wall is thicker and the conductivity of the material is lower a larger temperature difference will be needed between the indoor air and the surface to melt and freeze the imbedded PCM.

It should be noted that the temperature range of the indoor air in such heating and cooling systems has to be significantly larger than the range of the PCM, and even larger than the temperature range of the interior surfaces, in order to provide a temperature gradient between the indoor air and surfaces sufficient to yield the required heat flows..

In some cases the indoor air temperatures which would be needed to melt the PCM imbedded in the walls might be too high for human comfort and/or the air temperature needed for freezing it might be too low.

A possible design solution when the indoor air temperature neede for melting the PCM is too high for comfort, and/or when the 
temperature needed for freezing is too low, is to provide an air space behind a relatively thin layer of elements containing PCM (e.g. wall boards about 1"), and to blow the warm or cool air in this air space.

The "charging" of the PCM would need a fan to circulate the warm air during the sunny hours (in the case of solar heating), but the discharge at night would be passive, by natural heat flow from the freezing PCM into the indoor space. In a similar way, the PCM could be freezed at night by fan assisted cool air flow behind it while it will absorb heat from the interior when melting during the daytime. The thickness of the surface elements should be limited to that depth which would enable sufficient "passive" heat flow to melt and freeze the PCM across the whole depth of the element.

\section{Using Night Electricity as Auxiliary with PCM Elements}

A solar system with thermal storage by a PCM pellets element can use night electricity as an auxiliary energy source either for heating in winter or for cooling in summer.

The design details of the interfacing between the electrical system and the PCM element would depend on the type of the element, whether a concrete or a water type, and whether the element serves for heat storage, cold storage or a combination of heat/cold storage.

\section{Suggested required Testing}

- Fire hazards with waxes incorporated as PCM in plasterboard, interior tiles, etc.

- Long term stability of the PCM, considering the likelihood of moisture transfer to the material. This issue is important when water based PCM, such as sodium sulfate or calcium chloride, are used, as the percent water in the solution affects its properties. This subject may not be relevant when waxes are used as PCM, as wax is hydrophobic.

- Probability of PCM leaching out of the matrix material when in the Iiquid phase. This issue may be relevant to both water based PCM and waxes.

- The effective diurnal heat storage capacity of the combination of a conventional material and PCM, as a function of the thickness of the building element incorporating the PCM, when the PCM has to exchange heat with the interior air.

- The effective capability of an envelope element incorporating PCM (e.g. a stud wall filled with perlite/PCM mixture) to suppress the diurnal temperature swing and heat flow wave at the interior surface.

In summary, PCM can potentially provide thermal storage on a larger scale than conventional, sensible heat, materials. However, to play such a role, the problems, which at present limit the effective storage capacity of PCM in solar buildings, have to find a technological or design solution. If and when these problems will be solved it can be expected that thermal storage for several cloudy days in residential buildings, and 
storing night coolness to reduce the cooling load in commercial buildings, would be a more realistic proposition.

\section{B.6 References on PCM for Solar Heating and Cooling}

- Benard, C. Y. Body, A. Zanoly and J.P. Traisnel (1980) : "Laten Heat Trombe Walls and Sensible Heat Trombe Walls: Experimental Comparison For Different Couplings of the Wall to the Inside Enclosure". ICBEM Conference, Ames, Iowa.

- Cordon, W.A. (1988): private communication.

- Jaffrin, A. (1983) "Thermal Responses of a Latent Heat Radiant slab in a Hybrid (Active/Passive) House". ICBEM conference, Lousanne, France.

- Johnson, A. (1977): "Lightweight Thermal storage For solar Heated Buildings". Solar Energy, Vol. 19, p. 669.

- Johnson, T.E. (1978) : "Preliminary Performance of the MIT Solar Building \# 5". In: Passive Solar Design: A Survey of Monitored Buildings. AIA Research Corp., 1978.

- Sayler, I.O., A.K.Sircar, R.P.Chartoff, and D.E.Miller (1985): "Advanced Phase-Change Materials for Passive Solar Storage Applications". Society of Automotive Engineering/P-85/164/ pp. $3.699-3.709$.

- Shapiro, M.M., D. Feldman, D. Hawes and D. Banu (1987): "Ther Storage in Drywall Using Organic Phase Change Material". Passive Solar Journal, V-4 (4), pp. 419-438. 


\section{AppendixC Electrochromic Glazing with
Changeable Optical Properties}

Recent developments in new glazing, with new and changeable optical properties, may lead to much better thermal performance, indoor comfort and daylight conditions in buildings, than was achievable with conventional glazing. In some cases Patent applications procedures prevented discussion of the products. one of these developments, on which information was obtained, will be discussed below.

At the Electro-optics Technology Center of Tufts University research is being going on for the last 5 years by Professor Goldner on the development of electrochromic glazing, the "Smart window". The smart window is a composite of 5 layers: two transparent electrodes sandwiching an electrochromic polycrystalline layer and a counter electrode layer, which are separated by an ion conducting layer. (Goldner et al., 1987).

The "smart window" can change its properties between two reversible states, a clear (transparent) and a "colored" (reflective) ones, each having a different spectral reflectivity for solar radiation. The change from one state to the other is caused by the passage of a relatively small electrical current of alternating polarities $(+3$ or -3 volts). The optical state remains steady after the current has been stopped, till the reversed current is applied.

prototypes of small area "smart windows" have been fabricated by the Tufts team. The stability of the prototypes was tested by switching voltage between $+/-3$ volts for more than 3000 times, "with little detectable change in the optical and electrochemical properties" (Goldner et al., 1987).

The spectral reflectivity and transmissivity of various samples of "smart windows" of different compositions were measured. Test results were reported in various papers and research reports of professor Goldner and his colleagues, for which the author is thankful (see list of references). This information will be the basis for the comments given below.

No direct measurements of the spectral transmission of solar radiation, (taking into effect the intensity of solar radiation at the different wavelengths) was reported. This information, which is essential for evaluating the quantitative effect of the "smart window", can of course be calculated by multiplying the spectral solar intensity by the respective spectral transitivity of the "smart window".

No data was published in the papers that I got on the reflectiv of the "smart window" in the longwave (thermal) radiation band. However, professor Goldner has indicated in a telephone conversation that as the five layers are deposited on glass, and there probably will be an insulating and protective glass cover, the emissivity of the "smart window" can be assumed to be that of glass, namely about 0.9 . 
To evaluate the daylighting and thermal impacts of the selective transmissivity and reflectivity of the "smart window" the energy distribution in the solar spectrum should be recalled. The visible band ( 0.4 to 0.75 microns) accounts for about $45 \%$ of the total solar energy. About $5 \%$ is in the ultraviolet and about $50 \%$ is in the infrared band.

About $70 \%$ of the energy which is in the infrared solar band is between the wavelengths of 0.75 and 1.15 microns and about $30 \%$ is between 1.15 and 1.8 microns. Beyond 1.8 microns the energy in the solar spectrum is negligible.

In the clear state the average transparency of representative sample of the "smart window" (Goldner et al, 1987) was about $76 \%$ in the visible light and about $76 \%$ in the infrared band of .75 to $.95 \mathrm{microns,} 68 \%$ in the band .95 to $1.15 \mathrm{mi}$, $56 \%$ in the 1.15 to $1.4 \mathrm{mi}, 40 \%$ in the 1.4 to $1.8 \mathrm{mi}$ and about $11 \%$ beyond 1.8 microns.

In the colored state the glazing's average transmissivity in the visible part of the solar spectrum was about $38 \%$, in the $.75-.95 \mathrm{mi} 22 \%$, in the .95-1.15 band $18 \%$, in the $1.15-1.4$ band $11 \%$, in the $1.4-1.8$ band $9 \%$ and beyond $1.8 \mathrm{mi}$ about $2 \%$, as can be seen from figure.. (Goldner et al, 1987).

Based on these optical properties approximate calculations of the visible and infrared solar radiation transmitted through the "smart window" glazing in the two states were done by the author, on the basis of the transmittance data shown in figure.... and the solar energy contained in each spectral band. The results of these calculations are given in Table C.1.

The Table shows also similar calculations for clear and for Low Emissivity (low-E) glasses. Low-E glass transmits about $70 \%$ of the visible band and an average of about $40 \%$ in the infrared.

\section{Evaluating the Expected Impact of the "SMART WINDOW" in Buildings}

Assuming that "smart window" glazing could be manufactured at sizes and at a cost appropriate for building's applications, some comments can be made on the basis of the reported properties of the glazing at the two states. These comments compare the "smart window" to conventional glazing and deals with different applications of solar energy in buildings.

\section{Comparing "SMART WINDOW" to Clear Glass}

\section{"Smart window" in the bleached state}

Transmissivity of a representative sample of smart window in the clear state, in the visible solar band (at incident angle of 20 deg.) was about $76 \%$. In the "colored" state this value drops to about $38 \%$. This should be compared to transmissivity of about $88 \%$ for clear glass in the visible light and an average of about $70 \%$ in the infrared.

Therefore, to have the same level of daylighting, when the "smart window" is in the clear state, only a small increase in the area of the glazing would be needed. 


\begin{tabular}{|c|c|c|c|c|c|c|c|c|c|}
\hline \multirow{3}{*}{$\begin{array}{l}\text { CLAZING } \\
\text { IRANSIUSSION } \\
\text { AND GAIN }\end{array}$} & \multicolumn{7}{|c|}{ SOAR SRECTRN BAMOS (MOCROMS) } & \multirow{3}{*}{ 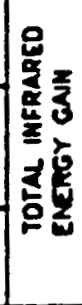 } & \multirow{3}{*}{ 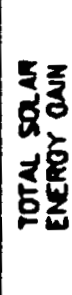 } \\
\hline & uv & | & \multicolumn{5}{|c|}{ INFRARED } & & \\
\hline & $\begin{array}{l}a_{3} \\
a .4\end{array}$ & $\begin{array}{l}a 4 \\
0>5\end{array}$ & a.75 & $\begin{array}{l}0.95 \\
1.15\end{array}$ & $\begin{array}{l}1.15 \\
1.4\end{array}$ & $\begin{array}{l}1.4 \\
1.8\end{array}$ & 1.8 & & \\
\hline Solor Froction & a.s & 0.25 & 0.21 & a.11 & a) & 200 & a.04 & 0.5 & 1 \\
\hline $\begin{array}{l}\text { Bleocned. } T \\
\text { Eneroy Goin }\end{array}$ & a.s & $\begin{array}{l}a .5 \\
0.34\end{array}$ & $\left|\begin{array}{l}0.76 \\
0.16\end{array}\right|$ & $\begin{array}{l}2068 \\
207\end{array}$ & $\begin{array}{l}56 \\
0.05\end{array}$ & $\begin{array}{l}0.10 \\
0.02\end{array}$ & a.1 & a.si & aes \\
\hline $\begin{array}{l}\text { Colored. T } \\
\text { Enoray Coin }\end{array}$ & a. & $\begin{array}{l}a .30 \\
0.17\end{array}$ & $\left|\begin{array}{l}0.22 \\
0.05\end{array}\right|$ & $\begin{array}{l}\text { a.18 } \\
\text { a.02 }\end{array}$ & $\begin{array}{l}a 11 \\
\text { a.d }\end{array}$ & $\begin{array}{l}\operatorname{aog} \\
\operatorname{con}\end{array} \mid$ & 1002 & 0.09 & $a .20$ \\
\hline $\begin{array}{l}\text { Ooor Gloow } T \\
\text { Energy Goin }\end{array}$ & $\begin{array}{l}0.5 \\
0.2\end{array}$ & 0.80 & $\left|\begin{array}{l}0.73 \\
0.16\end{array}\right|$ & $\begin{array}{l}0.65 \\
0.00\end{array}$ & $\begin{array}{l}0.88 \\
0.05\end{array}$ & $\begin{array}{l}0.55 \\
0.05\end{array} \mid$ & a.73 & 0.58 & $a \times 9$ \\
\hline Low-E. $T$ & $\begin{array}{l}0.3 \\
0.01\end{array}$ & $\begin{array}{l}a>0 \\
0.31\end{array}$ & $\begin{array}{l}0.55 \\
0.12\end{array}$ & $\begin{array}{l}0.38 \\
0.05\end{array}$ & $\begin{array}{l}028 \\
0.03\end{array}$ & $\left|\begin{array}{l}0.18 \\
0.01\end{array}\right|$ & a. & $a .21$ & 0.52 \\
\hline
\end{tabular}

TABLE C. 1:Solar Energy Transmitted Through "Smart Window"

Comparing the "smart window" in the bleached state to clear glass from the infrared heat gain aspect it should be noted (in Table C.I) that in this state the total gain of the "smart window" is about $34 \%$ of the impinging solar radiation. Clear glass, with average transmission of 708 in the infrared, would yield' a total infrared gain of about $398(.55 * .70)$.

In summary, in the clear state the "smart window" transmits about the same amount of energy in the visible and in the infra red bands of the solar spectrum. Also the clear glass transmits about the same visible light and infrared energy, both a little more than the "smart window".

"Smart window" in the "colored" state

The main difference between the "smart window" and conventional clear glass, and in their impact on building design, is expected to be when the glazing is in the "colored" state. In this state the difference in the transmissivities in the visible and in the infrared spectral bands is greater than in the bleached state, while clear glass has more similar transmissivities in the two bands.

In this state the transmissivity of the "smart window" to visibl radiation is less than half, and its transmission of the infrare is less than one quarter, compared with that of clear glass.

As can be seen from Table..., the relative reduction in the transmitted energy in the infrared band in the "colored" state, as compared with the bleached state, is significantly greater (from 34 to $8 \%$ ) than in the visible band (from 34 to $17 \%$ ). Therefore in summer, or at any hot hour, when the glazing is 
assumed to be in the colored state, it will transmit much more light than unwanted heat.

This feature may be of advantage in buildings with large glazing area, either for general architectural reasons (e.g. the character of the facade), or because the desire to "open" the building to a view, etc.

However, the impact on building design of the reduction in the transmitted light may be quite significant, especially in buildings where the amount of daylighting is important. It means that, to get the same amount of daylighting from a "smart window" in the colored state as from conventional glazing, the area of the "smart window" glazing would have to be more than twice that of conventional glazing. Alternatively, more electrical lighting would be used in a building with "smart windows" to provide the required light level.

It should be noted, however, that the infrared heat gain through the larger glazing area of "smart window" would be about one half of that gained from the smaller size of conventional glazing, due to the much lower infrared transmissivity.

The main advantage of the "smart window" over clear glass would be in the following cases:

a) In such buildings where the benefit from a reduction in infrared heat gain from a given area of glazing, usually in summer, is greater than the cost of additional electricity for lighting, which may be needed to compensate for the lower Iight transmission of the "smart window".

b) In windows with orientations where the impinging solar energy in summer is larger than in winter, for instance, on eastern, western and northern windows. It can be assumed that window size in these orientations, in buildings which desire natural lighting, will be designed to provide the required daylight in winter. Therefore in summer, when these windows receive much more solar radiation than in the winter, the indoor daylight level would be adequate, in spite of the reduction in the transmitted light.

c) Special cases are those of skylights and atria, where the glazing is horizontal, or facing mainly the sky. In this situation the difference in the intensity of the impinging radiation in summer and in winter is maximized. A "smart window" which would transmit in winter almost as much light as clear glass but in summer will minimize the infrared heat gain, will then exhibit its highest advantage.

d) Buildings where view is important and should be kept free from interference at all times. The use of operable blinds or curtains would block the view partialiy or completely. In these cases the ability to keep the view through the "smart windows", while reducing the heat gain, would be a great asset.

Note, however, that in this case the low emissivity glass, discussed below, might be an attractive alternative, if its cost would be significantly lower than the "smart window". 
Comparing "SMART WINDOW" to Low Emissivity (LOW-E) Glass

A natural "competition" to the "smart window", whenever high level of lighting is coupled with the desire to minimize heat gain, would be the low emissivity (low-E) glass. Note, however, that the optical properties of this glass are fixed and it is not possible to modify them when meteorological conditions change.

It would be. therefore, of interest to compare the daylighting and the infrared and the total heat gains of these two glazing types.

From Table c.lit can be seen that the visible light transmitted through Low-E glass is a little less than through the "smart window" in the clear state ( $31 \% \mathrm{vs} .34 \%$ of the solar radiation, respectively), but much more than when the later is in the colored state $(17 \%)$. It means that for the same daylight level the area of a "smart window" would have to be about twice of that of low-E glazing.

The infrared heat gain through the Low-E glass (21\% of the solar radiation) is about $2 / 3$ of that through the "smart window" in the clear state $(34 \%)$ but much more-than when it is in the colored state (8\%). But taking into account the larger area needed for the same daylight level. the difference in the actual infrared heat gain would be much smaller (about $3 / 2$ ratio).

\section{PASSIVE SOLAR HEATING}

The main potential application of the "smart window" for passive solar heating seems to be in Direct Gain. system, where the ability to look out through the glazing is one of the attractive characteristics of the system. The appeal to use the "smart window" in Direct Gain will be a factor especially in regions with hot summers, where minimizing overheating by the large area of solar glazing is of major importance.

Also in sun-spaces there might be an interest in using "smart windows,

although in this solar system the advantages of this glazing, in comparison with conventional glazing, will be less obvious than in Direct Gain.

The main difference in the relative advantages of the "smart window" in these two passive solar systems is because the sun space can be ventilated in summer by opening part of the glazing This natural ventilation can minimize overheating of buildings, rendering the changeable transmissivity less important.

In considering "smart windows" for passive solar heating the properties of interest, affecting the performance in winter, are the total solar energy transmission in the clear state (as seen in figure C.I), and the thermal resistance of the glazing.

As the "smart window" is in fact a single sheet glazing, althoug a laminate of several thin film layers, its thermal resistance will not be significantly different from that of a single glass. In some climatic regions (e.g. southern california) this may be adequate. 
In most regions of the country double glazing would be required. The "smart window" would then be one layer in a double glazing element, presumably the external layer where it can be most effective in summer, when presumably it will be in the "colored" state.

Considering the somewhat lower solar energy transmissivity, compared with conventional glass, a larger area will be needed to get the same solar gain. The larger area will result in a corresponding higher conductive heat loss, reducing the overall heating efficiency of the system, as measured, for example, by the Solar Saving Fraction.

As can be seen from Table...., the total solar energy transmission in the bleached state is about 0.68 .

The main benefit from applying "smart windows" in Direct Gain buildings would be in summer, when the reduced total solar gain (26\% of the impinging radiation and about $1 / 3$ of the load from conventional glazing) can greatly reduce likelihood of overheating while preserving the view through the glazing.

Prof. Goldner has indicated in a telephone conversation that research is going on at Tufts on improvements of the spectral properties of the material, toward a clearer "step function" in its selective reflectivity in the visible and in the infrared solar spectrum. He is anticipating that with further improvements the transmittance of the "smart window" in the visible spectrum, when. in the colored state, will equal if not exceed that of low-E glass and approach that of clear glass.

Cost/benefit analysis of using "smart windows" in any application could be done only after the durability, production technology and cost of this material will be known.

\section{C.1 References on SmartWindows.}

- Goldner R.B. and R.D. Rauh (1983): "Electrochromic Materials for Controlled Radiant Energy Transfer In Buildings". Soc. Photo-optical Instrumentation Eng. V-428. pp. 38-44.

- Goldner, R.B., T.E. Haas, G. Seward, K.K. Wong, P. Norton, G. Foley, G.Berera, G.wei, S. Schulz and R. Chapman (1987): "Thin Film Solid state Ionic Material for Electrochromic Smart Window (TM) Glass". 6th Int. Conf. on Solid State Ionics. GarmischPartenkirchen, FRG, Sept. 1987.

- Goldner,R.B. and T.E. Haas (1988): "Optics and Materials Research for Controlled Radiant Energy Transfer in Buildings". Research Report to DOE. 


\section{AppendixD \\ Core Daylighting of Multi Story Nonresidential Buildings}

The DOE Experimental Program on Nonresidential Buildings has demonstrated that in the case of single story nonresidential buildings it is possible to provide daylightingto the whole building, regardless of its size. Spaces close to the periphery can get daylight from windows and clerestories in the external walls while spaces in the core of the building can be daylighted by roof monitors and/or skylights.

Rooms located along the periphery of multi story buildings, or around large internal courtyards, can also be daylighted by glazed areas in the external and the courtyard walls. However, the dimensions of many nonresidential buildings are too large and, at present, the "core" areas of such multi storied building must have complete electrical lighting.

At the same time the amount of sunlight which reaches the roof of the building is many times greater than the amount needed for lighting the core areas of multi storied buildings, especially in sunny regions with clear sky.

As an example, let assume direct normal solar light insolation of $5000 \mathrm{fc}$ (a level common in many regions) and indoor light level of $50 \mathrm{fc}$, with a light transmision system having an overal efficiency of $30 \%$. Let assume also that the maximum roof area which can be covered by light collectors, without mutual shading is $33 \%$. Even in this case the light reaching the roof could provide daylight for the total area of 10 stories, without takin into account daylighting of the peripheral areas by conventional windows.

However, at present, the technology for utilizing this source of Iight is still in the Laboratory research stage and not yet ready for application.

one way by which it may be possible to provide daylight to the core areas of large multi story buildings is to collect and concentrate the sunlight above the roof of the building and then to transfer it down, through different types of "Iight guides". The transmitted light would then be distributed in the core area of different floors. The need to concentrate the sunlight arise from the desire to minimize the area of the guides, to "sacrify" a minimum of usable floor area.

Although such systems are still at the research stage, recent developments in optical materials, such as high reflectance films, solid highly transparent new plastics, etc., may enable development of high performance light guides in not too far future.

Johnson and selkowitz (1986) describe several types of light guides and have developed a procedure for sizing the sunlight collector and the guide. The following description is based mostly on their paper. 


\section{D.1 Generic Types of Light-Guides}

All light guides have three basic components: the sunlight collector, the central vertical light guide and the light distribution system within the lighted area. Sunlight collectors and light guides can be of different types, such as:

- Nontracking collectors with hollow reflective guide.

- one axis Tracking collectors with hollow elongated reflective guide.

- Two axis Tracking collectors with the following light guides:

- Hollow reflective guide.

- Solid Dielectric guide.

Johnson and Selkowitz (1986) have calculated the required sizes of different types of light guides, which would provide the same amount of daylight $(1,000,000$ lumens) to an area of $10,000 \mathrm{sf}$ with a guide length of $50 \mathrm{ft}$. They do not discuss at all the design options of the distribution components but in the calculations they assume a light distribution efficiency (coefficient of utilization) of $50 \%$. The sizes of the Daylight collectors and the guides transmitting the light from the roof to the space below were calculated for different types of light transmission.

Sunlight Collectors

Sunlight collectors are much larger than the area of the light guide so that the sunlight can be concentrated. They can be in the form of Fresnel lens or ordinary lens. Because of their large size they should be made of lightweight materials. A typical material might be e.g. acrylic.

For a given amount of light output there is a trade-off between the size of the collector and the size of the light guide. When the guide aperture is smaller the collector's focal length should be shorter and this results in more surface reflections within the guide and more absorption (and loss) of the light. As consequence, the collector should be larger.

The properties of the collector which affect its output are its light transmittance and its focusing accuracy.

Nontracking (Fixed) Collectors with Hollow Reflective Guide.

The collector for a nontracking system would typically be a Fresnel lens. The field of view of such collector is limited and therefore it should be directed to the sky region where the sun is located during periods of peak energy demand. The available daylight is variable, depending on the position of the sun with respect to the collector and the sky conditions. The "design" luminance would be the average over the period of time when the sun is unobstructed and is within the collector's field of view.

The collector focuses the sunlight on a diffuser at the aperture of the guide. Johnson and selkowitz comment that in a nontracking system the cost of the collector is not so significant in 
comparison with the cost of the occupancy space displaced by the guide. Therefore in such system the guide's area should be minimized and the collector's area increased to get a given amount of daylight.

At Lawrence Berkeley Laboratory (IBL) tests are conducted with a new high-reflectance, silver-backed film, which exhibit $95 \%$ reflectance. Such film can serve as the lining for the light guide.

Johnson and Selkowitz have calculated the aperture area of a square hollow guide, with non-concentrating collector, which is needed to provide the required illumination, to be $140 \mathrm{sf}$, namel about $1.5 \%$ of the illuminated floor area. The required area of the stationary light collector was not computed in this example.

\section{Two axis Tracking collectors with a square hollow reflective light guide.}

Johnson and Selkowitz (1986) have calculated also the required dimensions of the collector and guide of a system with a two axis tracking collector and a square reflective guide.

For the specified performance they came out with a collector area of $533 \mathrm{sf}$. and a guide aperture area of $0.32 \mathrm{sf}$, yielding a geometric concentration ratio of 1600 . They state that "taking into account collector losses and the transmitted beam's obliquity relative to the light guide wall, the luminous flux incident on the wall would only be about 50 suns; and since the wall is $95 \%$ reflective only about 2.5 suns of luminous flux would actually be absorbed."

The publication does not include calculations of the expected temperature rise of the guide's material. which would result from the absorbed solar radiation. This may be a limiting factor for the concentration ratio of the collectors.

\section{Two axis tracking collector with solid dielectric light guide}

This light guide, as described by Johnson and Selkowitz, "consists of a solid circular-section rod of high-transmittance optical material that is coated with a thin cladding of a different material whose refractive index is slightly lower than that of the core material. Iight is confined inside the core via total internal reflection at the core-cladding interface." Kaino et al. (1983) describe such a plastic material that could transport highly concentrated sunlight over a $50 \mathrm{ft}$ distance with around $80 \%$ transmission efficiency.

Johnson and selkowitz have calculated the required sizes of the collector and the guide of such a system. For the specified performance the collector should be of 327 sf and the guide aperture $0.015 \mathrm{sf}$. This yields geometric concentration of 22,000 "which is greater by an order of magnitude than the practical concentration limit of hollow light guides."

Johnson and selkowitz state that with this type of light guide "the transmittance does not depend on the light guide's aperture dimension, so there is no reason the aperture area would need to be concentrated in a single central light guide - it could be divided up among several smaller light guides, or a large 
number of flexible optical fibers could be used. Smaller light guides would be preferable to a large central light guide for a number of reasons: They would have better heat dissipation; they could fit into small conduits and bent around tight corners more easily; the output flux could be delivered at several widely separated distribution points; and the 327 sf collector area could be divided up among several collectors of reasonable size and cost rather than consolidating it all in a single $20 \mathrm{ft}$ diameter collector unit."

One axis Tracking collectors with hollow elongated reflective guide.

This type of light guide was not discussed in the paper of Johnson and selkowitz but it seems to the author that it would be simpler and less expensive than a two-axis tracking system and would require far less guide aperture area than the nontracking square system.

In such a system the collector, e.g. an elongated Fresnel lens, will have the same length as the guide aperture but will be wider than the width of the guide, according to the designed concentration ratio.

The collector tilt could always follow the projection of the sun altitude in a plane perpendicular to its long axis.

The daily amount of sunlight collectable by such a collector would be higher than with a nontracking one, and it would be able to collect and transmit light practically at all times, like a two axis tracking collector, although its concentration ratio would be smaller.

It would be desirable to evaluate the performance of this type. 


\section{APPENDIXE}

\section{Concepts of Opaque Walls with Changeable Properties}

opaque (not glazed) walls with changeable thermal conductance or heat capacity might be very useful in improving indoor comfort, reducing the need for and time of operation of air-conditioning, and thus reduce the energy consumption in buildings.

Such walls would be particularly desirable in regions with large diurnal temperature swings, with hot days and cool nights. When at low conductance (high thermal resistance), during the daytime hours, they can reduce the rate of indoor temperature rise. When at high conductance, in the evening, it would increase the rate of cooling, thus keeping the indoor within the comfort range. A similar selective modification of the rates of heating and cooling could, of course, be accomplished by having a well insulated building closed during the day and ventilated during the evening and night hours. but in many cases such controlled ventilation is not practical.

Modulation of the thermal conductance of the walls would be of special interest in cases where selective night ventilation is not desirable, e.g. because of security and privacy considerations, or when the nocturnal air temperature is too low and ventilation at rates needed for structural cooling would cause cold discomfort to the inhabitants.

several, presently available, techniques can be utilized to obtain variable properties in opaque walls, such as:

a) Changing the thermal properties of the wall by retractable or movable components.

b) Rotating insulating louvers inside the wall's airspace.

c) Rotatable heat storing louvers inside the wall's airspace.

A common design problem to all techniques which utilize moveable elements within an airspace of a wall is the need for an access to these elements for inspection, maintenance and repairs.

Changing the wall's properties by retractable "curtains"

When low emissivity (metalized) thin "curtains" are installed in an air space of a wall they increase its thermal resistance in two ways:

They divide the space into a series of narrower parallel air spaces, thus reducing the convective heat transfer across the wall. If, in addition, the curtains are metalized, and thus having low emissivity, they form radiant barriers, reducing the radiant heat transfer across the wall. The outcome is a significantly lower thermal conductance of the air space, in comparison with the conductance of an "empty" space. 
If such curtains can be rolled up or down, either manually at will or by control of a thermostat or a timer, it would be possible to change the thermal conductance of the wall according to changing objectives of heat flow between the interior of the building and the outdoor.

For example, in summer the curtain could be rolled down during the daytime, thus reducing the heat flow into the building. In the evening, however, they should be rolled up, increasing the cooling rate of the building.

\section{Rotatable insulated louvers inside the wall's airspace}

Rotatable louvers of insulating materials (e.g. polystyrene), with reflecting coating on both sides, can be installed in the airspace between the studs of a wall. When in parallel position to the wall they form a radiant insulated barrier within the airspace.

By rotation, when perpendicular to the wall, they leave openings for convective and radiant heat transfer from the warm to the cool side of the wall, increasing its thermal conductance.

The louvers can be either vertical or horizontal. Vertical louvers can be structurally less strong and rigid than horizontal ones.

\section{Rotatable heat storing louvers inside the wall's airspace}

Rotatable louvers can be composed of two layers, one with a high thermal resistance and the other with high heat capacity, e.g. a. thin layer of PCM with phase transition temperature which should be chosen according to the type of the climate, and installed inside the airspace of a wall. This combination is similar to the system developed by Faiman (see above), but placed within the airspace of an opague wall. The wall itself would preferably have an external layer made of a metal, e.g. aluminum or enameled steel.

Some construction details of the wall, as well as its use, should be different in cold and in hot regions. In cold regions such a wall, when facing south, could serve as a solar collector. Therefore its exterior metal skin would be glazed and finished with a dark color. The wall could then serve as a combined vertical collector and heat storage element in winter. The phase transition temperature of the PCM should be above byt close to the upper Iimit of the comfort zone, about $86^{\circ} \mathrm{F}\left(30^{\mathrm{C}} \mathrm{C}\right.$.

During winter daytime the PCM layer should face the external side. Heat from the glazed, solar heated, metal skin would be transferred by radiation and convection to the PCM. At night, with the louvers rotated and the PCM facing the interior surface and insulated (by the insulation layer of the louver) from the exterior side, the heat stored in the PCM will flow mainly to the indoor.

Tight seal of the louvers is not needed during the daytime but is important during the night, when the PCM faces the interior side and the insulation faces the exterior, although the louvers 
are within a "dead" airspace, to minimize the convective heat loss rate.

In regions with hot summers and mild winters the walls should not be glazed and finished with a light color. At any orientatio such a wall could reduce the rate of temperature rise during the day and increase the cooling rate at night. The phase transition temperature of the PCM should be so chosen that it would be few degrees $\left(4-6{ }_{F}, 2-3 \circ C\right)$ above the minimum outdoor temperature at the location of the building.

The metal skin will be cooled at night by convection and longwav radiation and will follow closely the outdoor temperature. The louvers should so be positioned during the night that the PCM would face the external skin of the wall. The PCM will then solidify by heat loss to the exterior metal skin of the wall. During the daytime hours the louvers should be rotated and the PCM facing the interior. Any heat flow from the external skin of the wall will first be reduced by the back insulation and then partly absorbed by the PCM, before entering the indoor space. At night, with the louvers rotated, the absorbed heat will flow mostly to the outdoor.

\section{E.1 Reference:}

Givoni, B., W. Kroner and C. Dry (1987): "Changeable Properties of the Building Envelope -Adaptability to Changing Performance Requirements". Int. Cong. of Building Energy Management. Lausanne, France. 